\title{
Gliridae from the late Oligocene of the province of Teruel (Spain)
}

\author{
Matthijs FREUDENTHAL ${ }^{1,2^{*}}$ \& Elvira MARTÍN-SUÁREZ
}

${ }^{1}$ Departamento de Estratigrafía y Paleontología, Universidad de Granada, España; mfreuden@ugr.es

${ }^{2}$ Netherlands Centre for Biodiversity, Naturalis, P.O. Box 9517, 2300 RA Leiden, The Netherlands

*Corresponding author

Freudenthal, M. \& Martín-Suárez, E. 2019. Gliridae from the late Oligocene of the province of Teruel (Spain). [Glíridos del Oligoceno superior de la provincia de Teruel (España)]. Spanish Journal of Palaeontology, 34 (2), $299-334$.

Manuscript received 14 September 2018

Manuscript accepted 6 September 2019 https://doi 10.7203/sjp.34.2.16117

(C) Sociedad Española de Paleontología ISSN 2255-0550

\section{ABSTRACT}

The Calatayud-Teruel Basin is one of the richest areas of Spain, when fossil mammals are concerned. Around the village of Montalbán many lower Oligocene fossil mammal localities are known and several upper Oligocene localities with rich micromammal faunas are present between the villages of Vivel del Río Martín and Martín del Río. Previous papers on these upper Oligocene localities were dedicated to the Cricetidae and to the zapodid Plesiosminthus, in this work we describe the fauna of Gliridae, composed of the genera Gliravus, Butseloglis, Peridyromys, Microdyromys, and Paraglis. Among these the latter genus is very poorly represented. Microdyromys is of special importance because its presence in our material permits a new concept of the phylogeny of the genus.

Keywords: Gliridae, Mammalia, Oligocene, Teruel.

\section{RESUMEN}

La depresión de Calatayud-Teruel es una de las zonas más ricas de España en mamíferos fósiles. Alrededor del pueblo de Montalbán se conocen muchos yacimientos del Oligoceno inferior y varios yacimientos del Oligoceno superior se encuentran entre los pueblos de Vivel del Río Martín y Martín del Río. Trabajos anteriores sobre estos yacimientos tratan de los cricétidos y del zapódido Plesiosminthus. En el presente trabajo describimos la fauna de Gliridae, compuesta por los géneros Gliravus, Butseloglis, Peridyromys, Microdyromys y Paraglis. Entre ellos, el material de Paraglis es muy escaso. Microdyromys es especialmente importante porque su presencia en nuestro material permite establecer una nueva filogenia del género.

Palabras clave: Gliridae, Mammalia, Oligoceno, Teruel. 


\section{INTRODUCTION}

The Calatayud-Teruel Basin is one of the richest areas of Spain, when fossil mammals are concerned. The easternmost part of this Basin, the depression of Montalbán, is formed by lower Oligocene deposits that have yielded rich vertebrate faunas. Farther to the west important deposits of late Oligocene age are present which, in the area of Mirambueno, between the villages of Martín del Río and Vivel del Río Martín, contain several important localities of fossil mammals. The first one of these, Vivel, was discovered by E. Moissenet in 1978; the other ones denominated Mirambueno 1-4D were discovered by our team during the years 1986-1991.

Previous papers on the localities studied here are Freudenthal et al. (1994) on Pseudocricetodon, Freudenthal (1994) on the other Cricetidae, Freudenthal (1997) providing faunal lists, and Freudenthal \& Martín-Suárez (2017) on the Dipodidae Plesiosminthus.

The aim of this paper is the contribution to the knowledge of the fossil Gliridae from the upper Oligocene sites of the Mirambueno area. Gliridae are an important part of the faunas and Hugueney et al. (1985) published the new species Gliravus bravoi from Vivel (now placed in the genus Butseloglis Vianey-Liaud, 2004). Here we will describe the entire glirid fauna from Mirambueno and Vivel, containing the genera Gliravus, Butseloglis (with a discussion on the original diagnosis of this genus), Peridyromys, Microdyromys (with a new diagnosis of this genus), and Paraglis.

\section{MATERIAL AND METHODS}

The localities studied are situated near the eastern border of the Calatayud-Teruel Basin, topographical map of Spain 1:50,000 Segura de los Baños 27-19 (492), between the villages of Martín del Río and Vivel del Río Martín, on the southwestern bank of the river Vivel (Fig. 1).

UTM coordinates of the fossiliferous localities were taken in the field and checked on the topographic map, which uses the ED50 datum point. Since the standard today is ETRS89 we converted our data (Table 1). However, we use ED50 data, since they are compatible with the printed map.

The fossil material will be stored, partly in the Museo de Geología of the University of Zaragoza (Spain) and partly in the Netherlands Centre for Biodiversity Naturalis, Leiden (The Netherlands).

The terminology of parts of the cheek teeth (Fig. 2) follows Freudenthal (2004). The taxonomy follows Freudenthal \& Martín-Suárez (2013). V' is the variability coefficient as defined by Freudenthal \& Cuenca (1984).

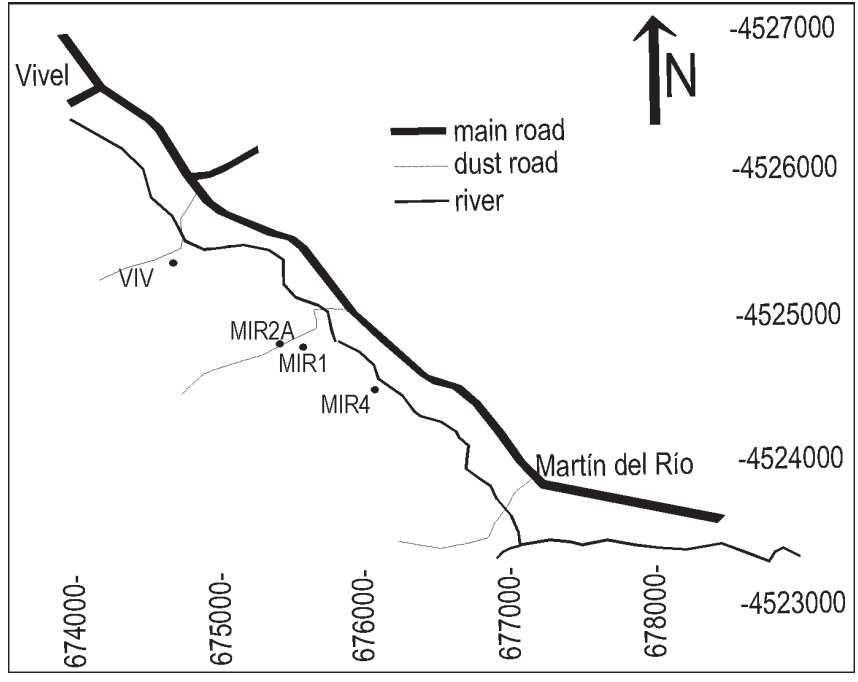

Figure 1. Map of the area of Mirambueno.

Table 1. UTM co-ordinates.

\begin{tabular}{lrc} 
& FIELD ED50 & ETRS89 \\
\hline MIR1 & $0675545 / 4524770$ & $0675436 / 4524560$ \\
MIR2A & $0675404 / 4524803$ & $0675295 / 4524593$ \\
MIR4 & $0676048 / 4524496$ & $0675939 / 4524286$ \\
VIV & $0674649 / 4525328$ & $0674540 / 4525118$ \\
\hline
\end{tabular}
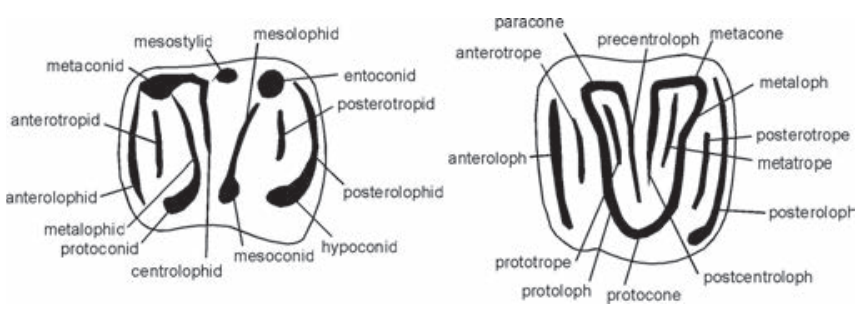

Figure 2. Nomenclature of parts of cheek teeth, adapted after Freudenthal (2004). When there is only one centroloph, and its homology cannot be decided, it is called midcentroloph. The figures are drawn as lefthand molars with the anterior side facing to the left.

Abbreviations used are explained in Table 2. In the taxonomic descriptions of the following section, numbers in parentheses indicate number of specimens that show the referred feature.

Measurements were taken with a Wild M8 binocular microscope, equipped with a mechanical stage with electronic sensors, connected to a computer through a Sony Magnescale measuring unit. Measurements are 
given in $\mathrm{mm}$. The orientation of the specimens for measuring was as described by Freudenthal (2004). Photographs were taken on the electron microscope FEI ESEM QUANTA 400 of the Centro de Instrumentación Científica of the University of Granada.

Table 2. Abbreviations used.

\begin{tabular}{|c|c|c|c|}
\hline Code & Locality & Country & MP/MN zone \\
\hline ARM7 & Armantes 7 & Spain & MN6 \\
\hline ATE3 & Ateca 3 & Spain & MN3 \\
\hline BOUZ & Bouzigues & France & MN2A \\
\hline $\mathrm{BU}$ & Buñol & Spain & MN4 \\
\hline CARRAS & Carrascosa del Campo & Spain & MP26 \\
\hline COD & Coderet & France & MP30 \\
\hline GAIM & Gaimersheim & Germany & MP28 \\
\hline GRB3 & Gröben 3 & Germany & MP24 \\
\hline HB & Hoogbutsel & Belgium & MP21 \\
\hline HEIM & Heimersheim & Germany & MP24 \\
\hline LP4A & Las Planas 4A & Spain & MN5 \\
\hline LP4B & Las Planas 4B & Spain & MN5 \\
\hline LP4C & Las Planas 4C & Spain & MN5 \\
\hline LP5H & Las Planas $5 \mathrm{H}$ & Spain & MN7/8 \\
\hline MA & Manchones & Spain & MN6 \\
\hline MIR1 & Mirambueno 1 & Spain & MP27 \\
\hline MIR2A & Mirambueno 2A & Spain & MP27 \\
\hline MIR4B & Mirambueno 4B & Spain & MP25 \\
\hline MIR4C & Mirambueno 4C & Spain & MP26 \\
\hline MIR4D & Mirambueno 4D & Spain & MP26 \\
\hline MLB10 & Montalbán 10 & Spain & MP23 \\
\hline MLB11B & Montalbán 11B & Spain & MP23 \\
\hline MLB11B+ & Montalbán 11B + 10 +1D & Spain & MP23 \\
\hline MLB1D & Montalbán 1D & Spain & MP23 \\
\hline MLB3C & Montalbán 3C & Spain & MP22 \\
\hline MLB3C + & Montalbán $3 \mathrm{C}+3 \mathrm{X}+8$ & Spain & MP22 \\
\hline MLB3X & Montalbán 3X & Spain & MP22 \\
\hline MLB3Y & Montalbán 3Y & Spain & MP22 \\
\hline MLB8 & Montalbán 8 & Spain & MP22 \\
\hline NFM & $\begin{array}{l}\text { Nouvelle Faculté de } \\
\text { Médecine }\end{array}$ & France & MN1 \\
\hline PAREJ & Pareja & Spain & MP26 \\
\hline OBERL & Oberleichtersbach & Germany & MP30 \\
\hline SS & Sansan & France & MN6 \\
\hline TOR & Toril & Spain & $\mathrm{MN7} / 8$ \\
\hline ULMW & Ulm-Westtangente & Germany & MN2A \\
\hline VA1A & Valdemoros $1 \mathrm{~A}$ & Spain & MN5 \\
\hline VA3B & Valdemoros $3 \mathrm{~B}$ & Spain & MN5 \\
\hline VICOST & St.Victor-la-Coste & France & MP29 \\
\hline VIV & Vivel del Río & Spain & MP28 \\
\hline VL2A & Villafeliche 2A & Spain & MN4 \\
\hline VL4A & Villafeliche 4A & Spain & MN5 \\
\hline VR7 & Vargas 7 & Spain & MN5 \\
\hline $\mathrm{p} 4, \mathrm{~m} 1, \mathrm{~m} 2, \mathrm{~m} 3$ & lower cheek teeth & & \\
\hline $\begin{array}{l}\mathrm{P} 4, \mathrm{M} 1, \mathrm{M} 2, \\
\mathrm{M} 3\end{array}$ & upper cheek teeth & & \\
\hline $\mathrm{mA}$ & million years & & \\
\hline med & metaconid & & \\
\hline ecd & entoconid & & \\
\hline pac & paracone & & \\
\hline $\mathrm{MN}$ & MN zone & & \\
\hline MP & MP zone & & \\
\hline
\end{tabular}

\section{SYSTEMATIC PALAEONTOLOGY}

Class MAMMALIA Linnaeus, 1758

Order RODENTIA Bowdich, 1821

Family Gliridae Muirhead, 1819

Subfamily Gliravinae Schaub, 1958

Genus Gliravus Stehlin \& Schaub, 1951

Type species Gliravus majori Stehlin \& Schaub, 1951

Original diagnosis. (Translated from German): "Brachyodont, with two premolars in the maxilla. Upper molars trigonodont with simple and small mesostyl. Trigone crests without intermediate cusps. Lower molars with four cusps and isolated mesoconid. Mesolophid not yet developed. Paraconid separated from protoconid, like in Sciurus vulgaris".

Remarks. Daams \& de Bruijn (1995) recognized 15 species of Gliravus and since then two new species have been described (Table 3). Daams \& de Bruijn included the genus Glamys Vianey-Liaud, 1989 in Gliravus. VianeyLiaud (2004) created the genus Butseloglis, which contains about half the species originally placed in Gliravus.

In our concept, Gliravus is restricted to three upper Oligocene species (MP25-26): G. majori Stehlin \& Schaub, 1951, G. alvarezae Lacomba \& Morales, 1987, and G. caracensis Daams, Freudenthal, Lacomba \& Alvarez, 1989. These species share the tendency towards a connection between anteroloph and posteroloph, lingually of the protocone (see Stehlin \& Schaub, 1951; fig. 198), and we think this character should form part of the diagnosis of the genus Gliravus. Consequently, the material attributed to Gliravus cf. majori by Vianey-Liaud (1969) is not a Gliravus, and the only certain specimen of G. majori is the holotype.

Freudenthal (2004) placed G. garouillensis VianeyLiaud, 1994 with doubt in Schizogliravus (= Butseloglis). Peigné et al. (2014) noted that some specimens of that species show the same tendency to form a ridge lingually of the protocone. Therefore G. garouillensis may well belong to Gliravus.

The attribution of the following species is doubtful: G. meridionalis Hartenberger, 1971, G. minor Bosma \& de Bruijn, 1982, G. pyrenaicus Agustí \& Arcas, 1997, and G. robiacensis Hartenberger, 1965. They are from the late Eocene (MP17) and seem to represent an as yet undescribed genus, since there is no record in the interval MP18-MP24.

The genus Butseloglis Vianey-Liaud, 2004 contains $B$. bravoi (Hugueney, Adrover \& Moissenet, 1985), B. bruijni (Hugueney, 1967), B. daamsi (Bosma \& de Bruijn, 1982), B. hispanicus (van Dam, 1998), B. itardiensis (Vianey- 
Liaud, 1989), B. micio (Misonne, 1957), B. montisalbani (Freudenthal, 2004), and B. tenuis (Bahlo, 1975).

The genus Glamys Vianey-Liaud, 1989 contains G. priscus (Stehlin \& Schaub, 1951), G. olallensis Freudenthal, 1996, G. umbriae Freudenthal, 2004, and possibly G. devoogdi (Bosma \& de Bruijn, 1979), G. fordi (Bosma \& de Bruijn, 1979), and G. minor (Bosma \& de Bruijn, 1982).

Gliravus majori Stehlin \& Schaub, 1951

Type-locality. Quercy.

Holotype. Skull with P3-M3 dext., Q.P.625, Basel.

Original diagnosis. (Translated from German and adapted): "The anteroloph occupies the entire width of the crown, and in M3 it forms, together with the posteroloph, a continuous internal cingulum".

Table 3. Species originally described as Gliravus and our taxonomic interpretation.

\begin{tabular}{|c|c|c|c|}
\hline species & genus & type locality & age \\
\hline $\begin{array}{l}\text { alvarezae Lacomba \& } \\
\text { Morales, } 1987\end{array}$ & Gliravus & $\begin{array}{l}\text { Carrascosa } \\
\text { del Campo }\end{array}$ & MP25 \\
\hline $\begin{array}{l}\text { bravoi Hugueney, } \\
\text { Adrover \& Moissenet, } \\
1985\end{array}$ & Butseloglis & Vivel del Río & MP28 \\
\hline bruijni Hugueney, 1967 & Butseloglis & Coderet & MP30 \\
\hline $\begin{array}{l}\text { caracensis Daams, } \\
\text { Freudenthal, Lacomba \& } \\
\text { Alvarez, } 1989\end{array}$ & Gliravus & Pareja & MP25 \\
\hline $\begin{array}{l}\text { daamsi Bosma \& de } \\
\text { Bruijn, } 1982\end{array}$ & Butseloglis & $\begin{array}{l}\text { Headon Hill } \\
2\end{array}$ & MP17 \\
\hline $\begin{array}{l}\text { devoogdi Bosma \& de } \\
\text { Bruijn, } 1979\end{array}$ & Glamys & $\begin{array}{l}\text { Headon Hill } \\
7\end{array}$ & MP19 \\
\hline $\begin{array}{l}\text { fordi Bosma \& de Bruijn, } \\
1979\end{array}$ & Glamys & $\begin{array}{l}\text { Bouldnor } \\
\text { Cliff }\end{array}$ & MP21 \\
\hline $\begin{array}{l}\text { hispanicus van Dam, } \\
1998\end{array}$ & Butseloglis & Sossís 2B & MP17 \\
\hline $\begin{array}{l}\text { itardiensis Vianey-Liaud, } \\
1989\end{array}$ & Butseloglis & Itardies & MP23 \\
\hline $\begin{array}{l}\text { majori Stehlin \& Schaub, } \\
1951\end{array}$ & Gliravus & Quercy & $?$ \\
\hline $\begin{array}{l}\text { meridionalis } \\
\text { Hartenberger, } 1971\end{array}$ & $?$ & Fons 4 & MP17 \\
\hline micio (Misonne, 1957) & Butseloglis & Hoogbutsel & MP21 \\
\hline $\begin{array}{l}\text { minor Bosma \& de } \\
\text { Bruijn, } 1982\end{array}$ & $?$ & $\begin{array}{l}\text { Headon Hill } \\
2\end{array}$ & MP17 \\
\hline $\begin{array}{l}\text { priscus Stehlin \& Schaub, } \\
1951\end{array}$ & Glamys & La Débruge & MP18 \\
\hline $\begin{array}{l}\text { pyrenaicus Agustí \& } \\
\text { Arcas, } 1997\end{array}$ & $?$ & Sossís 1 & MP17 \\
\hline $\begin{array}{l}\text { robiacensis Hartenberger, } \\
1965\end{array}$ & $?$ & Robiac Sud & MP16 \\
\hline tenuis Bahlo, 1975 & Butseloglis & Heimersheim & MP23 \\
\hline
\end{tabular}

\section{Description of Gliravus majori from Mirambueno} 4B. (Fig. 3, Table 4).

p4. Shape blunt. Anterolophid interrupted. Anterotropid absent (9) or small (1). Metalophid free (2) or high connected to the metaconid (8). Centrolophid absent (5), short (4), or of medium length (1). Centrolophidmetaconid connection absent (9) or low (1). Mesostylid absent. Mesoconid placed on the labial border (2) or more centrally (8). Mesolophid short (3), directed towards the metaconid (3), connected to the metaconid (2), directed towards the entoconid (1), or connected to the entoconid (1). Posterotropid absent (8) or very small (2).

m1. Anterolophid labially free. Anterotropid absent. Metalophid free (1), low connected to the metaconid (7), or high connected to the metaconid (6). Centrolophid absent (13) or of medium length (2). Centrolophid-metaconid connection absent (14) or high (1). Mesostylid absent. Mesoconid placed on the labial border (9) or more centrally (6). Mesolophid of medium length (2), directed towards the metaconid (7), connected to the metaconid (5), or to lingual border (1). Posterotropid absent (11), very small (1), or of medium length (3).

m2. Anterolophid labially free. Anterotropid absent. Metalophid free (4), low connected to the metaconid (9), or high connected to the metaconid (4). Centrolophid absent (14) or short (3). Centrolophid-metaconid connection absent (14) or high (3). Mesostylid absent. Mesoconid placed on the labial border (6) or more centrally (10). Mesolophid directed towards the metaconid (6), connected to the metaconid (9), or directed towards the entoconid (2). Posterotropid absent (15) or very small (2).

m3. Anterolophid labially free. Anterotropid absent. Metalophid free (3), low connected to the metaconid (2), or high connected to the metaconid (9). Centrolophid absent (10), short (3), or of medium length (3). Centrolophidmetaconid connection absent (13), low (1), or high (1). Mesostylid absent (11) or crest (1). Mesoconid placed on the labial border (4) or more centrally (14). Mesolophid short (1), directed towards the metaconid (3), connected to the metaconid (4), directed towards the entoconid (3), or connected to the entoconid (6). Posterotropid absent.

P4. Anteroloph short (2) or long (5). Anterotrope absent. Precentroloph absent (4) or long (2). Midcentroloph absent (4), short (2), or long (1). Postcentroloph absent. Prototrope absent. Metatrope absent. Centrolophs not connected. Posterotrope absent. Endoloph formed by the protocone alone (4), anteriorly interrupted (1), or posteriorly interrupted (2). Lingual border smooth.

M1. Anteroloph lingually free. Anterotrope absent. Precentroloph absent (13), short (2), or long (1). Precentroloph absent (14) or connected to the paracone (2). Midcentroloph absent (14), short (1), or long (1). Postcentroloph absent (2) or long (14). Postcentroloph absent (3), connected to the metacone (4), or free from the metacone (9). Prototrope absent. Metatrope absent. 

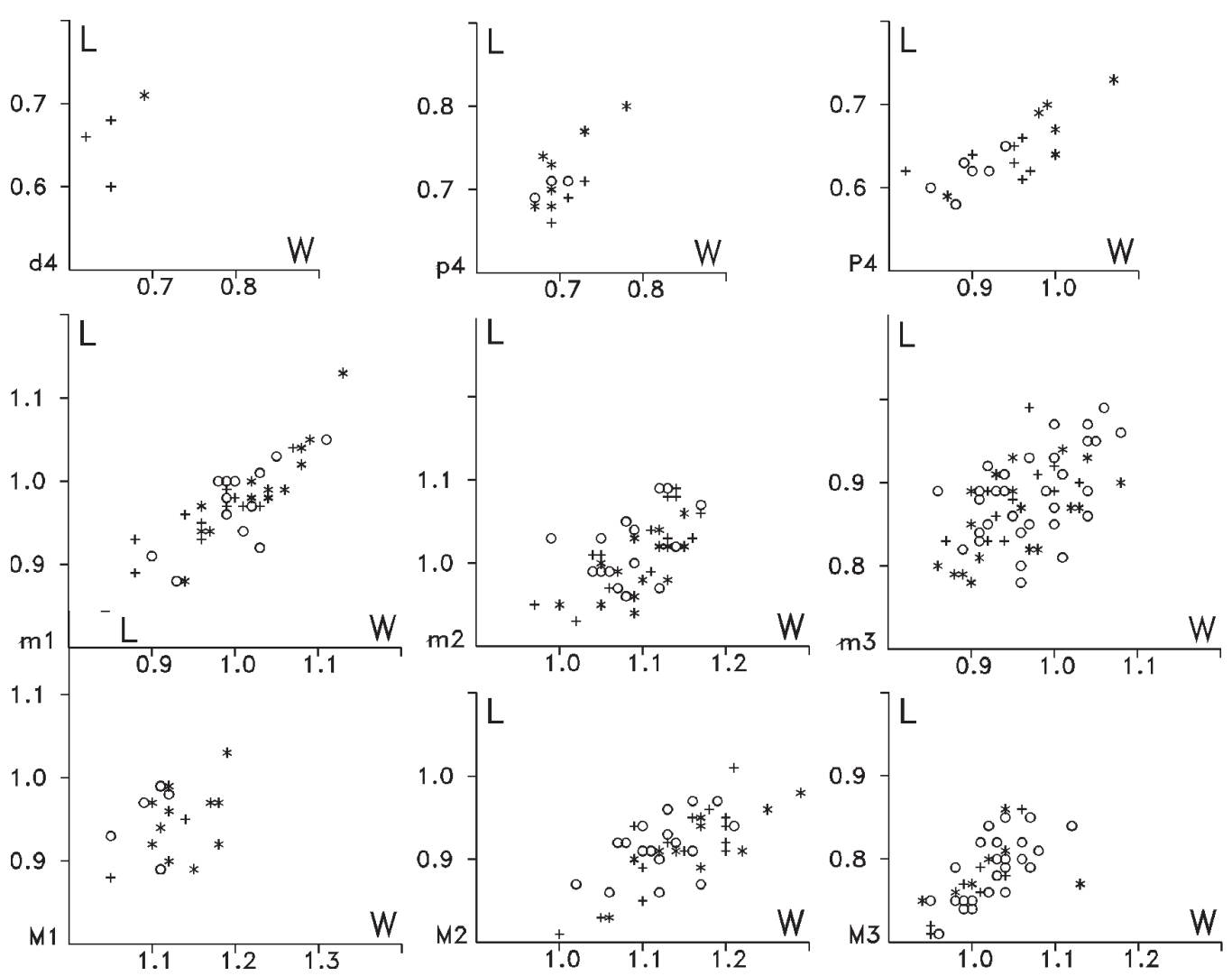

Gliravus majori

* MIRAB

- MIR4C

+ MIR4D

Figure 3. Length/width diagrams of Gliravus majori from Mirambueno.

Centrolophs not connected. Posterotrope absent. Endoloph formed by the protocone alone (10), partially around protocone (2), or all around protocone (1).

M2. Anteroloph lingually free. Anterotrope absent. Precentroloph absent (9), short (1), or long (1). Precentroloph absent (9) or connected to the paracone (2). Midcentroloph absent (6) or long (6). Postcentroloph absent (7) or long (5). Postcentroloph absent (6), connected to the metacone (1), or free from the metacone (4). Prototrope absent. Metatrope absent. Centrolophs not connected. Posterotrope absent. Endoloph formed by the protocone alone (3), partially around protocone (4), or all around protocone (3).

M3. Anteroloph lingually free (4) or lingually high connected (1). Anterotrope absent. Prototrope absent. Metatrope absent. Crests inside the trigone: 1 crest (6) or two crests (1). Mesostyl absent (4) or present (3). Posterotrope absent. Endoloph formed by the protocone alone (1), partially around protocone (2), or all around protocone (2). Lingual border smooth.

\section{Description of Gliravus majori from Mirambueno} 4C. (Fig. 3, Figs. 4.1-4.4, Table 4).

p4. Shape blunt. Anterolophid interrupted (1) or continuous (2). Anterotropid absent. Metalophid free (2) or high connected to the metaconid (1). Centrolophid absent. Centrolophid-metaconid connection absent. Mesostylid absent. Mesoconid absent. Mesolophid absent. Posterotropid absent.

m1. Anterolophid labially free. Anterotropid absent (13), very small (1), or small (1). Metalophid free (7), low connected to the metaconid (4), or high connected to the metaconid (3). Centrolophid absent (14) or short (1). Centrolophid-metaconid connection absent (14) or low (1). Mesostylid absent. Mesoconid placed on the labial border (10) or more centrally (5). Mesolophid directed towards the metaconid (10) or connected to the metaconid (5). Posterotropid absent (7), very small (6) or small (2).

m2. Anterolophid labially free. Anterotropid absent. Metalophid free (4), low connected to the metaconid (9), or high connected to the metaconid (2). Centrolophid absent (13), short (2), or of medium length (1). Centrolophidmetaconid connection absent (15) or low (1). Mesoconid placed on the labial border (1) or more centrally (15). Mesolophid curved forward (1), directed towards the metaconid (8), connected to the metaconid (6), or directed towards the entoconid (1). Posterotropid absent (12), very small (2), or small (2).

m3. Anterolophid labially free (31) or labially connected (1). Anterotropid absent (31) or very small (1). 
Table 4. Measurements of Gliravus majori, G. alvarezae (CARRAS), and G. caracensis (PAREJ).

\begin{tabular}{|c|c|c|c|c|c|c|c|c|c|c|c|c|}
\hline \multirow[b]{2}{*}{$\mathrm{d} 4$} & \multicolumn{6}{|c|}{ Length } & \multicolumn{6}{|c|}{ Width } \\
\hline & $\mathrm{N}$ & Min. & Mean & Max. & $V^{\prime}$ & $\sigma$ & $\mathrm{N}$ & Min. & Mean & Max. & $V^{\prime}$ & $\sigma$ \\
\hline MIR4D & 3 & 0.60 & 0.647 & 0.68 & 12.5 & & 3 & 0.62 & 0.640 & 0.65 & 4.7 & \\
\hline $\begin{array}{l}\text { MIR4B } \\
\text { p4 }\end{array}$ & 1 & & 0.710 & & & & 1 & & 0.690 & & & \\
\hline CARRAS & 15 & 0.74 & 0.85 & 1.02 & 31.8 & & 15 & 0.73 & 0.81 & 0.92 & 23.0 & \\
\hline PAREJ & 1 & & 0.73 & & & & 1 & & 0.69 & & & \\
\hline MIR4D & 3 & 0.66 & 0.687 & 0.71 & 7.3 & & 3 & 0.69 & 0.710 & 0.73 & 5.6 & \\
\hline MIR4C & 3 & 0.69 & 0.703 & 0.71 & 2.9 & & 3 & 0.67 & 0.690 & 0.71 & 5.8 & \\
\hline $\begin{array}{l}\text { MIR4B } \\
\text { m1 }\end{array}$ & 7 & 0.68 & 0.729 & 0.80 & 16.2 & 0.046 & 9 & 0.63 & 0.701 & 0.78 & 21.3 & 0.045 \\
\hline CARRAS & 34 & 0.89 & 1.01 & 1.17 & 27.2 & & 34 & 0.95 & 1.05 & 1.24 & 26.5 & \\
\hline PAREJ & 21 & 0.91 & 0.95 & 0.99 & 8.4 & & 21 & 0.92 & 0.99 & 1.10 & 17.8 & \\
\hline MIR4D & 11 & 0.89 & 0.962 & 1.04 & 15.5 & 0.038 & 11 & 0.88 & 0.974 & 1.07 & 19.5 & 0.058 \\
\hline MIR4C & 14 & 0.88 & 0.968 & 1.05 & 17.6 & 0.051 & 14 & 0.90 & 1.009 & 1.11 & 20.9 & 0.058 \\
\hline $\begin{array}{l}\text { MIR4B } \\
\mathrm{m} 2\end{array}$ & 14 & 0.88 & 0.988 & 1.13 & 24.9 & 0.062 & 13 & 0.93 & 1.029 & 1.13 & 19.4 & 0.060 \\
\hline CARRAS & 36 & 0.87 & 1.11 & 1.17 & 29.4 & & 36 & 0.95 & 1.13 & 1.25 & 27.3 & \\
\hline PAREJ & 21 & 0.90 & 0.95 & 1.03 & 13.5 & & 21 & 0.93 & 1.06 & 1.16 & 22.0 & \\
\hline MIR4D & 13 & 0.93 & 1.021 & 1.09 & 15.8 & 0.051 & 13 & 0.97 & 1.094 & 1.17 & 18.7 & 0.060 \\
\hline MIR4C & 15 & 0.96 & 1.019 & 1.09 & 12.7 & 0.043 & 16 & 0.99 & 1.084 & 1.17 & 16.7 & 0.046 \\
\hline $\begin{array}{l}\text { MIR4B } \\
\mathrm{m} 1,2\end{array}$ & 14 & 0.94 & 0.996 & 1.06 & 12.0 & 0.037 & 15 & 0.97 & 1.085 & 1.15 & 17.0 & 0.051 \\
\hline CARRAS & 70 & 0.87 & 1.061 & 1.17 & 29.4 & & 70 & 0.95 & 1.091 & 1.25 & 27.3 & \\
\hline PAREJ & 42 & 0.90 & 0.950 & 1.03 & 13.5 & & 42 & 0.92 & 1.025 & 1.16 & 23.1 & \\
\hline MIR4D & 24 & 0.89 & 0.994 & 1.09 & 20.2 & 0.054 & 24 & 0.88 & 1.039 & 1.17 & 28.3 & 0.084 \\
\hline MIR4C & 29 & 0.88 & 0.994 & 1.09 & 21.3 & 0.053 & 30 & 0.90 & 1.049 & 1.17 & 26.1 & 0.063 \\
\hline $\begin{array}{l}\text { MIR4B } \\
\text { m3 }\end{array}$ & 28 & 0.88 & 0.992 & 1.13 & 24.9 & 0.050 & 28 & 0.93 & 1.059 & 1.15 & 21.2 & 0.061 \\
\hline CARRAS & 12 & 0.85 & 0.92 & 1.00 & 16.2 & & 12 & 0.94 & 0.99 & 1.04 & 10.1 & \\
\hline PAREJ & 9 & 0.84 & 0.88 & 0.90 & 6.9 & & 9 & 0.89 & 0.95 & 1.01 & 12.6 & \\
\hline MIR4D & 11 & 0.83 & 0.885 & 0.99 & 17.6 & 0.048 & 11 & 0.87 & 0.955 & 1.03 & 16.8 & 0.046 \\
\hline MIR4C & 32 & 0.78 & 0.888 & 0.99 & 23.7 & 0.053 & 31 & 0.86 & 0.973 & 1.08 & 22.7 & 0.056 \\
\hline $\begin{array}{l}\text { MIR4B } \\
\text { P4 }\end{array}$ & 18 & 0.78 & 0.859 & 0.94 & 18.6 & 0.053 & 18 & 0.86 & 0.953 & 1.08 & 22.7 & 0.064 \\
\hline CARRAS & 18 & 0.78 & 0.88 & 0.89 & 13.2 & & 18 & 0.89 & 1.08 & 1.25 & 33.6 & \\
\hline PAREJ & 5 & 0.60 & 0.69 & 0.75 & 22.2 & & 5 & 0.92 & 0.99 & 1.08 & 16.0 & \\
\hline MIR4D & 8 & 0.61 & 0.643 & 0.71 & 15.2 & 0.032 & 8 & 0.82 & 0.931 & 0.97 & 16.8 & 0.050 \\
\hline MIR4C & 7 & 0.58 & 0.626 & 0.68 & 15.9 & 0.033 & 6 & 0.85 & 0.897 & 0.94 & 10.1 & 0.031 \\
\hline $\begin{array}{l}\text { MIR4B } \\
\text { M1 }\end{array}$ & 7 & 0.59 & 0.669 & 0.73 & 21.2 & 0.045 & 6 & 0.87 & 0.985 & 1.07 & 20.6 & 0.065 \\
\hline MIR4D & 3 & 0.88 & 0.930 & 0.96 & 8.7 & & 2 & 1.05 & 1.095 & 1.14 & 8.2 & \\
\hline MIR4C & 5 & 0.89 & 0.952 & 0.99 & 10.6 & 0.041 & 5 & 1.05 & 1.096 & 1.12 & 6.5 & 0.028 \\
\hline $\begin{array}{l}\text { MIR4B } \\
\text { M2 }\end{array}$ & 12 & 0.89 & 0.955 & 1.03 & 14.6 & 0.042 & 13 & 1.06 & 1.130 & 1.19 & 11.6 & 0.040 \\
\hline MIR4D & 14 & 0.81 & 0.914 & 1.01 & 22.0 & 0.054 & 14 & 1.00 & 1.141 & 1.21 & 19.0 & 0.065 \\
\hline MIR4C & 17 & 0.86 & 0.915 & 0.97 & 12.0 & 0.035 & 17 & 1.02 & 1.121 & 1.20 & 16.2 & 0.048 \\
\hline $\begin{array}{l}\text { MIR4B } \\
\text { M1,2 }\end{array}$ & 10 & 0.83 & 0.918 & 0.98 & 16.6 & 0.042 & 10 & 1.06 & 1.168 & 1.29 & 19.6 & 0.071 \\
\hline CARRAS & 66 & 0.92 & 1.03 & 1.16 & 23.1 & & 66 & 1.09 & 1.24 & 1.45 & 28.3 & \\
\hline PAREJ & 58 & 0.82 & 0.92 & 1.02 & 21.7 & & 58 & 0.98 & 1.12 & 1.27 & 25.8 & \\
\hline MIR4D & 17 & 0.81 & 0.916 & 1.01 & 22.0 & 0.051 & 16 & 1.00 & 1.135 & 1.21 & 19.0 & 0.065 \\
\hline MIR4C & 22 & 0.86 & 0.924 & 0.99 & 14.1 & 0.039 & 22 & 1.02 & 1.115 & 1.20 & 16.2 & 0.045 \\
\hline $\begin{array}{l}\text { MIR4B } \\
\text { M3 }\end{array}$ & 22 & 0.83 & 0.938 & 1.03 & 21.5 & 0.045 & 23 & 1.06 & 1.147 & 1.29 & 19.6 & 0.057 \\
\hline CARRAS & 17 & 0.84 & 0.95 & 1.07 & 24.1 & & 17 & 0.86 & 1.00 & 1.10 & 24.5 & \\
\hline MIR4D & 7 & 0.71 & 0.770 & 0.86 & 19.1 & 0.050 & 7 & 0.95 & 1.001 & 1.06 & 10.9 & 0.042 \\
\hline MIR4C & 25 & 0.71 & 0.787 & 0.85 & 17.9 & 0.039 & 24 & 0.95 & 1.024 & 1.12 & 16.4 & 0.042 \\
\hline MIR4B & 7 & 0.75 & 0.789 & 0.86 & 13.7 & 0.038 & 7 & 0.94 & 1.021 & 1.13 & 18.4 & 0.060 \\
\hline
\end{tabular}


Metalophid free (5), low connected to the metaconid (6), or high connected to the metaconid (18). Centrolophid absent (14), short (12), or of medium length (4). Centrolophidmetaconid connection absent (15), low (3), or high (12). Mesostylid absent (15), present (5), or crest (5). Mesoconid placed on the labial border (9) or more centrally (23). Mesolophid directed towards the metaconid (1), connected to the metaconid (1), directed towards the entoconid (15), or connected to the entoconid (14). Posterotropid absent (31) or very small (1).

P4. Anteroloph absent (3), short (2), of medium length (1), or long (1). Anterotrope absent. Precentroloph absent (6) or long (1). Midcentroloph absent (4), short (1), or of medium length (2). Postcentroloph absent (6) or long (1). Prototrope absent. Metatrope absent. Centrolophs not connected. Posterotrope absent. Endoloph formed by the protocone alone. Lingual border smooth.

M1. Anteroloph lingually free. Anterotrope absent. Precentroloph absent (5) or long (1). Precentroloph absent (5) or connected to the paracone (1). Midcentroloph absent. Postcentroloph absent (1), short (1), or long (5). Postcentroloph absent (1), connected to the metacone (2), or free from the metacone (4). Prototrope absent. Metatrope absent. Centrolophs not connected. Posterotrope absent. Endoloph formed by the protocone alone (5), partially around protocone (1), or all around protocone (1). Lingual border smooth.

M2. Anteroloph lingually free. Anterotrope absent. Precentroloph absent (17) or long (1). Precentroloph absent (17) or connected to the paracone (1). Midcentroloph absent (5), of medium length (2), or long (10). Postcentroloph absent (13) or long (4). Postcentroloph absent (13), connected to the metacone (2), or free from the metacone (2). Prototrope absent. Metatrope absent. Centrolophs not connected. Posterotrope absent. Endoloph formed by the protocone alone (13), partially around protocone (4), or all around protocone (1). Lingual border smooth.

M3. Anteroloph lingually free (21), lingually low connected (2), or lingually high connected (1). Anterotrope absent. Prototrope absent. Metatrope absent. Centrolophs not connected. Crests inside the trigone: 1 crest (23) or two crests (2). Mesostyl absent. Posterotrope absent. Endoloph formed by the protocone alone (10), partially around protocone (8), or all around protocone (6).

\section{Description of Gliravus majori from Mirambueno} 4D. (Fig. 3, Table 4).

d4. Anterolophid interrupted. Anterotropid absent. Centrolophid absent (1) or long (1). Centrolophidmetaconid connection absent (1) or low (1). Mesostylid absent. Mesoconid placed centrally. Mesolophid absent. Posterotropid absent.

p4. Shape blunt. Anterolophid continuous. Anterotropid absent. Metalophid high connected to the metaconid. Centrolophid absent. Centrolophid-metaconid connection absent. Mesostylid absent. Mesoconid placed centrally. Mesolophid absent. Posterotropid absent.

m1. Anterolophid labially free. Anterotropid absent. Metalophid free (5), low connected to the metaconid (4), or high connected to the metaconid (2). Centrolophid absent (9) or short (2). Centrolophid-metaconid connection absent (10) or low (1). Mesostylid absent. Mesoconid placed on the labial border (10) or more centrally (1). Mesolophid directed towards the metaconid (7), connected to the metaconid (3), or directed towards the entoconid (1). Posterotropid absent (7) or small (4).

In two specimens there is a longitudinal connection (ectolophid) between metalophid, mesolophid and posterolophid

m2. Anterolophid labially free. Anterotropid absent. Metalophid free (6), low connected to the metaconid (5), or high connected to the metaconid (2). Centrolophid absent (12) or short (1). Centrolophid-metaconid connection absent. Mesostylid absent (11), present (1), or crest (1). Mesoconid placed on the labial border (6) or more centrally (7). Mesolophid of medium length (1), directed towards the metaconid (8), or connected to the metaconid (4). Posterotropid absent (8), very small (2), or small (3).

In one specimen there is a longitudinal connection (ectolophid) between metalophid, mesolophid and posterolophid

m3. Anterolophid labially free. Anterotropid absent. Metalophid free (1) or high connected to the metaconid (9). Centrolophid absent (4), short (1), or of medium length (4). Centrolophid-metaconid connection absent (5) or low (5). Mesostylid absent. Mesoconid placed on the labial border (4) or more centrally (7). Mesolophid directed towards the entoconid. Posterotropid absent.

P4. Anteroloph absent (1), short (4), or long (3). Anterotrope absent. Precentroloph absent. Midcentroloph absent (5), short (2), of medium length (1), or long (1). Postcentroloph absent (6), of medium length (1), or long (2). Prototrope absent. Metatrope absent. Centrolophs not connected. Posterotrope absent. Endoloph formed by the protocone alone (5) or posteriorly interrupted (4). Lingual border smooth.

M1. Anteroloph lingually free. Anterotrope absent. Precentroloph absent. Precentroloph absent. Midcentroloph absent (1) or long (2). Postcentroloph absent (2) or long (1). Postcentroloph absent (2) or free from the metacone (1). Prototrope absent. Metatrope absent. Centrolophs not connected. Posterotrope absent. Endoloph formed by the protocone alone (1) or partially around protocone (2).

M2. Anteroloph lingually free. Anterotrope absent. Precentroloph absent (12) or long (1). Precentroloph absent (12) or connected to the paracone (1). Midcentroloph absent (5) or long (8). Postcentroloph absent (9) or long (4). Postcentroloph absent (9) or connected to the metacone (4). Prototrope absent. Metatrope absent. Centrolophs not connected. Posterotrope absent. Endoloph formed by the 
protocone alone (8), partially around protocone (3), or all around protocone (2).

M3. Anteroloph lingually free (6) or lingually low connected (1). Anterotrope absent. Crests inside the trigone: 1 crest (6) or two crests (1). Mesostyl absent. Posterotrope absent. Endoloph complete (1), partially around protocone (2), or all around protocone (4).

Remarks. In MIR4D, the three specimens of $\mathrm{p} 4$ are extremely reduced, and consist of only two crests: the posterolophid, and an anterior crest for which we cannot say whether it is the anterolophid or the metalophid. MIR4B 86, MIR4C1025 and MIR4C1026 show this feature too.

Discussion on the Gliravus species. G. alvarezae is characterized by a continuous cingulum, lingually of the protocone, in all upper molars. In G. caracensis, this feature is present but not frequent $(8$ out of $61 \mathrm{M} 1,2)$ and in 26 specimens such a cingulum is present but incomplete. In G. majori, this character is only present in the M3 and incomplete in $\mathrm{M} 2$, but G. majori is only known by its type specimen, a skull fragment from the Quercy, and cannot be evaluated statistically. Therefore, we may assume that G. alvarezae and G. majori are different species, but the comparison of G. majori and G. caracensis is not possible.

The three species are roughly of the same size, but there are some problems. In MIR4B there is one large $\mathrm{m} 1$ (MIR4B 94, $1.13 \times 1.13$ ), well outside the range of the rest of the material (Fig. 3), and consequently the variability coefficient $V^{\prime}$ is very high (24.9), and suggests the presence of a second species (Table 4). Comparing the measurements of our material with the published data of G. alvarezae we found the latter species to present a very wide size range in all elements, certainly not common within a single species (Table 4). Only the size limits of $\mathrm{m} 1$ are comparable to our material, for all other elements the maximum is considerably larger, and precisely in $\mathrm{m} 1$ we suspect the presence of a second species. An additional problem is the scale in the figure of Lacomba \& Morales (1987; pl. 2, fig. 13): according to the scale the holotype of $G$. alvarezae would have a length of 1.21 , outside the limits of the measurements table in the same paper.

\section{Genus Butseloglis Vianey-Liaud, 2004}

Synonymy. Schizogliravus Freudenthal, 2004

Though the publication of the paper by Vianey-Liaud is marked as 2003, it appeared in 2004. Freudenthal (2004) created the genus Schizogliravus in a paper that appeared several months later.

Type species. Butseloglis micio (Misonne, 1957) from Hoogbutsel (Belgium), lectotype: m2 dext., Ct.M. 1143 (Natural Science Institute, Brussels).
Diagnosis. The original diagnosis of this genus is based on skull characters, in spite of the fact that no such material is found in Hoogbutsel, the type-locality of the typespecies. Probably Gliravus itardiensis Vianey-Liaud, 1989, type-locality Itardies, is the basis for the skull characters in the diagnosis of Butseloglis.

Freudenthal (1996) considered the difference beweeen B. itardiensis and B. micio to be the presence/absence of an anterotropid in m1,2. In fact, Vianey-Liaud (1989) reported all $24 \mathrm{ml}, 2$ from Itardies to lack the anterotropid and the anterotropid of $\mathrm{m} 1,2$ in $B$. itardiensis from OLA4A is absent, except for one case of a very small anterotropid among $143 \mathrm{ml}, 2$. On the other hand, Vianey-Liaud (1994) said that $101 \mathrm{~m} 1,2$ of $B$. micio from Hoogbutsel present all variations of the anterotropid between absent and welldeveloped. In our opinion such a different morphology of $\mathrm{m} 1,2$ justifies the distinction of two species.

However, the homogenity of the material attributed to Butseloglis micio by Vianey-Liaud (1994) is questionable; maybe (most of) the m1,2 with anterotropid belong to another species, probably a Bransatoglis. If that is true $B$. itardiensis indeed may be a synonym of $B$. micio.

The lectotype of B. micio lacks the anterotropid and its general aspect is fully compatible with the diagnosis of Butseloglis, as given hereafter.

In view of the fact that skull characters are hardly ever known for fossil glirid species, we prefer the diagnosis of Schizogliravus Freudenthal, 2004, to characterize Butseloglis: P4 triangular like in Glamys with a fairly well developed anteroloph. Upper molars with two centrolophs that are frequently connected lingually, or with one single centroloph, which may be the precentroloph or the postcentroloph; extra crests practically absent. In the lower molars, the anterotropid is absent to rare, the centrolophid varies between absent and frequent, but is not very well developed, the posterotropid may be frequent. The posterolingual corner of M3 is strongly reduced.

\section{Butseloglis bruijni (Hugueney, 1967)}

Type locality. Coderet, France (MP30).

Holotype. $\mathrm{m} 2$ sin., 96182, Lyon.

Original diagnosis. (Translated from French). "About the size of Gliravus majori Stehlin and Schaub, Gliravus bruijni differs from all the currently known species of the genus by the absence of a mesoconid in the lower molars; the mesolophid, more or less reduced has a tendency to fuse with the hypoconid; the anterolophid, displaced by the forward position of the protoconid, is short; there are no accessory crests in the posterosinusid; the lower molars have three roots. In the upper molars, generally asymmetrical, the protocone has a tendency to split, the cingulums do not or hardly reach beyond the point of 
the trigone; the anterior one may be in contact with the protocone; presence of one or two centrolophs of variable direction. P4 very molariform".

Description of Butseloglis bruijni from Mirambueno 1. (Figs. 4.5-4.8, Fig. 5, Table 5).

p4. Shape blunt (1) or pointed (1). Anterolophid interrupted. Anterotropid absent. Metalophid low connected to the metaconid (1) or high connected to the metaconid (1). Centrolophid absent. Centrolophid-metaconid connection absent. Mesostylid absent. Mesoconid on the hypoconid. Mesolophid short. Posterotropid absent.

m1. Anterolophid labially free. Anterotropid absent. Metalophid low connected to the metaconid. Centrolophid absent. Centrolophid-metaconid connection absent. Mesostylid absent. Mesoconid placed centrally. Mesolophid of medium length (1) or directed towards the metaconid (1). Posterotropid absent.

m2. Anterolophid labially free. Anterotropid absent. Metalophid low connected to the metaconid (5) or high connected to the metaconid (2). Centrolophid absent. Centrolophid-metaconid connection absent. Mesostylid absent. Mesoconid placed on the labial border (1), placed centrally (2), or on the hypoconid (4). Mesolophid of medium length (2), curved forward (1), directed towards the entoconid (3), or long and straight (1). Posterotropid absent (6) or very small (1).

m3. Anterolophid labially free. Anterotropid absent. Metalophid low connected to the metaconid (1) or high connected to the metaconid (1). Centrolophid absent. Centrolophid-metaconid connection absent. Mesostylid absent. Mesoconid placed centrally. Mesolophid directed towards the entoconid. Posterotropid absent.

P4. Anteroloph absent (1), short (1), of medium length (3), or long (6). Anterotrope absent (10) or short (1). Precentroloph absent (5), short (4), or of medium length (2). Midcentroloph absent. Postcentroloph absent (10) or short (1). Prototrope absent. Metatrope absent. Centrolophs not connected. Posterotrope absent. Endoloph formed by the protocone alone. Lingual border smooth.

M1. Anteroloph lingually free. Anterotrope absent. Precentroloph absent (2) or of medium length (2). Precentroloph absent (2) or connected to the paracone (1). Midcentroloph absent. Postcentroloph absent (2), short (1), or of medium length (1). Postcentroloph absent (2) or connected to the metacone (1). Prototrope absent. Metatrope absent. The centrolophs are not connected. Posterotrope absent. Endoloph formed by the protocone alone. Lingual border smooth.

M2. Anteroloph lingually free. Anterotrope absent. Precentroloph absent (5), short (1), or long (2). Precentroloph absent (5), connected to the paracone (2), or free from the paracone (1), generally vague. Midcentroloph absent. Postcentroloph absent. Prototrope absent. Metatrope absent. Centrolophs not connected.
Posterotrope absent. Endoloph formed by the protocone alone. Lingual border smooth.

M3. Anteroloph lingually free (6) or lingually high connected (1). Anterotrope absent. Precentroloph absent (4) or long (2). Postcentroloph absent (4) or long (2). Prototrope absent. Metatrope absent. Centrolophs not connected. Crests inside the trigone: absent (1), one crest (5), or four crests (1). Mesostyl absent (6) or present (1). Posterotrope absent. Endoloph formed by the protocone alone (6) or complete (1). Lingual border smooth.

\section{Description of Butseloglis bruijni from Mirambueno} 2A. (Fig. 5, Table 5).

d4. Anterolophid continuous. Anterotropid absent. Metalophid high connected to the metaconid. Centrolophid absent. Centrolophid-metaconid connection absent. Mesostylid absent. Mesoconid placed centrally. Mesolophid of medium length. Posterotropid absent.

p4. Shape blunt. Anterolophid interrupted (1) or continuous (1). Anterotropid absent. Metalophid high connected to the metaconid. Centrolophid absent. Centrolophid-metaconid connection absent. Mesostylid absent. Mesoconid placed centrally (1) or on the hypoconid (1). Mesolophid absent. Posterotropid absent.

m1. Anterolophid labially free. Anterotropid absent. Metalophid high connected to the metaconid. Centrolophid absent. Centrolophid-metaconid connection absent. Mesostylid absent. Mesoconid on the hypoconid. Mesolophid directed towards the metaconid. Posterotropid absent.

m2. Anterolophid labially free. Anterotropid absent. Metalophid free (1) or low connected to the metaconid (4). Centrolophid absent (3), short (1), or short central (1). Centrolophid-metaconid connection absent (4) or low (1). Mesostylid absent. Mesoconid placed on the labial border (2), placed centrally (1), or on the hypoconid (2). Mesolophid directed towards the metaconid (2), directed towards the entoconid (2), or connected to the entoconid (1). Posterotropid absent (2) or very small (3).

m3. Anterolophid labially free. Anterotropid absent. Metalophid low connected to the metaconid (2) or high connected to the metaconid (1). Centrolophid absent (2) or short (1). Centrolophid-metaconid connection absent (2) or high (1). Mesostylid absent. Mesoconid placed centrally (2) or on the hypoconid (1). Mesolophid directed towards the entoconid (1) or connected to the entoconid (2). Posterotropid absent.

D4. Anteroloph long. Anterotrope absent. Precentroloph long. Postcentroloph short. Prototrope absent. Metatrope absent. Centrolophs not connected. Posterotrope absent. Endoloph formed by the protocone alone. Lingual border smooth.

P4. Anteroloph long. Anterotrope absent. Precentroloph of medium length. Midcentroloph absent. Postcentroloph absent. Prototrope absent. Metatrope absent. Centrolophs 


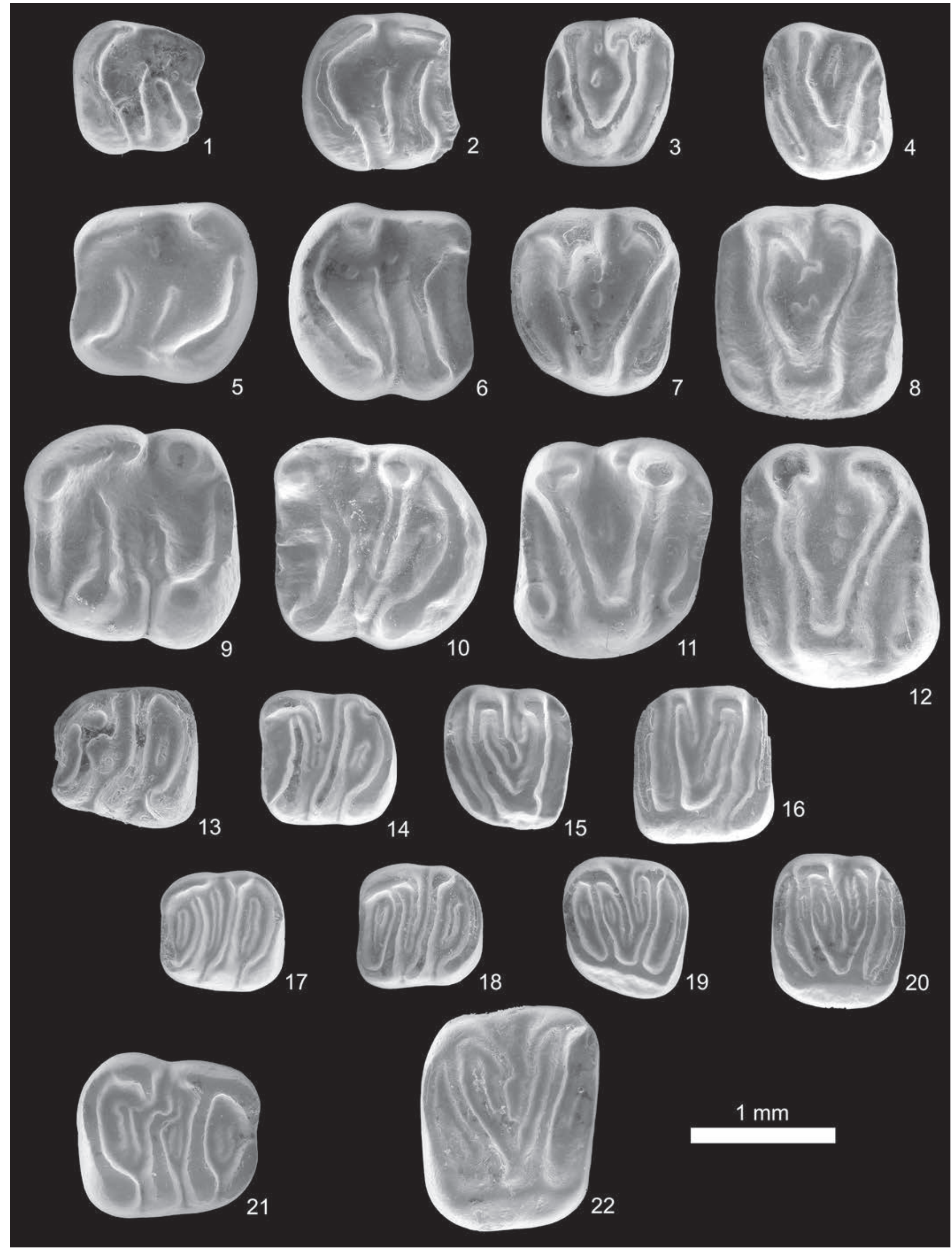


not connected. Posterotrope absent. Endoloph posteriorly interrupted. Lingual border smooth.

M1. Anteroloph lingually free. Anterotrope absent. Precentroloph absent. Precentroloph absent. Midcentroloph absent. Postcentroloph long. Postcentroloph free from the metacone. Prototrope absent. Metatrope absent. Centrolophs not connected. Posterotrope absent. Endoloph formed by the protocone alone. Lingual border smooth.

M2. Anteroloph lingually free. Anterotrope absent. Precentroloph absent (1), of medium length (2), or long (1). Precentroloph absent (1), connected to the paracone (2), or free from the paracone (1). Midcentroloph absent. Postcentroloph absent (3) or short (1). Postcentroloph absent (3) or connected to the metacone (1). Prototrope absent (3) or short (1). Metatrope absent. Centrolophs not connected. Posterotrope absent. Endoloph formed by the protocone alone (3) or all around protocone (1). Lingual border smooth.

\section{Description of Butseloglis bruijni from Mirambueno} 4C and 4D. (Fig. 5, Table 5).

p4. Shape blunt (12) or pointed (2). Anterolophid interrupted (9) or continuous (1). Anterotropid absent. Metalophid free (4), low connected to the metaconid (3), or high connected to the metaconid (5). Centrolophid absent (10) or of medium length (3). Centrolophid-metaconid connection absent (11) or low (3). Mesostylid absent. Mesoconid placed centrally (3) or on the hypoconid (11). Mesolophid short (2), curved forward (1), directed towards the metaconid (4), or directed towards the entoconid (7). Posterotropid absent (11) or very small (1).

In some specimens there are several structures between metalophid and mesolophid for which the homologies uncertain.

m1. Anterolophid labially free. Anterotropid absent. Metalophid free (3) or low connected to the metaconid (2). Centrolophid absent (3) or short (1). Centrolophidmetaconid connection absent. Mesostylid absent. Mesoconid placed on the labial border (2), placed centrally (2), or on the hypoconid (1). Mesolophid of medium length (1), curved forward (2), directed towards the metaconid (1), or directed towards the entoconid (1). Posterotropid absent.

m2. Anterolophid labially free. Anterotropid absent. Metalophid free (6) or low connected to the metaconid (2). Centrolophid absent (4), short (3), or of medium length
(1). Centrolophid-metaconid connection absent. Mesostylid absent. Mesoconid placed on the labial border (5) or more centrally (3). Mesolophid of medium length (2), directed towards the metaconid (2), directed towards the entoconid (4), or connected to the entoconid (1). Posterotropid absent (4), very small (1), small (2), or long (1).

m3. Anterolophid labially free (20) or labially connected (1). Anterotropid absent (20) or very small (1). Metalophid free (9) or low connected to the metaconid (10). Centrolophid absent (12), short (6), or of medium length (2). Centrolophid-metaconid connection absent. Mesostylid absent. Mesoconid placed on the labial border (19) or more centrally (2). Mesolophid directed towards the metaconid (2), directed towards the entoconid (5), or connected to the entoconid (14). Posterotropid absent (16), very small (3), or small (2).

P4. Anteroloph of medium length (6) or long (7). Anterotrope absent. Precentroloph absent (2), short (2), of medium length (5), or long (4); in two cases double. Midcentroloph absent (13) or of medium length (1). Postcentroloph absent (4), short (2), of medium length (5), or long (3). Prototrope absent (12) or short (1). Metatrope absent. Centrolophs not connected (13) or connected (1). Posterotrope absent. Endoloph formed by the protocone alone.

M1. Anteroloph lingually free. Anterotrope absent (12), short (3), or of medium length (1). Precentroloph absent (4), short (6), or long (4); in two cases the long precentroloph is interrupted. Precentroloph absent (4), connected to the paracone (9), or free from the paracone (1). Midcentroloph absent (16) or long (1). Postcentroloph absent (1), of medium length (1), or long (13). Postcentroloph absent (1), connected to the metacone (11), or free from the metacone (2). Prototrope absent. Metatrope absent. Centrolophs not connected (11) or connected lingually (4). Posterotrope absent. Endoloph formed by the protocone alone.

M2. Anteroloph lingually free. Anterotrope absent. Precentroloph absent (1) or of medium length (3). Precentroloph absent (1), connected to the paracone (2), or free from the paracone (1). Midcentroloph absent. Postcentroloph of medium length (2) or long (2). Postcentroloph connected to the metacone (2) or free from the metacone (1). Prototrope absent. Metatrope absent. Centrolophs not connected (2) or connected lingually (1). Posterotrope absent. Endoloph formed by the protocone alone.

Figure 4. (1-4) Gliravus majori from Mirambueno 4C; 1) m1 dext. MIR4C 1035. 2) m2 dext. MIR4C 1052. 3) M1 dext. MIR4C 1103. 4) M2 sin. MIR4C 1105. (5-8) Butseloglis bruijni from Mirambueno1. 5) m1 sin. RGM 417560. 6) m2 dext. RGM 417567. 7) M1 sin. RGM 417579. 8) M2 sin. RGM 417584. (9-12) Butseloglis bravoi from Vivel del Río. 9) m1 sin. VIV 445. 10) $\mathrm{m} 2$ sin. VIV 455. 11) M1 dext. VIV 480. 12) M2 sin. VIV 488. (13-16) Peridyromys murinus from Vivel del Río. 13) $\mathrm{m} 1$ sin. RGM 417950. 14) $\mathrm{m} 2$ sin. RGM 417955. 15) M1 sin. RGM 417972. 16) M2 dext. RGM 417978. (1720) Microdyromys cf. legidensis from Vivel del Río. 17) $\mathrm{m} 1 \mathrm{sin}$. VIV 334. 18) $\mathrm{m} 2 \mathrm{sin}$. VIV 343. 19) M1 sin. VIV 368. 20) M2 sin. VIV 390. (21-22) Paraglis cf. fugax, MIR2A from Mirambueno 2A. 21) m1 dext. MIR2A 154. 22) M2 dext. MIR2A RGM 418411. 


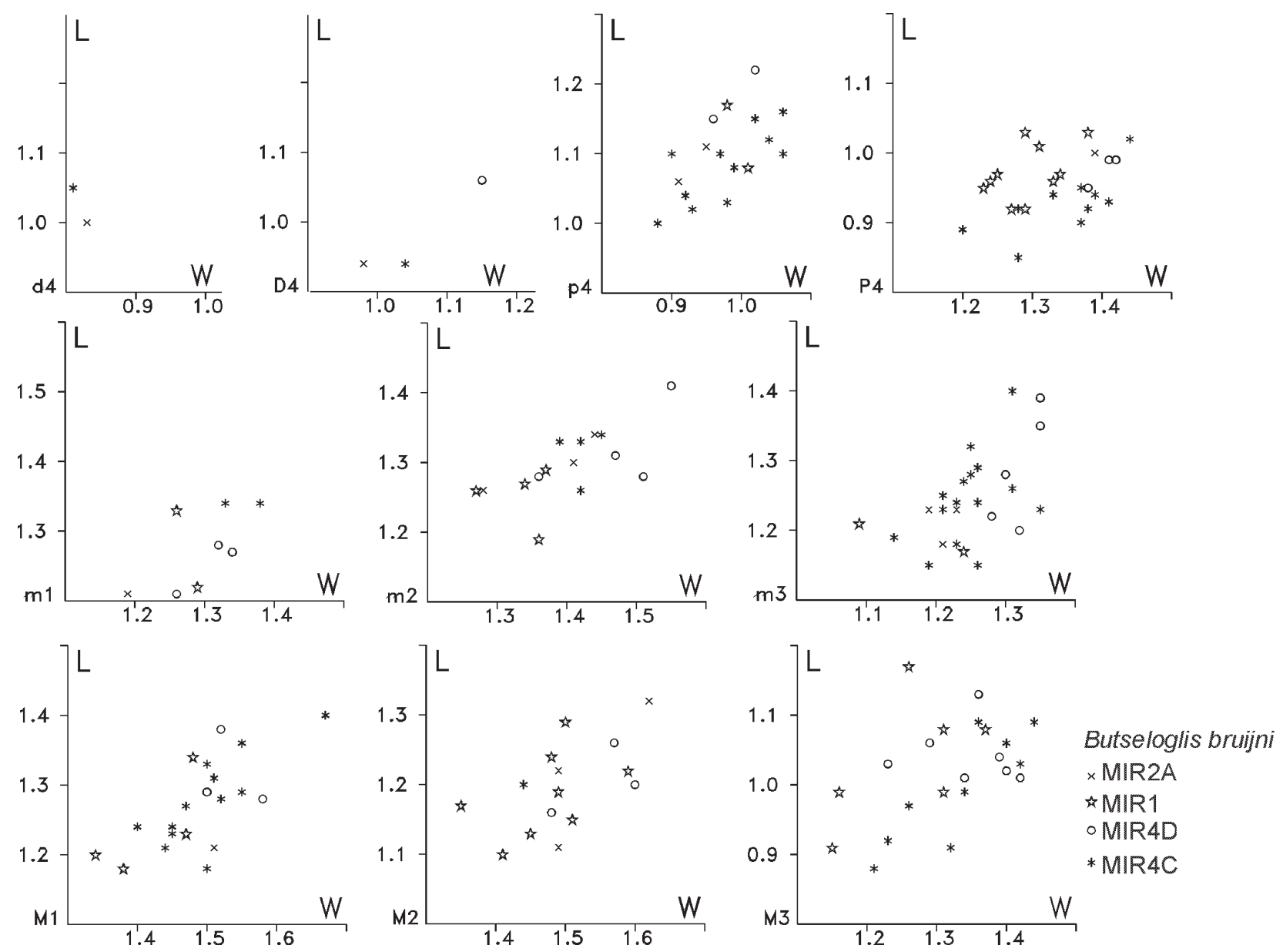

Figure 5. Length/width diagrams of Butseloglis bruijni from Mirambueno.

M3. Anteroloph lingually free. Anterotrope absent (15) or short (1). The centrolophs are not connected (15) or connected (1). Crests inside the trigone: 1 crest (11) or two crests (5). Mesostyl absent (12) or present (3). Posterotrope absent. Endoloph formed by the protocone alone. In various specimens there are longitudinal connections.

Remarks. The available material is quite poor. Nevertheless, some tendencies may be noticed in the development of several features in the sequence MIR4B - MIR1 - MIR2A.

From MIR4 to MIR1 the dental pattern becomes more simple: tropes are lost, centroloph(id)s are lost. The mesoconid leaves the lingual border and may connect to the hypoconid. The metalophid-metaconid connection becomes more frequent.

Vianey-Liaud (1994) supposed that the mesoconid of the lower molars disappeared at some time between MP20 and MP25, and that the morphotype bruijni is established in MP25 without subsequent important changes. VianeyLiaud et al. (1995) saw a progressive shift of the base of the mesolophid towards the hypoconid from MP25 to
MP30. This was based on very few data, and by now much more information is available, which basically confirms the ideas expressed by that author.

In Table 6 we compare frequency data for the position of the mesoconid/mesolophid of $\mathrm{p} 4$ and $\mathrm{m} 2$ of B. itardiensis from OLA4A (MP21), B. montisalbani from MLB8 (MP22) and MLB1D (MP23) and B. bruijni from Mirambueno, without implying an evolutionary relationship between these species. We call the base of the mesolophid mesoconid, even if it is not inflated to form a cusp.

From MP21 to MP23 the base of the mesolophid begins to shift from the labial border towards a more central position, and from MP26 onwards it may fuse with the hypoconid. In our material from Mirambueno there may be a mesoconid on the labial border, in other specimens the base of the mesolophid is placed more centrally, or the mesolophid arises from the hypoconid. In the younger localities Coderet and Pech Desse (Vianey-Liaud, 1994) the mesolophid of B. bruijni is always placed on the hypoconid and there is no mesoconid. Our interpretation is that the mesoconid gradually shifts from the border to a more central position and then fuses with the hyponid. 
Table 5. Measurements of Butseloglis bruijni.

\begin{tabular}{|c|c|c|c|c|c|c|c|c|c|c|c|c|}
\hline \multirow[b]{2}{*}{$\mathrm{d} 4$} & \multicolumn{6}{|c|}{ Length } & \multicolumn{6}{|c|}{ Width } \\
\hline & $\mathrm{N}$ & Min. & Mean & Max. & $\mathrm{V}^{\prime}$ & $\sigma$ & $\mathrm{N}$ & Min. & Mean & Max. & $\mathrm{V}^{\prime}$ & $\sigma$ \\
\hline MIR2A & 1 & & 1.000 & & & & 1 & & 0.830 & & & \\
\hline MIR4C & 1 & & 1.050 & & & & 1 & & 0.810 & & & \\
\hline $\mathrm{p} 4$ & & & & & & & & & & & & \\
\hline MIR2A & 2 & 1.06 & 1.085 & 1.11 & 4.6 & & 2 & 0.91 & 0.930 & 0.95 & 4.3 & \\
\hline MIR1 & 2 & 1.08 & 1.125 & 1.17 & 8.0 & & 2 & 0.98 & 0.995 & 1.01 & 3.0 & \\
\hline MIR4D & 3 & 1.05 & 1.140 & 1.22 & 15.0 & & 2 & 0.96 & 0.990 & 1.02 & 6.1 & \\
\hline $\begin{array}{l}\text { MIR4C } \\
\text { m1 }\end{array}$ & 11 & 1.00 & 1.082 & 1.16 & 14.8 & 0.053 & 11 & 0.88 & 0.977 & 1.06 & 18.6 & 0.064 \\
\hline MIR2A & 1 & & 1.210 & & & & 1 & & 1.190 & & & \\
\hline MIR1 & 2 & 1.22 & 1.275 & 1.33 & 8.6 & & 2 & 1.26 & 1.275 & 1.29 & 2.4 & \\
\hline MIR4D & 3 & 1.21 & 1.253 & 1.28 & 5.6 & & 3 & 1.26 & 1.307 & 1.34 & 6.2 & \\
\hline $\begin{array}{l}\text { MIR4C } \\
\text { m2 }\end{array}$ & 2 & 1.34 & 1.340 & 1.34 & 0.0 & & 2 & 1.33 & 1.355 & 1.38 & 3.7 & \\
\hline MIR2A & 4 & 1.26 & 1.290 & 1.34 & 6.2 & 0.038 & 4 & 1.27 & 1.355 & 1.44 & 12.5 & 0.083 \\
\hline MIR1 & 5 & 1.19 & 1.252 & 1.29 & 8.1 & 0.038 & 6 & 1.18 & 1.325 & 1.43 & 19.2 & 0.088 \\
\hline MIR4D & 4 & 1.28 & 1.320 & 1.41 & 9.7 & 0.062 & 4 & 1.36 & 1.473 & 1.55 & 13.1 & 0.082 \\
\hline $\begin{array}{l}\text { MIR4C } \\
\mathrm{m} 1,2\end{array}$ & 5 & 1.20 & 1.292 & 1.34 & 11.0 & 0.061 & 4 & 1.39 & 1.420 & 1.45 & 4.2 & 0.024 \\
\hline MIR2A & 5 & 1.21 & 1.274 & 1.34 & 10.2 & 0.049 & 5 & 1.19 & 1.322 & 1.44 & 19.0 & 0.103 \\
\hline MIR1 & 7 & 1.19 & 1.259 & 1.33 & 11.1 & 0.046 & 8 & 1.18 & 1.313 & 1.43 & 19.2 & 0.078 \\
\hline MIR4D & 7 & 1.21 & 1.291 & 1.41 & 15.3 & 0.060 & 7 & 1.26 & 1.401 & 1.55 & 20.6 & 0.109 \\
\hline $\begin{array}{l}\text { MIR4C } \\
\text { m3 }\end{array}$ & 7 & 1.20 & 1.306 & 1.34 & 11.0 & 0.055 & 6 & 1.33 & 1.398 & 1.45 & 8.6 & 0.042 \\
\hline MIR2A & 3 & 1.18 & 1.213 & 1.23 & 4.1 & & 3 & 1.19 & 1.210 & 1.23 & 3.3 & \\
\hline MIR1 & 2 & 1.17 & 1.190 & 1.21 & 3.4 & & 2 & 1.09 & 1.165 & 1.24 & 12.9 & \\
\hline MIR4D & 5 & 1.20 & 1.288 & 1.39 & 14.7 & 0.082 & 5 & 1.28 & 1.320 & 1.35 & 5.3 & 0.031 \\
\hline $\begin{array}{l}\text { MIR4C } \\
\text { D4 }\end{array}$ & 16 & 1.12 & 1.238 & 1.40 & 22.2 & 0.070 & 15 & 1.14 & 1.247 & 1.35 & 16.9 & 0.051 \\
\hline MIR2A & 1 & & 0.940 & & & & 1 & & 0.980 & & & \\
\hline MIR4D & 1 & & 1.060 & & & & 1 & & 1.150 & & & \\
\hline $\begin{array}{l}\text { MIR4C } \\
\text { P4 }\end{array}$ & 1 & & 0.940 & & & & 1 & & 1.040 & & & \\
\hline MIR2A & 1 & & 1.000 & & & & 1 & & 1.390 & & & \\
\hline MIR1 & 10 & 0.92 & 0.972 & 1.03 & 11.3 & 0.040 & 10 & 1.23 & 1.293 & 1.38 & 11.5 & 0.048 \\
\hline MIR4D & 3 & 0.95 & 0.977 & 0.99 & 4.1 & & 3 & 1.38 & 1.403 & 1.42 & 2.9 & \\
\hline $\begin{array}{l}\text { MIR4C } \\
\text { M1 }\end{array}$ & 11 & 0.85 & 0.931 & 1.02 & 18.2 & 0.045 & 10 & 1.20 & 1.345 & 1.44 & 18.2 & 0.073 \\
\hline MIR2A & 1 & & 1.210 & & & & 1 & & 1.510 & & & \\
\hline MIR1 & 5 & 1.18 & 1.246 & 1.34 & 12.7 & 0.065 & 4 & 1.34 & 1.418 & 1.48 & 9.9 & 0.068 \\
\hline MIR4D & 3 & 1.28 & 1.317 & 1.38 & 7.5 & & 4 & 1.50 & 1.533 & 1.58 & 5.2 & 0.034 \\
\hline $\begin{array}{l}\text { MIR4C } \\
\text { M2 }\end{array}$ & 12 & 1.18 & 1.278 & 1.40 & 17.1 & 0.064 & 12 & 1.40 & 1.501 & 1.67 & 17.6 & 0.070 \\
\hline MIR2A & 4 & 1.11 & 1.218 & 1.32 & 17.3 & 0.086 & 3 & 1.49 & 1.533 & 1.62 & 8.4 & \\
\hline MIR1 & 8 & 1.10 & 1.186 & 1.29 & 15.9 & 0.062 & 8 & 1.35 & 1.473 & 1.59 & 16.3 & 0.071 \\
\hline MIR4D & 3 & 1.16 & 1.207 & 1.26 & 8.3 & & 3 & 1.48 & 1.550 & 1.60 & 7.8 & \\
\hline $\begin{array}{l}\text { MIR4C } \\
\text { M1,2 }\end{array}$ & 1 & & 1.200 & & & & 1 & & 1.440 & & & \\
\hline MIR2A & 5 & 1.11 & 1.216 & 1.32 & 17.3 & 0.074 & 4 & 1.49 & 1.528 & 1.62 & 8.4 & 0.062 \\
\hline MIR1 & 13 & 1.10 & 1.209 & 1.34 & 19.7 & 0.068 & 12 & 1.34 & 1.454 & 1.59 & 17.1 & 0.073 \\
\hline MIR4D & 6 & 1.16 & 1.262 & 1.38 & 17.3 & 0.077 & 7 & 1.48 & 1.540 & 1.60 & 7.8 & 0.044 \\
\hline $\begin{array}{l}\text { MIR4C } \\
\text { M3 }\end{array}$ & 13 & 1.18 & 1.272 & 1.40 & 17.1 & 0.065 & 13 & 1.40 & 1.496 & 1.67 & 17.6 & 0.069 \\
\hline MIR1 & 8 & 0.91 & 1.030 & 1.17 & 25.0 & 0.079 & 7 & 1.15 & 1.253 & 1.37 & 17.5 & 0.083 \\
\hline MIR4D & 7 & 1.01 & 1.043 & 1.13 & 11.2 & 0.042 & 7 & 1.23 & 1.347 & 1.42 & 14.3 & 0.067 \\
\hline MIR4C & 9 & 0.88 & 0.993 & 1.09 & 21.3 & 0.079 & 9 & 1.21 & 1.331 & 1.44 & 17.4 & 0.083 \\
\hline
\end{tabular}


Table 6. Characters of the mesoconid in Butseloglis itardiensis (OLA4A), B. montisalbani (MLB8 and MLB1D) and B. bruijni (MIR).

\begin{tabular}{lllllll} 
& MP21 & MP22 & MP23 & MP26 & MP27 & MP27 \\
\hline mesoconid & OLA4A & MLB8 & MLB1D & MIR4 & MIR1 & MIR2A \\
p4 & $\mathrm{N}$ & $\mathrm{N}$ & $\mathrm{N}$ & $\mathrm{N}$ & $\mathrm{N}$ & $\mathrm{N}$ \\
labial border & 70 & 17 & 24 & & & \\
absent & 0 & 0 & 0 & 0 & 0 & \\
centrally & 1 & 3 & 8 & 3 & 0 & 1 \\
on hypoconid & 0 & 0 & 0 & 11 & 2 & 1
\end{tabular}

$\begin{array}{lllllll}\mathrm{m} 1 & & & & & \\ \text { labial border } & 56 & 28 & 40 & 2 & 0 & 0 \\ \text { centrally } & 0 & 0 & 2 & 2 & 2 & 0 \\ \text { on hypoconid } & 0 & 0 & 0 & 1 & 0 & 1\end{array}$

$\mathrm{m} 2$

$\begin{array}{lllllll}\text { labial border } & 81 & 39 & 51 & 5 & 1 & 2 \\ \text { centrally } & 0 & 1 & 3 & 3 & 2 & 1 \\ \text { on hypoconid } & 0 & 0 & 0 & 0 & 4 & 2\end{array}$

$\mathrm{m} 3$

\begin{tabular}{lllllll} 
labial border & 81 & 15 & 58 & 19 & 0 & 0 \\
centrally & 1 & 0 & 1 & 2 & 2 & 2 \\
on hypoconid & 1 & 0 & 0 & 0 & 0 & 1 \\
\hline
\end{tabular}

The entire process is most advanced in $\mathrm{p} 4$ and gradually decreases from $\mathrm{p} 4$ to $\mathrm{m} 3$. In Mirambueno, the bruijnimorphology is not yet fully established; our material is insufficient to decide whether it permits to distinguish it as a different species.

Butseloglis bravoi (Hugueney, Adrover \& Moissenet, 1985)

Type locality. Vivel del Río.

Holotype. m2 sin., VRA 4, Zaragoza.

Original diagnosis. (Translated from French). "The largest species of the genus (Gliravus), similar to G. bruijni because of the connection metalophid-hypoconid, but different -apart from its size- by the presence of a mesoconid".

Description of Butseloglis bravoi from VIV1. (Figs. 4.9-4.12, Fig. 6, Table 7). The lower molars may present little longitudinal connections. The mesolophid is placed on the hypoconid; there may be an additional mesoconid.

d4. Anterolophid interrupted (2) or continuous (1). Anterotropid absent. Metalophid low connected to the metaconid (2) or high connected to the metaconid (3). Centrolophid absent. Centrolophid-metaconid connection absent. Mesostylid absent. Mesoconid absent. Mesolophid absent (1), short (1), of medium length (2), or directed towards the entoconid (1). Posterotropid absent. p4. Shape blunt. Anterolophid interrupted. Anterotropid absent. Metalophid free (1), low connected to the metaconid (1), or high connected to the metaconid (1). Centrolophid absent. Centrolophid-metaconid connection absent. Mesostylid absent. Mesoconid absent. Mesolophid short (2) or directed towards the metaconid (1). Posterotropid absent.

m1. Anterolophid labially free. Anterotropid absent. Metalophid free (4), low connected to the metaconid (8), or high connected to the metaconid (2). Centrolophid absent. Centrolophid-metaconid connection absent. Mesostylid absent (12), present (1), or crest (1). Mesoconid placed on the labial border (5) or on the hypoconid (9). Mesolophid of medium length (5), directed towards the metaconid (1), directed towards the entoconid (7), or to lingual border (1). Posterotropid absent (8) or very small (5).

m2. Anterolophid labially free. Anterotropid absent. Metalophid free (5), low connected to the metaconid (9), or high connected to the metaconid (1). Centrolophid absent (14) or short (1). Centrolophid-metaconid connection absent. Mesostylid absent. Mesoconid placed on the labial border (2) or on the hypoconid (13). Mesolophid short (1), of medium length (2), directed towards the metaconid (1), directed towards the entoconid (8), connected to the entoconid (2), or long and straight (1). Posterotropid absent (11), very small (3), or small (1).

m3. Anterolophid labially free. Anterotropid absent. Metalophid free (2) or low connected to the metaconid (15). Centrolophid absent (13), short (3), or medium central (1). Centrolophid-metaconid connection absent. Mesostylid absent (15) or present (2). Mesoconid placed centrally (8) or on the hypoconid (9). Mesolophid directed towards the entoconid (4) or connected to the entoconid (13). Posterotropid absent (9) or very small (8).

D4. Anteroloph of medium length. Anterotrope absent. Precentroloph of medium length (1) or long (3). Postcentroloph absent. Prototrope absent. Metatrope absent. Centrolophs not connected. Posterotrope absent. Endoloph formed by the protocone alone. Lingual border smooth.

P4. Anteroloph of medium length (2) or long (5). Anterotrope absent. Precentroloph short (1), of medium length (2), or long (5). Midcentroloph absent. Postcentroloph absent. Prototrope absent. Metatrope absent. Centrolophs not connected. Posterotrope absent. Endoloph formed by the protocone alone (7) or posteriorly interrupted (1). Lingual border smooth.

M1. Anteroloph lingually free. Anterotrope absent. Precentroloph absent (7), short (1), of medium length (2), or long (6). Precentroloph absent (7), connected to the paracone (1), or free from the paracone (8). Midcentroloph absent (13), short (1), of medium length (1), or long (1). Postcentroloph absent (12), of medium length (1), or long (3). Postcentroloph absent (12) or free from the metacone (4). Prototrope absent. Metatrope absent (15) or short (1). 

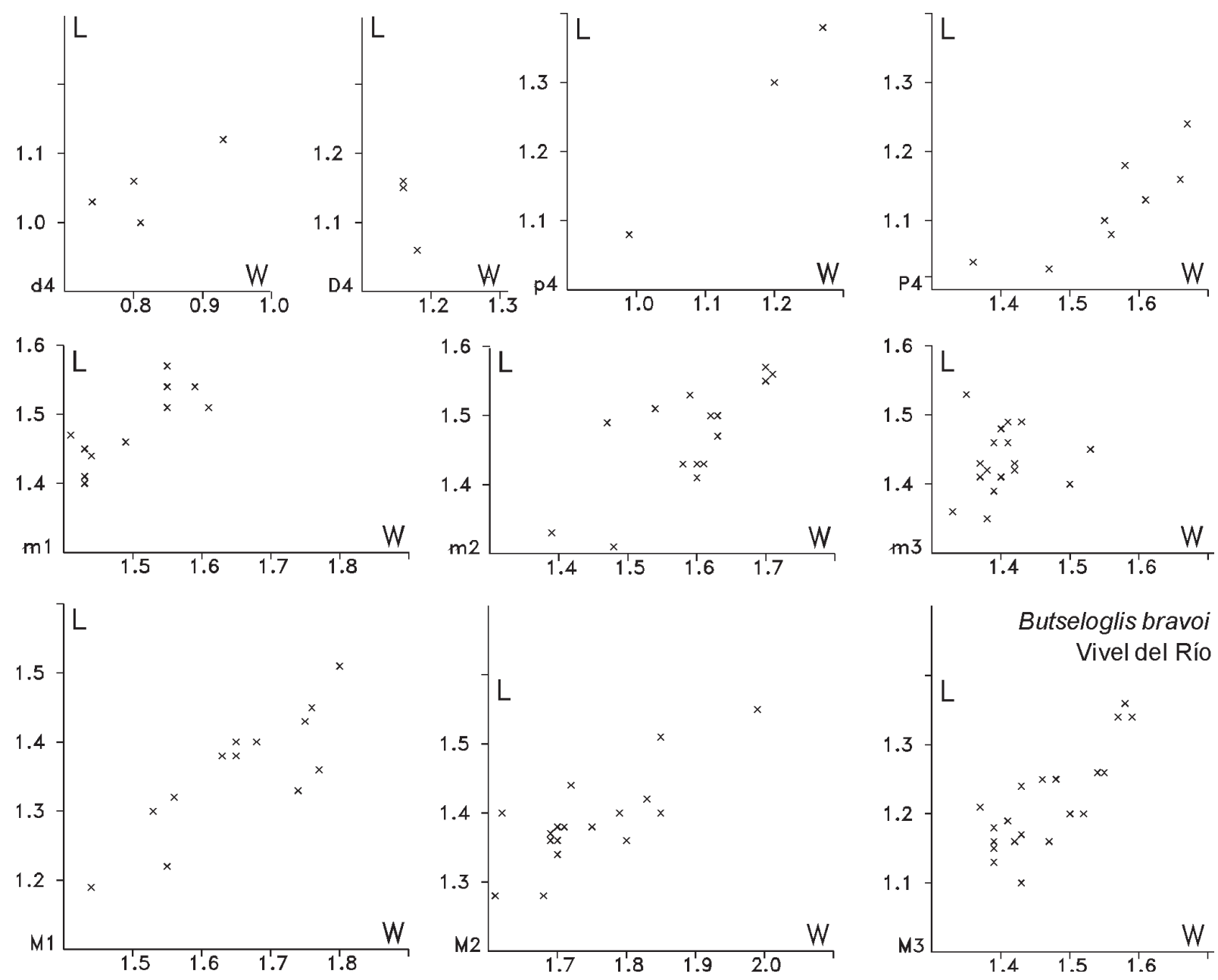

Figure 6. Length/width diagrams of Butseloglis bravoi from Vivel del Río.

Centrolophs not connected (15) or connected midway (1). Posterotrope absent. Endoloph formed by the protocone alone. Lingual border smooth.

M2. Anteroloph lingually free. Anterotrope absent. Precentroloph absent (8), short (2), of medium length (3), or long (6). Precentroloph absent (8) or free from the paracone (11). Midcentroloph absent (17), of medium length (1), or long (1). Postcentroloph absent (6), short (4), of medium length (5), or long (3). Postcentroloph absent (5) or free from the metacone (13). Prototrope absent. Metatrope absent. Centrolophs not connected. Posterotrope absent. Endoloph formed by the protocone alone. Lingual border smooth. In a few specimens there are some small cusps inside trigone.

M3. Anteroloph lingually free. Anterotrope absent. Precentroloph absent (7), short (2), of medium length (2), or long (4). Postcentroloph absent (4), short (2), of medium length (6), or long (2). Crests inside the trigone: 1 crest (9), two crests (9), or three crests (2). Mesostyl absent (9) or present (11). Posterotrope absent. Endoloph formed by the protocone alone (17) or anteriorly interrupted (1). Lingual border smooth.
Subfamily Peridyromyinae Freudenthal \& MartínSuárez, 2013

Diagnosis. Daams (1981) gave the following diagnosis for the Myomiminae: "Concave occlusal surface, main cusps fairly well developed, extra ridges narrower than main ridges, relatively high-crowned molars in some genera, generally no endoloph in the M1,2 and a simple dental pattern.” Freudenthal \& Martín-Suárez (2013) made this the diagnosis of Peridyromyinae and excluded Myomimus.

Genera included. Peridyromys; Altomiramys Díaz-Molina \& López-Martínez, 1979; Armantomys; Miodyromys Kretzoi, 1943; Praearmantomys de Bruijn, 1966a; Pseudodryomys de Bruijn, 1966a; Simplomys García-Paredes et al., 2009; Tempestia van de Weerd, 1976; Ramys García Moreno \& López Martínez, 1986 and Vasseuromys Baudelot \& de Bonis, 1966.

Genus Peridyromys Stehlin \& Schaub, 1951 
Table 7. Measurements of Butseloglis bravoi (* = publ. Hugueney et al., 1985).

\begin{tabular}{|c|c|c|c|c|c|c|c|c|c|c|c|c|}
\hline \multirow[b]{2}{*}{$\mathrm{d} 4$} & \multicolumn{6}{|c|}{ Length } & \multicolumn{6}{|c|}{ Width } \\
\hline & $\mathrm{N}$ & Min. & Mean & Max. & $\mathrm{V}^{\prime}$ & $\sigma$ & $\mathrm{N}$ & Min. & Mean & Max. & $\mathrm{V}^{\prime}$ & $\sigma$ \\
\hline $\begin{array}{l}\text { VIV* } \\
\text { p4 }\end{array}$ & 4 & 1.00 & 1.053 & 1.12 & 11.3 & 0.051 & 5 & 0.73 & 0.802 & 0.93 & 24.1 & 0.080 \\
\hline VIV & 6 & 1.14 & 1.20 & 1.25 & 9.2 & & 6 & 1.06 & 1.13 & 1.19 & 11.6 & \\
\hline $\begin{array}{l}\text { VIV* } \\
\text { m1 }\end{array}$ & 3 & 1.08 & 1.253 & 1.38 & 24.4 & & 3 & 0.99 & 1.153 & 1.27 & 24.8 & \\
\hline VIV & 19 & 1.37 & 1.49 & 1.57 & 13.6 & & 19 & 1.29 & 1.47 & 1.59 & 20.8 & \\
\hline $\begin{array}{l}\mathrm{VIV}^{*} \\
\mathrm{~m} 2\end{array}$ & 14 & 1.40 & 1.481 & 1.57 & 11.4 & 0.055 & 11 & 1.41 & 1.498 & 1.61 & 13.2 & 0.074 \\
\hline VIV & 19 & 1.33 & 1.49 & 1.58 & 17.2 & & 19 & 1.43 & 1.62 & 1.81 & 23.5 & \\
\hline $\begin{array}{l}\mathrm{VIV}^{*} \\
\mathrm{~m} 1,2\end{array}$ & 15 & 1.31 & 1.468 & 1.57 & 18.1 & 0.078 & 15 & 1.39 & 1.589 & 1.71 & 20.6 & 0.089 \\
\hline VIV & 38 & 1.33 & 1.490 & 1.58 & 17.2 & & 38 & 1.29 & 1.545 & 1.81 & 33.5 & \\
\hline $\begin{array}{l}\mathrm{VIV}^{*} \\
\text { m3 }\end{array}$ & 29 & 1.31 & 1.474 & 1.57 & 18.1 & 0.067 & 26 & 1.39 & 1.551 & 1.71 & 20.6 & 0.094 \\
\hline VIV & 17 & 1.31 & 1.42 & 1.53 & 15.5 & & 17 & 1.36 & 1.44 & 1.59 & 15.6 & \\
\hline $\begin{array}{l}\text { VIV* } \\
\text { D4 }\end{array}$ & 17 & 1.35 & 1.434 & 1.53 & 12.5 & 0.048 & 17 & 1.33 & 1.405 & 1.53 & 14.0 & 0.049 \\
\hline $\begin{array}{l}\text { VIV* } \\
\text { P4 }\end{array}$ & 3 & 1.06 & 1.123 & 1.16 & 9.0 & & 4 & 1.16 & 1.190 & 1.26 & 8.3 & 0.048 \\
\hline VIV & 13 & 0.96 & 1.10 & 1.20 & 22.2 & & 13 & 1.44 & 1.52 & 1.65 & 13.6 & \\
\hline $\begin{array}{l}\text { VIV* } \\
\text { M1 }\end{array}$ & 8 & 1.03 & 1.120 & 1.24 & 18.5 & 0.072 & 8 & 1.36 & 1.558 & 1.67 & 20.5 & 0.102 \\
\hline $\begin{array}{l}\text { VIV* } \\
\text { M2 }\end{array}$ & 14 & 1.19 & 1.362 & 1.51 & 23.7 & 0.086 & 14 & 1.44 & 1.666 & 1.81 & 22.8 & 0.113 \\
\hline $\begin{array}{l}\text { VIV* } \\
\text { M1,2 }\end{array}$ & 17 & 1.28 & 1.389 & 1.55 & 19.1 & 0.068 & 19 & 1.54 & 1.735 & 1.99 & 25.5 & 0.102 \\
\hline VIV & 30 & 1.25 & 1.37 & 1.46 & 15.5 & & 30 & 1.44 & 1.70 & 1.87 & 26.0 & \\
\hline $\begin{array}{l}\text { VIV* } \\
\text { M3 }\end{array}$ & 31 & 1.19 & 1.377 & 1.55 & 26.3 & 0.076 & 33 & 1.44 & 1.705 & 1.99 & 32.1 & 0.111 \\
\hline VIV & 22 & 1.15 & 1.24 & 1.39 & 18.9 & & 22 & 1.38 & 1.49 & 1.62 & 16.0 & \\
\hline $\mathrm{VIV}^{*}$ & 20 & 1.10 & 1.216 & 1.36 & 21.1 & 0.072 & 21 & 1.37 & 1.471 & 1.59 & 14.9 & 0.074 \\
\hline
\end{tabular}

Original diagnosis. (Translated from German and adapted): The anterior side of the trigone of M1 and M2 points obliquely backward. Lingual cusps and lingual end of the posteroloph fused. In the trigone there are two small, accessory ridges (centrolophs), of which the anterior one joins the paracone. Lower molars with welldeveloped mesoconid-entoconid ridge (=mesolophid). The protoconid ridge (=metalophid) does not reach the metaconid. Paraconid (=anteroconid), metaconid and mesolophid (=centrolophid) form a continuous ridge, which curves twice at right angles.

Type species Peridyromys murinus (Pomel, 1853)

Peridyromys murinus (Pomel, 1853)

Type locality and neotype. The original material of Pomel, from Langy, France, is lost. Stehlin \& Schaub coined the name to material from Montaigu-le-Blin. De
Bruijn (1966) designated as neotype a maxilla with M1M2, MA 3215, kept at the Basel Museum.

Description of Peridyromys murinus from Mirambueno 1. (Fig. 7, Table 8).

d4. Anterolophid interrupted. Anterotropid absent. Metalophid free. Centrolophid absent. Centrolophidmetaconid connection absent. Mesostylid absent. Mesoconid placed on the labial border. Mesolophid connected to the entoconid. Posterotropid absent.

p4. Shape blunt. Anterolophid continuous. Anterotropid absent. Metalophid free. Centrolophid absent. Centrolophidmetaconid connection absent. Mesostylid absent. Mesoconid placed on the labial border. Mesolophid connected to the entoconid. Posterotropid absent.

m1. Anterolophid labially free (5) or labially connected (6). Anterotropid absent (9), small (1), or of medium length (1). Metalophid free (1), low connected to the metaconid (7), or high connected to the metaconid 

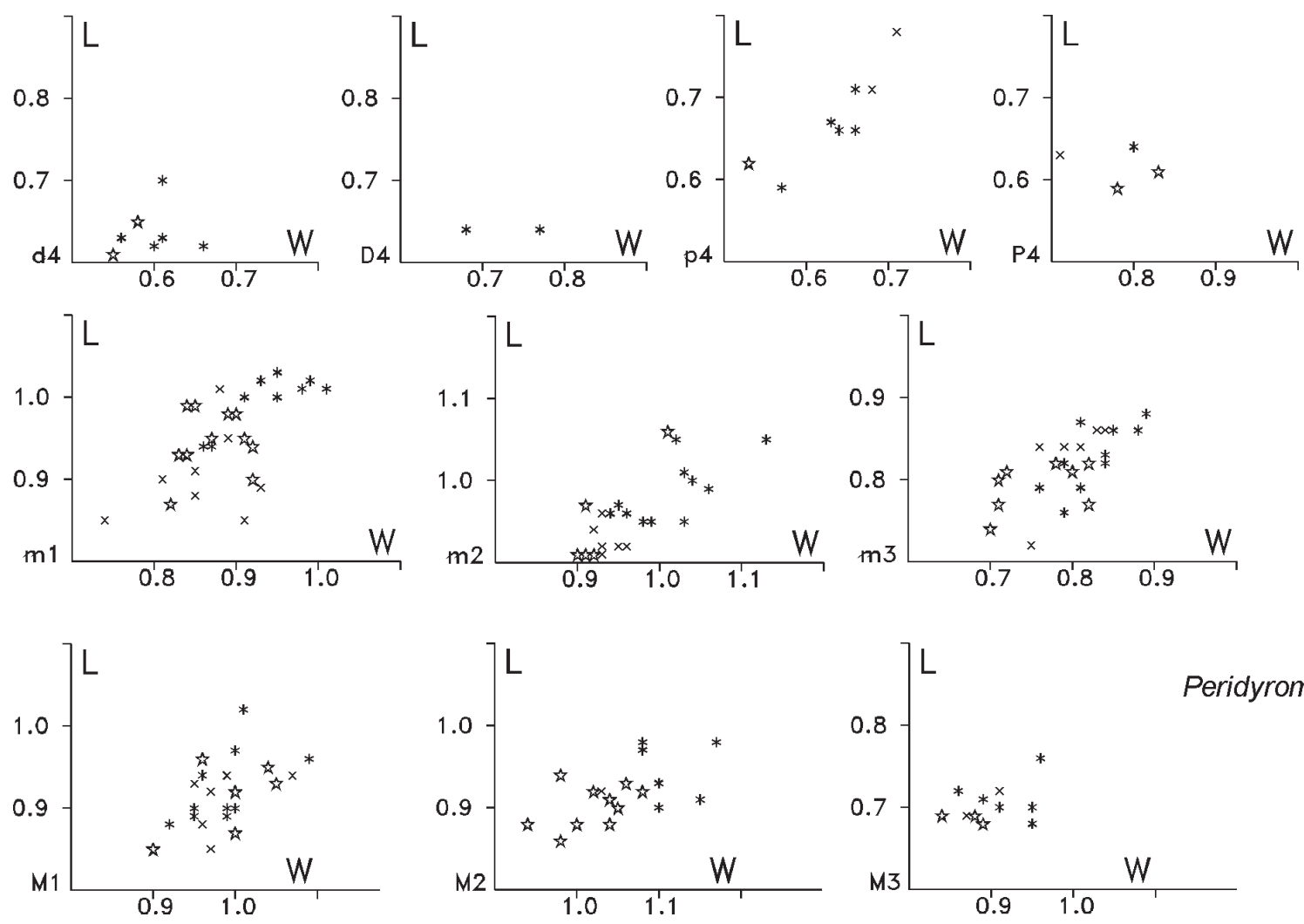

Peridyromys murinus

* VIV

$\times$ MIR2A

* MIR1

Figure 7. Length/width diagrams of Peridyromys murinus from Mirambueno and Vivel del Río.

(3). Centrolophid of medium length (2) or long (9). Centrolophid-metaconid connection low (1) or high (10). Mesostylid absent. Mesoconid placed on the labial border. Mesolophid connected to the entoconid. Posterotropid absent (5), very small (1), small (1), of medium length (3), or long (1).

m2. Anterolophid labially free (3) or labially connected (2). Anterotropid absent. Metalophid low connected to the metaconid (3) or high connected to the metaconid (2). Centrolophid of medium length (1) or long (4). Centrolophid-metaconid connection low (1) or high (4). Mesostylid absent. Mesoconid placed on the labial border. Mesolophid connected to the entoconid. Posterotropid absent (2), very small (1), or of medium length (2).

m3. Anterolophid labially free. Anterotropid absent. Metalophid free (1), low connected to the metaconid (5), or high connected to the metaconid (1). Centrolophid short (5), short central (1), or of medium length (1). Centrolophid-metaconid connection absent (1), low (3), or high (3). Mesostylid absent. Mesoconid placed on the labial border. Mesolophid directed towards the entoconid (1) or connected to the entoconid (6). Posterotropid absent (6) or very small (1).

P4. Anteroloph of medium length (1) or long (1). Anterotrope absent. Precentroloph absent (1) or short (1). Midcentroloph absent. Postcentroloph absent. Prototrope absent. Metatrope absent. Centrolophs not connected.
Posterotrope absent. Endoloph formed by the protocone alone. Lingual border smooth.

M1. Anteroloph lingually free. Anterotrope absent. Precentroloph long. Precentroloph connected to the paracone. Midcentroloph absent. Postcentroloph short (2), of medium length (3), or long (1). Postcentroloph connected to the metacone. Prototrope absent. Metatrope absent. Centrolophs not connected (3), connected lingually (1), or connected midway (2). Posterotrope absent. Endoloph formed by the protocone alone (2) or anteriorly interrupted (4). Lingual border smooth.

M2. Anteroloph lingually free. Anterotrope absent. Precentroloph long. Precentroloph connected to the paracone. Midcentroloph absent. Postcentroloph short (4), of medium length (5), or long (1). Postcentroloph connected to the metacone. Prototrope absent. Metatrope absent. Centrolophs not connected (9) or connected midway (1). Posterotrope absent. Endoloph formed by the protocone alone (2) or anteriorly interrupted (7). Lingual border smooth.

M3. Anteroloph lingually high connected. Anterotrope absent (2) or short (1). Precentroloph absent (1) or long (1). Postcentroloph absent (1) or long (1). Prototrope absent. Metatrope absent. Centrolophs not connected. Crests inside the trigone: 1 crest. Mesostyl absent (2) or present (1). Posterotrope absent. Endoloph complete. Lingual border smooth. 
Table 8. Measurements of Peridyromys murinus.

\begin{tabular}{|c|c|c|c|c|c|c|c|c|c|c|c|c|}
\hline & & & & ength & & & & & & /idth & & \\
\hline $\mathrm{d} 4$ & $\mathrm{~N}$ & Min. & Mean & Max. & $\mathrm{V}^{\prime}$ & $\sigma$ & $\mathrm{N}$ & Min. & Mean & Max. & $\mathrm{V}^{\prime}$ & $\sigma$ \\
\hline VIV & 5 & 0.62 & 0.640 & 0.70 & 12.1 & 0.034 & 5 & 0.56 & 0.608 & 0.66 & 16.4 & 0.036 \\
\hline MIR1 & 2 & 0.61 & 0.630 & 0.65 & 6.3 & & 2 & 0.55 & 0.565 & 0.58 & 5.3 & \\
\hline p4 & & & & & & & & & & & & \\
\hline VIV & 5 & 0.59 & 0.658 & 0.71 & 18.5 & 0.043 & 5 & 0.57 & 0.632 & 0.66 & 14.6 & 0.037 \\
\hline MIR2A & 2 & 0.71 & 0.745 & 0.78 & 9.4 & & 2 & 0.68 & 0.695 & 0.71 & 4.3 & \\
\hline $\begin{array}{l}\text { MIR1 } \\
\mathrm{m} 1\end{array}$ & 1 & & 0.620 & & & & 1 & & 0.530 & & & \\
\hline VIV & 9 & 0.94 & 0.997 & 1.03 & 9.1 & 0.034 & 9 & 0.86 & 0.939 & 1.01 & 16.0 & 0.052 \\
\hline MIR2A & 8 & 0.85 & 0.905 & 1.01 & 17.2 & 0.053 & 8 & 0.74 & 0.858 & 0.93 & 22.8 & 0.061 \\
\hline $\begin{array}{l}\text { MIR1 } \\
\text { m2 }\end{array}$ & 11 & 0.87 & 0.946 & 0.99 & 12.9 & 0.038 & 11 & 0.82 & 0.870 & 0.92 & 11.5 & 0.038 \\
\hline VIV & 11 & 0.95 & 0.985 & 1.05 & 10.0 & 0.038 & 11 & 0.94 & 1.011 & 1.13 & 18.4 & 0.056 \\
\hline MIR2A & 6 & 0.91 & 0.928 & 0.96 & 5.3 & 0.018 & 6 & 0.92 & 0.935 & 0.96 & 4.3 & 0.016 \\
\hline $\begin{array}{l}\text { MIR1 } \\
\mathrm{m} 1,2\end{array}$ & 5 & 0.91 & 0.952 & 1.06 & 15.2 & 0.066 & 5 & 0.91 & 0.932 & 1.01 & 10.4 & 0.044 \\
\hline VIV & 20 & 0.94 & 0.991 & 1.05 & 11.1 & 0.036 & 20 & 0.86 & 0.979 & 1.13 & 27.1 & 0.064 \\
\hline MIR2A & 14 & 0.85 & 0.915 & 1.01 & 17.2 & 0.043 & 14 & 0.74 & 0.891 & 0.96 & 25.9 & 0.061 \\
\hline $\begin{array}{l}\text { MIR1 } \\
\text { m3 }\end{array}$ & 16 & 0.87 & 0.948 & 1.06 & 19.7 & 0.046 & 16 & 0.82 & 0.889 & 1.01 & 20.8 & 0.049 \\
\hline VIV & 10 & 0.76 & 0.828 & 0.88 & 14.6 & 0.040 & 10 & 0.76 & 0.826 & 0.89 & 15.8 & 0.041 \\
\hline MIR2A & 6 & 0.72 & 0.827 & 0.86 & 17.7 & 0.053 & 6 & 0.75 & 0.798 & 0.84 & 11.3 & 0.039 \\
\hline $\begin{array}{l}\text { MIR1 } \\
\text { D4 }\end{array}$ & 8 & 0.74 & 0.793 & 0.82 & 10.3 & 0.029 & 8 & 0.70 & 0.758 & 0.82 & 15.8 & 0.053 \\
\hline $\begin{array}{l}\text { VIV } \\
\text { P4 }\end{array}$ & 2 & 0.64 & 0.640 & 0.64 & 0.0 & & 2 & 0.68 & 0.725 & 0.77 & 12.4 & \\
\hline VIV & 2 & 0.64 & 0.655 & 0.67 & 4.6 & & 1 & & 0.800 & & & \\
\hline MIR2A & 1 & & 0.630 & & & & 1 & & 0.710 & & & \\
\hline $\begin{array}{l}\text { MIR1 } \\
\text { M1 }\end{array}$ & 2 & 0.59 & 0.600 & 0.61 & 3.3 & & 2 & 0.78 & 0.805 & 0.83 & 6.2 & \\
\hline VIV & 12 & 0.88 & 0.930 & 1.02 & 14.7 & 0.043 & 10 & 0.92 & 0.986 & 1.09 & 16.9 & 0.046 \\
\hline MIR2A & 6 & 0.85 & 0.910 & 0.94 & 10.1 & 0.037 & 6 & 0.95 & 0.985 & 1.07 & 11.9 & 0.044 \\
\hline $\begin{array}{l}\text { MIR1 } \\
\text { M2 }\end{array}$ & 6 & 0.85 & 0.913 & 0.96 & 12.2 & 0.044 & 6 & 0.90 & 0.992 & 1.05 & 15.4 & 0.055 \\
\hline VIV & 7 & 0.90 & 0.941 & 0.98 & 8.5 & 0.034 & 6 & 1.08 & 1.113 & 1.17 & 8.0 & 0.038 \\
\hline MIR2A & 1 & & 0.920 & & & & 1 & & 1.030 & & & \\
\hline $\begin{array}{l}\text { MIR1 } \\
\text { M1,2 }\end{array}$ & 11 & 0.86 & 0.902 & 0.94 & 8.9 & 0.025 & 10 & 0.94 & 1.019 & 1.08 & 13.9 & 0.043 \\
\hline VIV & 19 & 0.88 & 0.934 & 1.02 & 14.7 & 0.039 & 16 & 0.92 & 1.034 & 1.17 & 23.9 & 0.076 \\
\hline MIR2A & 7 & 0.85 & 0.911 & 0.94 & 10.1 & 0.034 & 7 & 0.95 & 0.991 & 1.07 & 11.9 & 0.043 \\
\hline $\begin{array}{l}\text { MIR1 } \\
\text { M3 }\end{array}$ & 17 & 0.85 & 0.906 & 0.96 & 12.2 & 0.032 & 16 & 0.90 & 1.009 & 1.08 & 18.2 & 0.048 \\
\hline VIV & 6 & 0.68 & 0.712 & 0.76 & 11.1 & 0.027 & 6 & 0.86 & 0.920 & 0.96 & 11.0 & 0.040 \\
\hline MIR2A & 2 & 0.69 & 0.705 & 0.72 & 4.3 & & 2 & 0.87 & 0.890 & 0.91 & 4.5 & \\
\hline MIR1 & 3 & 0.68 & 0.687 & 0.69 & 1.5 & & 3 & 0.84 & 0.870 & 0.89 & 5.8 & \\
\hline
\end{tabular}

\section{Description of Peridyromys murinus from} Mirambueno 2A. (Fig. 7, Table 8).

p4. Shape blunt. Anterolophid continuous. Anterotropid absent. Metalophid free. Centrolophid absent. Centrolophid-metaconid connection absent. Mesostylid absent. Mesoconid placed on the labial border. Mesolophid connected to the entoconid. Posterotropid absent (1) or of medium length (1). m1. Anterolophid labially free (3) or labially connected (5). Anterotropid absent (7) or very small (1). Metalophid free (4), low connected to the metaconid (3), or high connected to the metaconid (1). Centrolophid short (1), of medium length (1), or long (6). Centrolophidmetaconid connection low (3) or high (5). Mesostylid absent. Mesoconid placed on the labial border. Mesolophid connected to the metaconid (1) or connected to the entoconid (7). Posterotropid absent (1), small (2), or of medium length (5). 
m2. Anterolophid labially free (2) or labially connected (4). Anterotropid absent (5) or very small (1). Metalophid free (1) or low connected to the metaconid (5). Centrolophid of medium length (1) or long (5). Centrolophid-metaconid connection low (1) or high (5). Mesostylid absent. Mesoconid placed on the labial border. Mesolophid connected to the entoconid. Posterotropid absent (2), of medium length (3), or long (1).

m3. Anterolophid labially free (1) or labially connected (5). Anterotropid absent. Metalophid free (2), low connected to the metaconid (3), or high connected to the metaconid (1). Centrolophid absent (1), short (2), medium central (1), or of medium length (2). Centrolophidmetaconid connection absent (5) or low (1). Mesostylid absent. Mesoconid placed on the labial border. Mesolophid connected to the entoconid. Posterotropid absent (4) or of medium length (2).

P4. Anteroloph long. Anterotrope absent. Precentroloph long. Midcentroloph absent. Postcentroloph absent. Prototrope absent. Metatrope absent. Centrolophs not connected. Posterotrope absent. Endoloph anteriorly interrupted. Lingual border smooth.

M1. Anteroloph lingually free. Anterotrope absent. Precentroloph long. Precentroloph connected to the paracone. Midcentroloph absent. Postcentroloph short (2), of medium length (3), or long (1). Postcentroloph connected to the metacone. Prototrope absent. Metatrope absent. Centrolophs not connected (4), connected lingually (1), or connected midway (1). Posterotrope absent. Endoloph anteriorly interrupted. Lingual border smooth.

M2. Anteroloph lingually free. Anterotrope absent. Precentroloph long. Precentroloph connected to the paracone. Midcentroloph absent. Postcentroloph short. Postcentroloph connected to the metacone. Prototrope absent. Metatrope absent. Centrolophs connected midway. Posterotrope absent. Endoloph anteriorly interrupted. Lingual border smooth.

M3. Anteroloph lingually free (1) or lingually high connected (1). Anterotrope absent. Precentroloph absent (1) or long (1). Postcentroloph short (1) or long (1). Prototrope absent. Metatrope absent. The centrolophs are not connected. Crests inside the trigone: 1 crest (1) or two crests (1). Mesostyl absent (1) or present (1). Posterotrope absent. Endoloph anteriorly interrupted (1) or complete (1). Lingual border smooth.

\section{Description of Peridyromys murinus from Vivel Del}

\section{Río. (Figs. 4.13-4.16, Fig. 7, Table 8).}

d4. Anterolophid continuous. Anterotropid absent (3) or small (1). Metalophid free (3) or high connected to the metaconid (1). Centrolophid absent. Centrolophidmetaconid connection absent. Mesostylid absent. Mesoconid placed on the labial border. Mesolophid short (2), of medium length (1), or connected to the entoconid (1). Posterotropid absent (3) or small (1). p4. Shape blunt. Anterolophid interrupted (1) or continuous (4). Anterotropid absent. Metalophid free (3) or high connected to the metaconid (2). Centrolophid absent (4) or of medium length (1). Centrolophid-metaconid connection absent (4) or high (1). Mesostylid absent. Mesoconid placed on the labial border. Mesolophid directed towards the entoconid (2) or connected to the entoconid (3). Posterotropid absent.

m1. Anterolophid labially free (4) or labially connected (5). Anterotropid absent (8) or small (1). Metalophid free (1), low connected to the metaconid (1), or high connected to the metaconid (7). Centrolophid short central (1), of medium length (1), or long (7). Centrolophid-metaconid connection absent (2), low (3), or high (4). Mesostylid absent. Mesoconid placed on the labial border. Mesolophid connected to the entoconid. Posterotropid absent (2), of medium length (1), or long (6).

m2. Anterolophid labially free (11) or labially connected (1). Anterotropid absent. Metalophid free (5), low connected to the metaconid (4), or high connected to the metaconid (3). Centrolophid short (1), of medium length (3), or long (8). Centrolophid-metaconid connection low (1) or high (11). Mesostylid absent. Mesoconid placed on the labial border. Mesolophid connected to the entoconid. Posterotropid absent (3), very small (2), small (2), of medium length (3), or long (2).

m3. Anterolophid labially free. Anterotropid absent. Metalophid free (2), low connected to the metaconid (5), or high connected to the metaconid (3). Centrolophid short (5), of medium length (3), or long (1). Centrolophidmetaconid connection absent (1), low (2), or high (5). Mesostylid absent. Mesoconid placed on the labial border. Mesolophid connected to the entoconid. Posterotropid absent (8) or small (2).

D4. Anteroloph long. Anterotrope absent. Precentroloph absent. Postcentroloph long. Prototrope absent. Metatrope absent. Centrolophs not connected. Posterotrope absent. Endoloph formed by the protocone alone. Lingual border smooth.

P4. Anteroloph of medium length (1) or long (1). Anterotrope absent. Precentroloph absent. Midcentroloph absent. Postcentroloph long. Prototrope absent. Metatrope absent. centrolophs not connected. Posterotrope absent. Endoloph formed by the protocone alone. Lingual border smooth.

M1. Anteroloph lingually free. Anterotrope absent. Precentroloph of medium length (1) or long (11). Precentroloph connected to the paracone. Midcentroloph absent. Postcentroloph short (5) or of medium length (7). Postcentroloph connected to the metacone. Prototrope absent. Metatrope absent. Centrolophs not connected (6), connected lingually (3), or connected midway (3). Posterotrope absent. Endoloph formed by the protocone alone (3) or anteriorly interrupted (8). Lingual border smooth. 
M2. Anteroloph lingually free. Anterotrope absent. Precentroloph long. Precentroloph connected to the paracone. Midcentroloph absent. Postcentroloph short (1), of medium length (5), or long (1). Postcentroloph connected to the metacone. Prototrope absent (6) or short (1). Metatrope absent (6) or of medium length (1). Centrolophs not connected (4), connected lingually (1), or connected midway (2). Posterotrope absent. Endoloph anteriorly interrupted. Lingual border smooth.

M3. Anteroloph lingually free (1), lingually low connected (1), or lingually high connected (4). Anterotrope absent. Precentroloph absent (3) or short (2). Postcentroloph long. Prototrope absent. Metatrope absent (5) or short (1). The centrolophs are not connected. Crests inside the trigone: 1 crest (3) or two crests (3). Mesostyl absent. Posterotrope absent. Endoloph formed by the protocone alone (1) or complete (5). Lingual border smooth.

Discussion. Peridyromys murinus has a long stratigraphic record of 12.2 Ma. The oldest populations are from MIR1 and MIR2A (MP27), here described. The youngest record is from Buñol (MN4; Daams, 1981). This seems to be a very long range for a species.

The posterotropid of $\mathrm{m} 1,2$ is more frequently present in our Oligocene populations than it is in Miocene populations (Table 9). As a general rule we may assume that old glirids have less crests than younger ones, or, in other words, increased number of crests is an advanced character. If we assume that to be true for Peridyromys the frequent presence of a posterotropid in m1,2 of Oligocene P. murinus and its predominant absence in younger populations may mean that the Oligocene and Miocene representatives are not directly related, and that we are dealing with two different lineages.

\section{Subfamily Bransatoglirinae Daams \& de Bruijn, 1995}

Genus Microdyromys de Bruijn, 1966

Type species Microdyromys koenigswaldi de Bruijn, 1966

Diagnosis of the genus. (Modified after Freudenthal \& Martín-Suárez, 2007b). Small Gliridae with a slightly or moderately concave occlusal surface and regular, parallel crests. Lingual wall of upper molars often crenulated. Tendency to form a complete endoloph in the older species, complete endoloph present in the younger ones. Both centrolophs long, the precentroloph being longer than the postcentroloph. Centrolophs generally not interconnected. In the upper molars extra crests (tropes) outside the trigone are rare, except for the youngest species. In the lower molars $(\mathrm{m} 1,2)$ the anterotropid is frequent and the posterotropid is almost constantly present.

Microdyromys koenigswaldi de Bruijn, 1966
Table 9. Absence/presence of posterotropid in $\mathrm{m} 1,2$ of Peridyromys (in \%). Data from Alvarez Sierra et al. (1990) and this work.

\begin{tabular}{llll} 
& & \\
posterotropid m1,2 & absent & present & $\mathrm{n}$ \\
Agreda & 99.5 & 0.5 & 209 \\
La Galocha 5 & 95 & 5 & 19 \\
San Juan & 100 & 0 & 17 \\
Bouzigues & 70 & 30 & 316 \\
Cetina & 93 & 7 & 55 \\
Santa Cilia & 94 & 6 & 32 \\
Vivel del Río & 23.8 & 76.2 & 21 \\
Mirambueno 2A & 21.4 & 78.6 & 14 \\
Mirambueno 1 & 43.7 & 56.3 & 16 \\
\hline
\end{tabular}

Holotype. M2 dext., VA3B 1516, Museo de Paleontología, Sabadell.

Type locality. Valdemoros 3B (MN4, Calatayud-Teruel Basin, Spain). According to de Bruijn $(1966,1967)$ only one species of Microdyromys is present in VA3B. Daams (1981) recognized $M$. koenigswaldi together with what he erroneously called $M$. monspeliensis. But the two were treated together, except for M1,2, and comparison with $M$. legidensis is not possible. For a discussion on the erroneous classification of M. monspeliensis see Freudenthal \& Martín-Suárez (2007a).

De Bruijn (1967) reported 28 M1,2 of M. koenigswaldi from VA3B, all of which have two centrolophs and a prototrope (morphotype H of Daams, 1981). On the other hand, Daams (1981) reported 31 M1,2, two of which lacked a prototrope (for $M$. koenigswaldi and $M$. monspeliensis sensu Daams, 1981 together). The length of the smallest specimen of de Bruijn (1967) is 9.1, that of Daams (1981) is 7.4. In a list kindly provided to us by Dr García Paredes (Madrid) appears a M1 dext. with catalogue number 1548 , measurements $7.5 \mathrm{x} \pm 8.7$, which apparently is the specimen Daams attributed to $M$. monspeliensis. Its catalogue number is not in the list of material from VA3B, given by de Bruijn (1967), and its provenance is doubtful. Thanks to Dr de Bruijn we have the complete catalogue lists of the Microdyromys material from VA3B; they are mostly typewritten and ordered by dental element. However, the numbers 1546 - 1560 are handwritten and form a random mixture of dental elements. Apparently they were added later and do not form part of the original collection.

Freudenthal $(1963 ;$ p.78) said in the description of Megacricetodon collongensis from VA3B: "This material comes from a bed of only a few centimeters thick, and therefore is very homogeneous". In fact this bed was a small lens that was only accessible during a very short time and all material that does not form part of the original 
collection, almost certainly is from another level, close to - but different from - VA3B. See also Freudenthal \& Martín-Suárez (2018).

The other specimens attributed to M. monspeliensis by Daams (1981) morphologically and metrically fit in the distribution of $M$. koenigswaldi, and the presence of M. monspeliensis sensu Daams (1981) in VA3B is not sustained. The only exception is $\mathrm{nr} 1473$, LxW $0.87 \mathrm{x}$ 0.81 , classified as $\mathrm{m} 3$ in the doctoral thesis of de Bruijn, classified as $\mathrm{m} 2$ by de Bruijn (pers. comm., 2018), and considered to be a $\mathrm{m} 1$ of which the length cannot be measured reliably by García Paredes (pers. comm., 2018).

Another problem is the presence of $M$. remmerti GarcíaParedes, Peláez Campomanes \& Alvarez Sierra, 2010 in VA3B. It is based on four specimens (one $\mathrm{p} 4$, one $\mathrm{m} 3$ and two M3), all of them belonging to the original (Utrecht) collection, but, in the absence of first and second molars, the available material is an insufficient basis. GarcíaParedes et al. (2010) considered M. remmerti to be a descendant of $M$. koenigswaldi, and its presence in VA3B would mean the co-occurrence of ancestor and descendant in the same locality, which we think is improbable. In our opinion only one species of Microdyromys is present in VA3B: M. koenigswaldi. Figure 8 shows the $\mathrm{LxW}$ diagrams of the material from VA3B, as obtained from the measurement lists of de Bruijn. In the graphs the conflicting numbers mentioned above are indicated.

\section{Microdyromys legidensis Daams, 1981}

Holotype. M2 sin., VL2A 1116, currently still in the Utrecht collections. Daams (1981) said: "The holotype will be stored in a collection to be designated by the Comisión Nacional de Geología (Spain)".
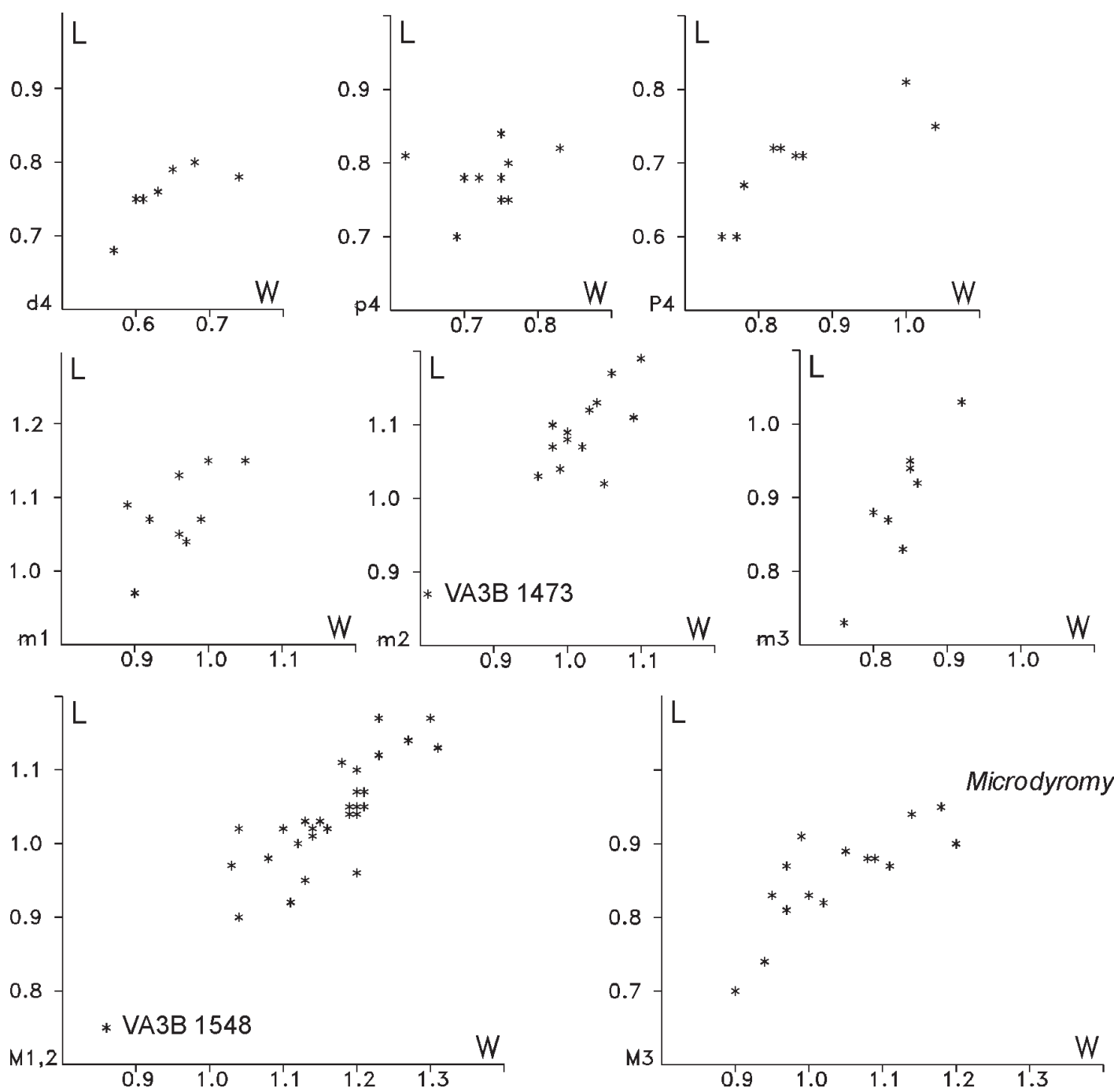

Figure 8. Length/width diagrams of Microdyromys koenigswaldi from Valdemoros 3B. 
Type locality. Villafeliche 2A (MN4, Calatayud-Teruel Basin, Spain).

Original diagnosis. Relatively small teeth with the intermediate morphotype $\mathrm{H}$ of M1,2 dominating.

N.B. Morphotype H of Daams (1981) refers to M1,2 having both precentroloph and postcentroloph, plus a prototrope.

Distribution. According to Daams (1981): St.-Victorla-Coste (MP29), Coderet (MP30), Bouzigues (MN2), Ateca 3 (MN4).

According to the differential diagnosis by Daams (1981) the only difference between M. legidensis (typelocality VL2A) and M. koenigswaldi (type-locality VA3B) is size, but, unfortunately, in VL2A he recognized (but not distinguished) M. legidensis and Peridyromys murinus; his morphological and measurement data lump these two species; only M1,2 was treated separately and can be used to compare size.

Not only is the M1,2 of M. koenigswaldi larger than that of $M$. legidensis; all Microdyromys populations younger than VL2A have a larger mean value for length and width of M1,2 than all older populations (Figs. 9-10). Therefore we consider M. legidensis from VL2A to be a valid species. However, the lack of detail for most of the dental

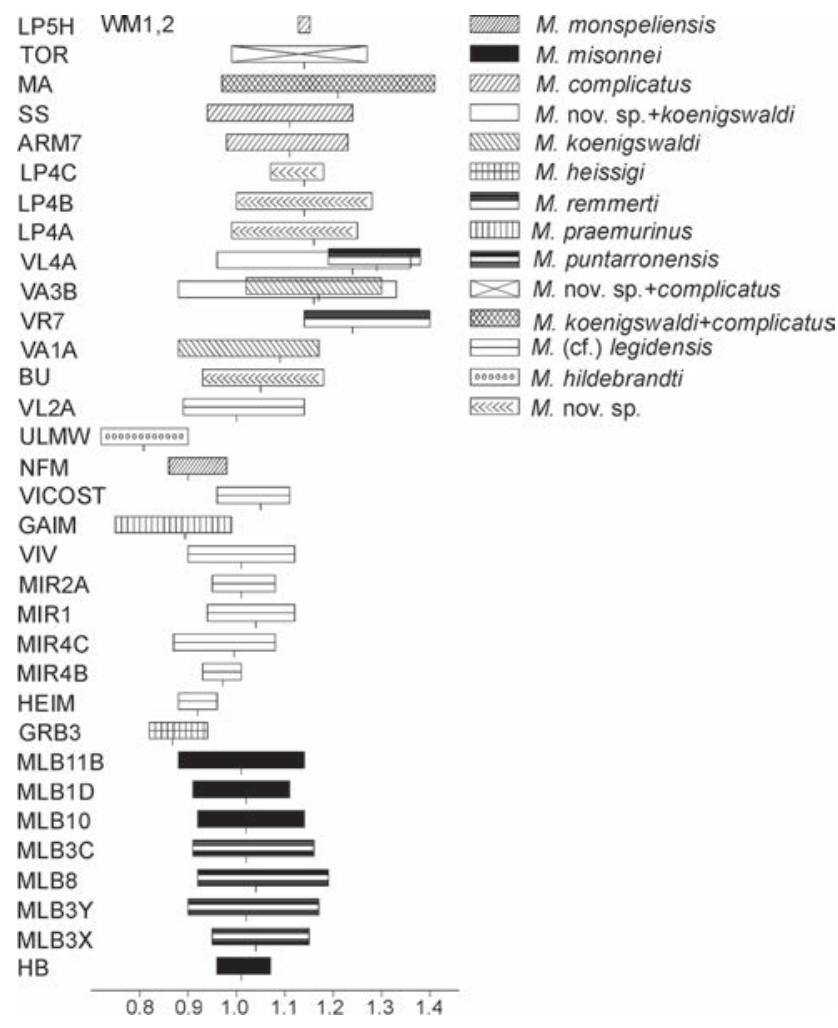

Figure 10. Distribution of the width of Microdyromys.

elements makes it impossible to classify other populations unambiguously. Consequently, we classify our material from the upper Oligocene as Microdyromys cf. legidensis.

Microdyromys cf. legidensis Daams, 1981

Synonymy.

1987 Microdyromys praemurinus, Hugueney et al. (1987).

1997 Microdyromys sp., Freudenthal (1997).

2007 Microdyromys praemurinus pro parte, Freudenthal \& Martín-Suárez (2007a).

Distribution. Mirambueno 1, 2A, 4B, 4C, 4D, Vivel del Río.

Description of Microdyromys cf. legidensis from Mirambueno 4B. (Fig. 11, Table 10).

p4. Shape blunt. Anterolophid continuous. Anterotropid very small. Mesostylid absent. Mesolophid connected to the entoconid. Posterotropid long.

m1. Anterolophid labially connected. Anterotropid of medium length (1) or long (1). Metalophid free (1) or low connected to the metaconid (1). Centrolophid of medium length (1) or long (1). Centrolophid-metaconid connection absent (1) or low (1). Mesostylid absent. Mesoconid

Figure 9. Distribution of the length of Microdyromys. 
placed on the labial border. Mesolophid connected to the entoconid. Posterotropid of medium length (1) or long (1).

m2. Anterolophid labially free (1) or labially connected (5). Anterotropid absent (5) or very small (1). Metalophid free (1), low connected to the metaconid (4), or high connected to the metaconid (1). Centrolophid absent (1), of medium length (3), or long (2). Centrolophidmetaconid connection low (4) or high (1). Mesostylid absent. Mesoconid placed on the labial border. Mesolophid connected to the entoconid. Posterotropid absent (1), of medium length (3), or long (2).

m3. Anterolophid labially connected. Anterotropid absent. Metalophid low connected to the metaconid. Centrolophid of medium length. Centrolophid-metaconid connection low (1) or high (1). Mesostylid absent. Mesoconid placed on the labial border. Mesolophid connected to the entoconid. Posterotropid absent (1) or long (1).

M1. Anteroloph lingually free (4) or lingually low connected (1). Anterotrope absent. Precentroloph long. Precentroloph connected to the paracone. Midcentroloph absent. Postcentroloph of medium length (2) or long (3). Postcentroloph connected to the metacone (4) or free from the metacone (1). Prototrope absent (1), short (3), or of medium length (1). Metatrope absent. Centrolophs not connected. Posterotrope absent. Endoloph anteriorly interrupted. Lingual border smooth (1) or crenulated (4).

Description of Microdyromys cf. legidensis from Mirambueno 4C. (Fig. 11, Table 10).

p4. Shape blunt. Anterolophid continuous. Anterotropid absent. Metalophid high connected to the metaconid. Centrolophid absent. Centrolophid-metaconid connection absent. Mesostylid absent. Mesoconid placed on the labial border. Mesolophid long and straight. Posterotropid long.

m1. Anterolophid labially connected. Anterotropid absent (2) or long (2). Metalophid low connected to the metaconid (1) or high connected to the metaconid (3). Centrolophid long. Centrolophid-metaconid connection low (2) or high (2). Mesostylid absent. Mesoconid placed on the labial border. Mesolophid connected to the entoconid. Posterotropid of medium length (1) or long (3).

$\mathbf{m} 2$. Anterolophid labially free (1) or labially connected (5). Anterotropid absent (4), very small (1), small (1), or long (1). Metalophid free (6) or low connected to the metaconid (1). Centrolophid of medium length (4) or long (3). Centrolophid-metaconid connection absent (2), low (1), or high (4). Mesostylid absent. Mesoconid placed on the labial border. Mesolophid connected to the metaconid (1), directed towards the entoconid (2), or connected to the entoconid (4). Posterotropid of medium length (1) or long (6).

m3. Anterolophid labially free. Anterotropid absent. Metalophid free. Centrolophid of medium length. Centrolophid-metaconid connection low. Mesostylid
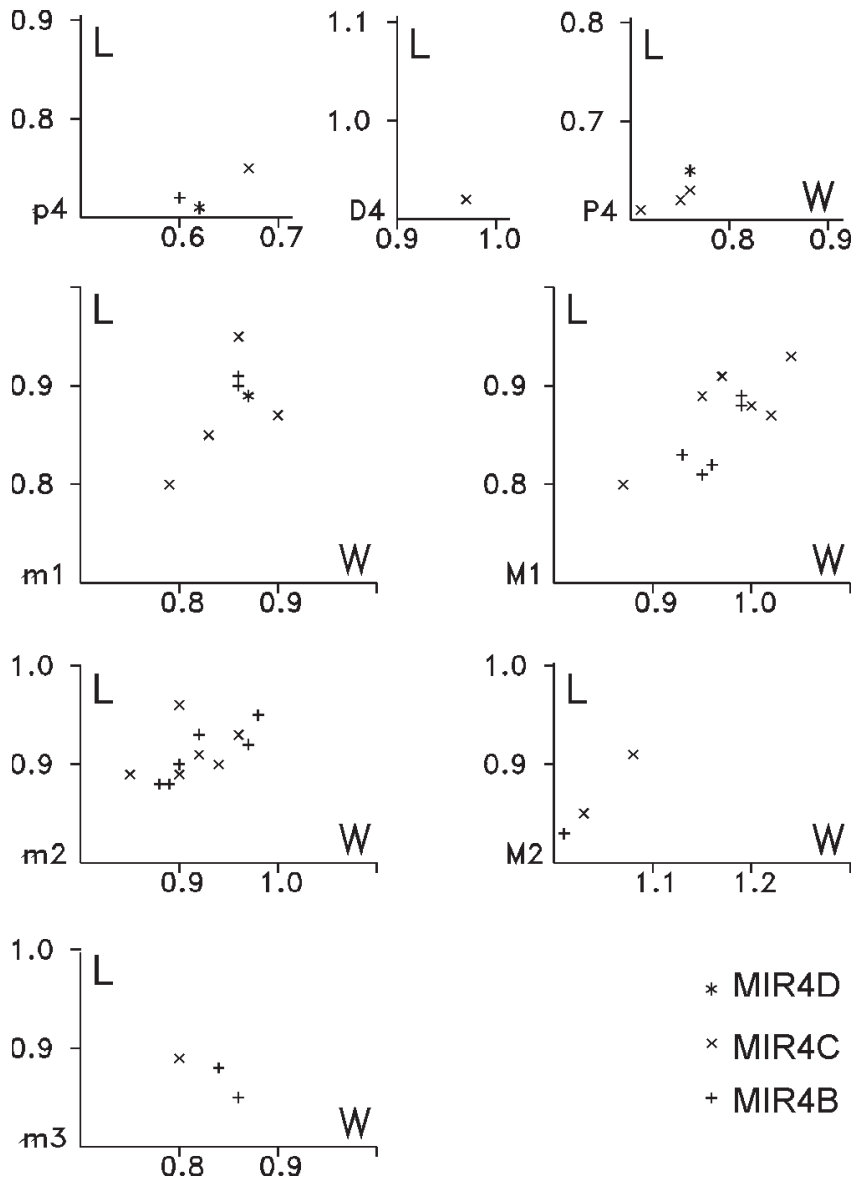

Figure 11. Length/width diagrams of Microdyromys cf. legidensis from Mirambueno 4.

absent. Mesoconid placed on the labial border. Mesolophid connected to the entoconid. Posterotropid of medium length.

D4. Anteroloph long. Anterotrope of medium length. Precentroloph long. Postcentroloph absent. Prototrope long. Metatrope absent. Centrolophs not connected. Posterotrope absent. Endoloph complete. Lingual border smooth.

P4. Anteroloph short (1) or of medium length (2). Anterotrope absent. Precentroloph of medium length (1) or long (2). Midcentroloph absent. Postcentroloph absent (1), of medium length (1), or long (1). Prototrope absent. Metatrope absent. Centrolophs not connected (1) or connected (2). Posterotrope absent. Endoloph complete. Lingual border smooth.

M1. Anteroloph lingually free (4) or lingually high connected (2). Anterotrope absent. Precentroloph long. Precentroloph connected to the paracone. Midcentroloph absent. Postcentroloph long, but always shorter than precentroloph. Postcentroloph connected to the metacone (2), free from the metacone (1), or placed centrally (3). Prototrope short (4) or of medium length (2). Metatrope absent. Centrolophs not connected. Posterotrope absent. Endoloph formed by the protocone alone (1), anteriorly 
Table 10. Measurements of Microdyromys cf. legidensis.

\begin{tabular}{|c|c|c|c|c|c|c|c|c|c|c|c|c|}
\hline & \multicolumn{6}{|c|}{ Length } & \multicolumn{6}{|c|}{ Width } \\
\hline $\mathrm{d} 4$ & $\mathrm{~N}$ & Min. & Mean & Max. & $\mathrm{V}^{\prime}$ & $\sigma$ & $\mathrm{N}$ & Min. & Mean & Max. & $\mathrm{V}^{\prime}$ & $\sigma$ \\
\hline VIV & 7 & 0.65 & 0.696 & 0.73 & 11.6 & 0.030 & 7 & 0.55 & 0.593 & 0.64 & 15.1 & 0.035 \\
\hline $\begin{array}{l}\text { MIR1 } \\
\text { p4 }\end{array}$ & 4 & 0.71 & 0.763 & 0.83 & 15.6 & 0.050 & 4 & 0.61 & 0.650 & 0.68 & 10.9 & 0.036 \\
\hline VIV & 14 & 0.69 & 0.736 & 0.81 & 16.0 & 0.036 & 14 & 0.59 & 0.638 & 0.73 & 21.2 & 0.040 \\
\hline MIR2A & 5 & 0.71 & 0.734 & 0.76 & 6.8 & 0.021 & 5 & 0.62 & 0.648 & 0.69 & 10.7 & 0.028 \\
\hline MIR1 & 3 & 0.78 & 0.793 & 0.82 & 5.0 & & 3 & 0.66 & 0.697 & 0.72 & 8.7 & \\
\hline MIR4D & 1 & & 0.710 & & & & 1 & & 0.620 & & & \\
\hline MIR4C & 1 & & 0.750 & & & & 1 & & 0.670 & & & \\
\hline $\begin{array}{l}\text { MIR4B } \\
\text { m1 }\end{array}$ & 1 & & 0.720 & & & & 1 & & 0.600 & & & \\
\hline VIV & 18 & 0.84 & 0.914 & 0.98 & 15.4 & 0.039 & 18 & 0.82 & 0.887 & 0.97 & 16.8 & 0.039 \\
\hline MIR2A & 7 & 0.86 & 0.931 & 0.98 & 13.0 & 0.038 & 7 & 0.80 & 0.896 & 0.95 & 17.1 & 0.047 \\
\hline MIR1 & 12 & 0.89 & 0.943 & 0.99 & 10.6 & 0.031 & 12 & 0.81 & 0.909 & 0.94 & 14.9 & 0.036 \\
\hline MIR4D & 1 & & 0.890 & & & & 1 & & 0.870 & & & \\
\hline MIR4C & 4 & 0.80 & 0.868 & 0.95 & 17.1 & 0.062 & 4 & 0.79 & 0.845 & 0.90 & 13.0 & 0.047 \\
\hline $\begin{array}{l}\text { MIR4B } \\
\mathrm{m} 2\end{array}$ & 2 & 0.90 & 0.905 & 0.91 & 1.1 & & 2 & 0.86 & 0.860 & 0.86 & 0.0 & \\
\hline VIV & 28 & 0.84 & 0.931 & 1.01 & 18.4 & 0.040 & 27 & 0.85 & 0.927 & 1.00 & 16.2 & 0.039 \\
\hline MIR2A & 6 & 0.88 & 0.935 & 1.00 & 12.8 & 0.045 & 4 & 0.88 & 0.940 & 1.01 & 13.8 & 0.055 \\
\hline MIR1 & 17 & 0.82 & 0.942 & 1.01 & 20.8 & 0.049 & 15 & 0.89 & 0.959 & 1.03 & 14.6 & 0.041 \\
\hline MIR4C & 7 & 0.88 & 0.909 & 0.96 & 8.7 & 0.028 & 6 & 0.85 & 0.912 & 0.96 & 12.2 & 0.038 \\
\hline $\begin{array}{l}\text { MIR4B } \\
\mathrm{m} 1,2\end{array}$ & 6 & 0.88 & 0.910 & 0.95 & 7.7 & 0.028 & 6 & 0.88 & 0.922 & 0.98 & 10.8 & 0.044 \\
\hline VIV & 46 & 0.84 & 0.924 & 1.01 & 18.4 & 0.040 & 45 & 0.82 & 0.911 & 1.00 & 19.8 & 0.043 \\
\hline MIR2A & 13 & 0.86 & 0.933 & 1.00 & 15.1 & 0.040 & 11 & 0.80 & 0.912 & 1.01 & 23.2 & 0.052 \\
\hline MIR1 & 29 & 0.82 & 0.942 & 1.01 & 20.8 & 0.042 & 27 & 0.81 & 0.937 & 1.03 & 23.9 & 0.046 \\
\hline MIR4D & 1 & & 0.890 & & & & 1 & & 0.870 & & & \\
\hline MIR4C & 11 & 0.80 & 0.894 & 0.96 & 18.2 & 0.045 & 10 & 0.79 & 0.885 & 0.96 & 19.4 & 0.052 \\
\hline $\begin{array}{l}\text { MIR4B } \\
\text { m3 }\end{array}$ & 8 & 0.88 & 0.909 & 0.95 & 7.7 & 0.024 & 8 & 0.86 & 0.906 & 0.98 & 13.0 & 0.047 \\
\hline VIV & 17 & 0.75 & 0.807 & 0.87 & 14.8 & 0.037 & 16 & 0.68 & 0.779 & 0.86 & 23.4 & 0.049 \\
\hline MIR2A & 2 & 0.80 & 0.825 & 0.85 & 6.1 & & 2 & 0.73 & 0.770 & 0.81 & 10.4 & \\
\hline MIR1 & 12 & 0.74 & 0.818 & 0.90 & 19.5 & 0.044 & 12 & 0.74 & 0.803 & 0.85 & 13.8 & 0.036 \\
\hline MIR4C & 1 & & 0.890 & & & & 1 & & 0.800 & & & \\
\hline $\begin{array}{l}\text { MIR4B } \\
\text { D4 }\end{array}$ & 2 & 0.85 & 0.865 & 0.88 & 3.5 & & 2 & 0.84 & 0.850 & 0.86 & 2.4 & \\
\hline VIV & 3 & 0.61 & 0.643 & 0.71 & 15.2 & & 3 & 0.72 & 0.723 & 0.73 & 1.4 & \\
\hline $\begin{array}{l}\text { MIR4C } \\
\text { P4 }\end{array}$ & 1 & & 0.920 & & & & 1 & & 0.970 & & & \\
\hline VIV & 14 & 0.59 & 0.630 & 0.68 & 14.2 & 0.024 & 13 & 0.71 & 0.758 & 0.80 & 11.9 & 0.037 \\
\hline MIR2A & 1 & & 0.650 & & & & 1 & & 0.780 & & & \\
\hline MIR1 & 13 & 0.58 & 0.632 & 0.68 & 15.9 & 0.033 & 13 & 0.73 & 0.790 & 0.84 & 14.0 & 0.035 \\
\hline MIR4D & 1 & & 0.650 & & & & 1 & & 0.760 & & & \\
\hline $\begin{array}{l}\text { MIR4C } \\
\text { M1 }\end{array}$ & 3 & 0.61 & 0.620 & 0.63 & 3.2 & & 3 & 0.71 & 0.740 & 0.76 & 6.8 & \\
\hline VIV & 31 & 0.79 & 0.877 & 0.95 & 18.4 & 0.040 & 28 & 0.90 & 0.974 & 1.05 & 15.4 & 0.037 \\
\hline MIR2A & 8 & 0.84 & 0.889 & 0.96 & 13.3 & 0.042 & 8 & 0.95 & 0.986 & 1.03 & 8.1 & 0.030 \\
\hline MIR1 & 7 & 0.86 & 0.910 & 0.97 & 12.0 & 0.045 & 6 & 0.96 & 1.023 & 1.08 & 11.8 & 0.042 \\
\hline MIR4C & 6 & 0.80 & 0.880 & 0.93 & 15.0 & 0.045 & 6 & 0.87 & 0.975 & 1.04 & 17.8 & 0.061 \\
\hline $\begin{array}{l}\text { MIR4B } \\
\text { M2 }\end{array}$ & 5 & 0.81 & 0.846 & 0.89 & 9.4 & 0.036 & 5 & 0.93 & 0.964 & 0.99 & 6.2 & 0.026 \\
\hline VIV & 35 & 0.79 & 0.882 & 0.97 & 20.5 & 0.040 & 35 & 0.98 & 1.038 & 1.12 & 13.3 & 0.038 \\
\hline MIR2A & 7 & 0.85 & 0.900 & 0.95 & 11.1 & 0.036 & 6 & 1.00 & 1.047 & 1.08 & 7.7 & 0.029 \\
\hline MIR1 & 15 & 0.80 & 0.885 & 0.98 & 20.2 & 0.048 & 14 & 0.94 & 1.059 & 1.12 & 17.5 & 0.055 \\
\hline MIR4C & 2 & 0.85 & 0.880 & 0.91 & 6.8 & & 2 & 1.03 & 1.055 & 1.08 & 4.7 & \\
\hline $\begin{array}{l}\text { MIR4B } \\
\text { M1,2 }\end{array}$ & 1 & & 0.830 & & & & 1 & & 1.010 & & & \\
\hline VIV & 66 & 0.79 & 0.880 & 0.97 & 20.5 & 0.040 & 63 & 0.90 & 1.010 & 1.12 & 21.8 & 0.049 \\
\hline MIR2A & 15 & 0.84 & 0.894 & 0.96 & 13.3 & 0.038 & 14 & 0.95 & 1.012 & 1.08 & 12.8 & 0.042 \\
\hline MIR1 & 22 & 0.80 & 0.893 & 0.98 & 20.2 & 0.048 & 20 & 0.94 & 1.048 & 1.12 & 17.5 & 0.053 \\
\hline MIR4C & 8 & 0.80 & 0.880 & 0.93 & 15.0 & 0.041 & 8 & 0.87 & 0.995 & 1.08 & 21.5 & 0.065 \\
\hline $\begin{array}{l}\text { MIR4B } \\
\text { M3 }\end{array}$ & 6 & 0.81 & 0.843 & 0.89 & 9.4 & 0.033 & 6 & 0.93 & 0.972 & 1.01 & 8.2 & 0.030 \\
\hline VIV & 24 & 0.63 & 0.703 & 0.83 & 27.4 & 0.046 & 23 & 0.79 & 0.866 & 0.96 & 19.4 & 0.051 \\
\hline MIR2A & 5 & 0.70 & 0.734 & 0.79 & 12.1 & 0.034 & 5 & 0.89 & 0.912 & 0.94 & 5.5 & 0.026 \\
\hline
\end{tabular}


interrupted (3), or complete (2). Lingual border smooth (3) or crenulated (3).

M2. Anteroloph lingually free. Anterotrope absent (1) or short (1). Precentroloph long. Precentroloph connected to the paracone. Midcentroloph absent. Postcentroloph long. Postcentroloph placed centrally. Prototrope long. Metatrope absent. centrolophs not connected. Posterotrope absent. Endoloph anteriorly interrupted . Lingual border crenulated.

Description of Microdyromys cf. legidensis from Mirambueno 1. (Fig. 12, Table 10).

d4. Anterolophid interrupted (1) or continuous (3). Anterotropid absent (2) or very small (2). Metalophid free (3) or high connected to the metaconid (1). Centrolophid absent (2), of medium length (1), or long (1). Centrolophidmetaconid connection absent (2), low (1), or high (1). Mesostylid absent. Mesoconid placed on the labial border. Mesolophid of medium length (1), directed towards the entoconid (1), or connected to the entoconid (2). Posterotropid absent (1), very small (1), of medium length (1), or long (1).

p4. Shape blunt. Anterolophid interrupted. Anterotropid absent (1) or very small (1). Metalophid free (1), low connected to the metaconid (1), or high connected to the metaconid (1). Centrolophid long. Centrolophidmetaconid connection absent (2) or low (1). Mesostylid absent. Mesoconid placed on the labial border. Mesolophid directed towards the entoconid (1) or connected to the entoconid (2). Posterotropid long.

m1. Anterolophid labially connected. Anterotropid absent (4), very small (3), of medium length (2), or long (3). Metalophid free (4), low connected to the metaconid (4), or high connected to the metaconid (5). Centrolophid long. Centrolophid-metaconid connection absent (3), low (2), or high (8). Mesostylid absent. Mesoconid placed on the labial border. Mesolophid directed towards the metaconid (1), connected to the metaconid (1), directed towards the entoconid (1), connected to the entoconid (9), or long and straight (1). Posterotropid long.

m2. Anterolophid labially connected. Anterotropid absent (4), very small (2), small (1), of medium length (9), or long (1). Metalophid free (9), low connected to the metaconid (5), or high connected to the metaconid (3). Centrolophid long. Centrolophid-metaconid connection absent (1), low (2), or high (14). Mesostylid absent. Mesoconid placed on the labial border. Mesolophid connected to the entoconid. Posterotropid of medium length (4) or long (13).

m3. Anterolophid labially free (3) or labially connected (7). Anterotropid absent (10) or small (2). Metalophid free (4), low connected to the metaconid (6), or high connected to the metaconid (1). Centrolophid of medium length (7) or long (5). Centrolophid-metaconid connection absent (2), low (1), or high (9). Mesostylid absent (11) or crest
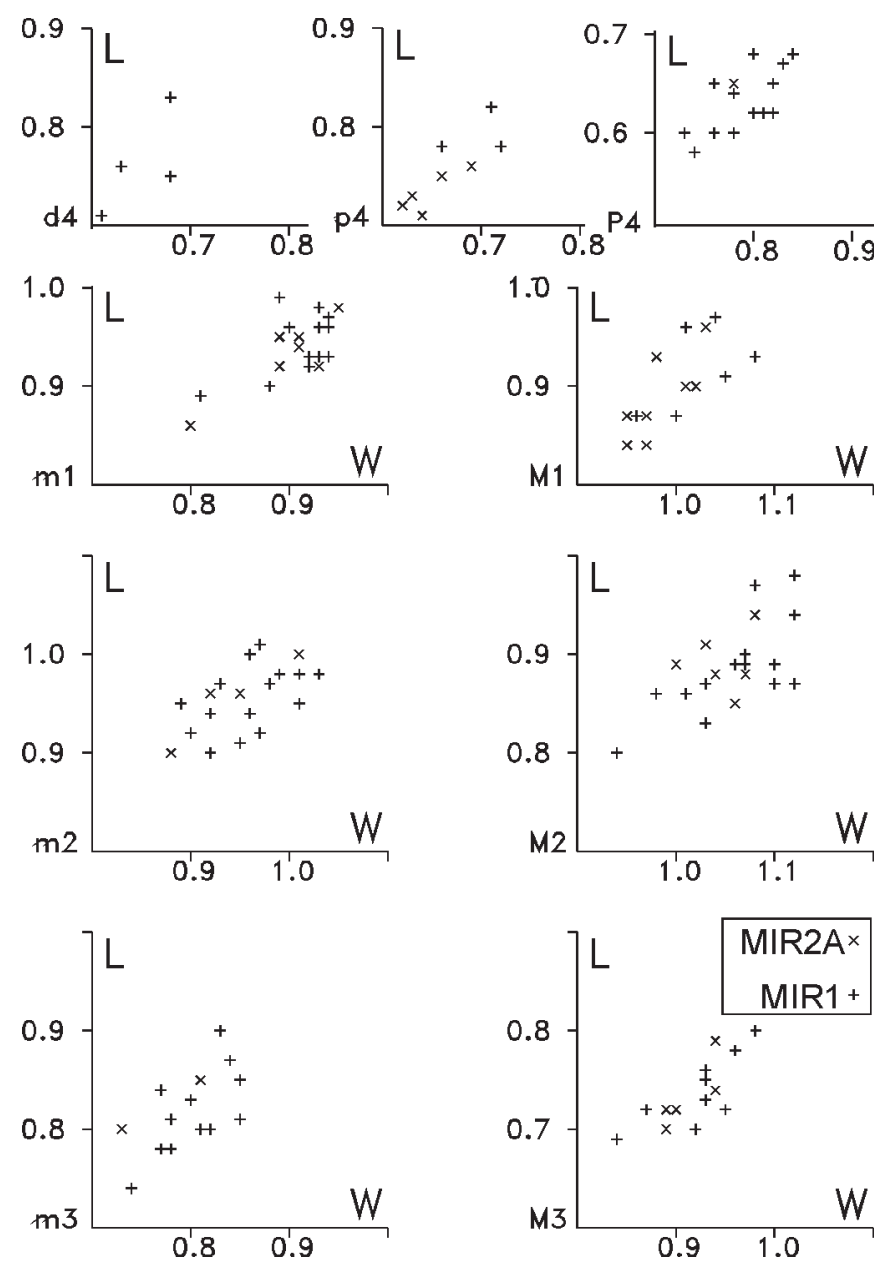

Figure 12. Length/width diagrams of Microdyromys cf. legidensis from Mirambueno 1 and 2.

(1). Mesoconid placed on the labial border. Mesolophid directed towards the entoconid (1) or connected to the entoconid (11). Posterotropid absent (2), very small (3), small (3), of medium length (2), or long (2).

P4. Anteroloph short (1), of medium length (8), or long (4). Anterotrope absent. Precentroloph absent (3) or long (10). Midcentroloph absent. Postcentroloph absent (6), short (4), or long (3). Prototrope absent. Metatrope absent (12) or short (1). Centrolophs not connected (12) or connected (1). Posterotrope absent. Endoloph formed by the protocone alone (2), anteriorly interrupted (1), posteriorly interrupted (3), or complete (7). Lingual border smooth.

M1. Anteroloph lingually free (2), lingually low connected (2), or lingually high connected (3). Anterotrope absent. Precentroloph long. Precentroloph connected to the paracone. Midcentroloph absent. Postcentroloph long. Postcentroloph connected to the metacone (6) or placed centrally (1). Prototrope absent (1), of medium length (2), or long (4). Metatrope absent. Centrolophs not connected (4) or connected lingually (3). Posterotrope absent. 
Endoloph formed by the protocone alone (1) or complete (6). Lingual border smooth (1) or crenulated (6).

M2. Anteroloph lingually low connected (2) or lingually high connected (11). Anterotrope absent (11) or short (3). Precentroloph long. Precentroloph connected to the paracone. Midcentroloph absent. Postcentroloph short (1) or long (14). Postcentroloph connected to the metacone (7), free from the metacone (3), or placed centrally (4). Prototrope absent (1), of medium length (5), or long (8). Metatrope absent (13) or long (1). Centrolophs not connected (13), connected lingually (1), or connected midway (1). Posterotrope absent. Endoloph anteriorly interrupted (2) or complete (10). Lingual border smooth (1) or crenulated (10).

M3. Anteroloph lingually high connected . Anterotrope absent (9) or long (1). Precentroloph long. Postcentroloph long. Prototrope absent. Metatrope short. Centrolophs not connected (8) or connected (3). Crests inside the trigone: three crests. Mesostyl absent (8) or present (3). Posterotrope absent. Endoloph complete. Lingual border smooth (3) or crenulated (6).

Description of Microdyromys cf. legidensis from Mirambueno 2A. (Fig. 12, Table 10).

p4. Shape blunt. Anterolophid interrupted (1) or continuous (3). Anterotropid absent. Metalophid low connected to the metaconid (1) or high connected to the metaconid (3). Centrolophid absent (2), short (1), of medium length (1), or long (1). Centrolophid-metaconid connection high. Mesostylid absent. Mesoconid placed on the labial border. Mesolophid connected to the entoconid. Posterotropid absent (2), very small (2), or long (1).

m1. Anterolophid labially connected. Anterotropid very small (1), small (1), of medium length (4), or long (1). Metalophid free (1), low connected to the metaconid (1), or high connected to the metaconid (5). Centrolophid long. Centrolophid-metaconid connection absent (1), low (1), or high (5). Mesostylid absent. Mesoconid placed on the labial border. Mesolophid connected to the entoconid. Posterotropid long.

m2. Anterolophid labially free (2) or labially connected (5). Anterotropid absent (2), small (3), or of medium length (2). Metalophid free (1), low connected to the metaconid (2), or high connected to the metaconid (4). Centrolophid long. Centrolophid-metaconid connection absent (1), low (4), or high (2). Mesostylid absent. Mesoconid placed on the labial border. Mesolophid connected to the metaconid (1) or connected to the entoconid (6). Posterotropid long.

m3. Anterolophid labially connected. Anterotropid absent (1) or small (1). Metalophid free (1) or high connected to the metaconid (1). Centrolophid of medium length (1) or long (1). Centrolophid-metaconid connection absent. Mesostylid absent. Mesoconid placed on the labial border. Mesolophid connected to the entoconid. Posterotropid long.
P4. Anteroloph long. Anterotrope absent. Precentroloph long. Midcentroloph absent. Postcentroloph long. Prototrope absent. Metatrope absent. Centrolophs connected. Posterotrope absent. Endoloph anteriorly interrupted. Lingual border smooth.

M1. Anteroloph lingually free (5), lingually low connected (2), or lingually high connected (1). Anterotrope absent. Precentroloph long. Precentroloph connected to the paracone. Midcentroloph absent. Postcentroloph long. Postcentroloph connected to the metacone (4) or free from the metacone (4). Prototrope of medium length (6) or long (2). Metatrope absent. centrolophs not connected. Posterotrope absent. Endoloph anteriorly interrupted (5) or complete (3). Lingual border smooth (4) or crenulated (4).

M2. Anteroloph lingually free (3), lingually low connected (1), or lingually high connected (3). Anterotrope absent. Precentroloph long. Precentroloph connected to the paracone. Midcentroloph absent. Postcentroloph of medium length (1) or long (6). Postcentroloph connected to the metacone (5) or free from the metacone (2). Prototrope short (2), of medium length (1), or long (4). Metatrope absent (6) or short (1). Centrolophs not connected. Posterotrope absent. Endoloph anteriorly interrupted (3) or complete (4). Lingual border smooth (4) or crenulated (3).

M3. Anteroloph lingually high connected . Anterotrope absent. Precentroloph long. Postcentroloph absent (1), short (2), or of medium length (1). Prototrope absent (1), short (1), or long (2). Metatrope absent. Centrolophs not connected. Crests inside the trigone: two crests (2) or three crests (3). Mesostyl absent (2) or present (3). Posterotrope absent. Endoloph complete. Lingual border smooth (3) or crenulated (2).

Description of Microdyromys cf. legidensis from Vivel del Río. (Figs. 4.17-4.20, Fig. 13, Table 10).

d4. Anterolophid interrupted (1) or continuous (6). Anterotropid absent. Metalophid lingually free (6) or high connected to the metaconid (1). Metalophid labially free (4) Centrolophid absent (6) or short (1). Centrolophidmetaconid connection absent (6) or high (1). Mesostylid absent. Mesoconid placed on the labial border. Mesolophid of medium length and interrupted (1) or connected to the entoconid (6). Posterotropid absent (1), very small (1), small (1), of medium length (1), or long (3).

p4. Shape blunt. Anterolophid interrupted (3) or continuous (11). Anterotropid absent (9), very small (5), or small (1). Metalophid free (1), low connected to the metaconid (1), or high connected to the metaconid (13). Centrolophid absent (1), short (2), of medium length (3), or long (9). Centrolophid-metaconid connection absent (2), low (7), or high (5). Mesostylid absent. Mesoconid placed on the labial border. Mesolophid directed towards the entoconid (2) or connected to the entoconid (12). Posterotropid absent (2), small (1), of medium length (4), or long (8). 

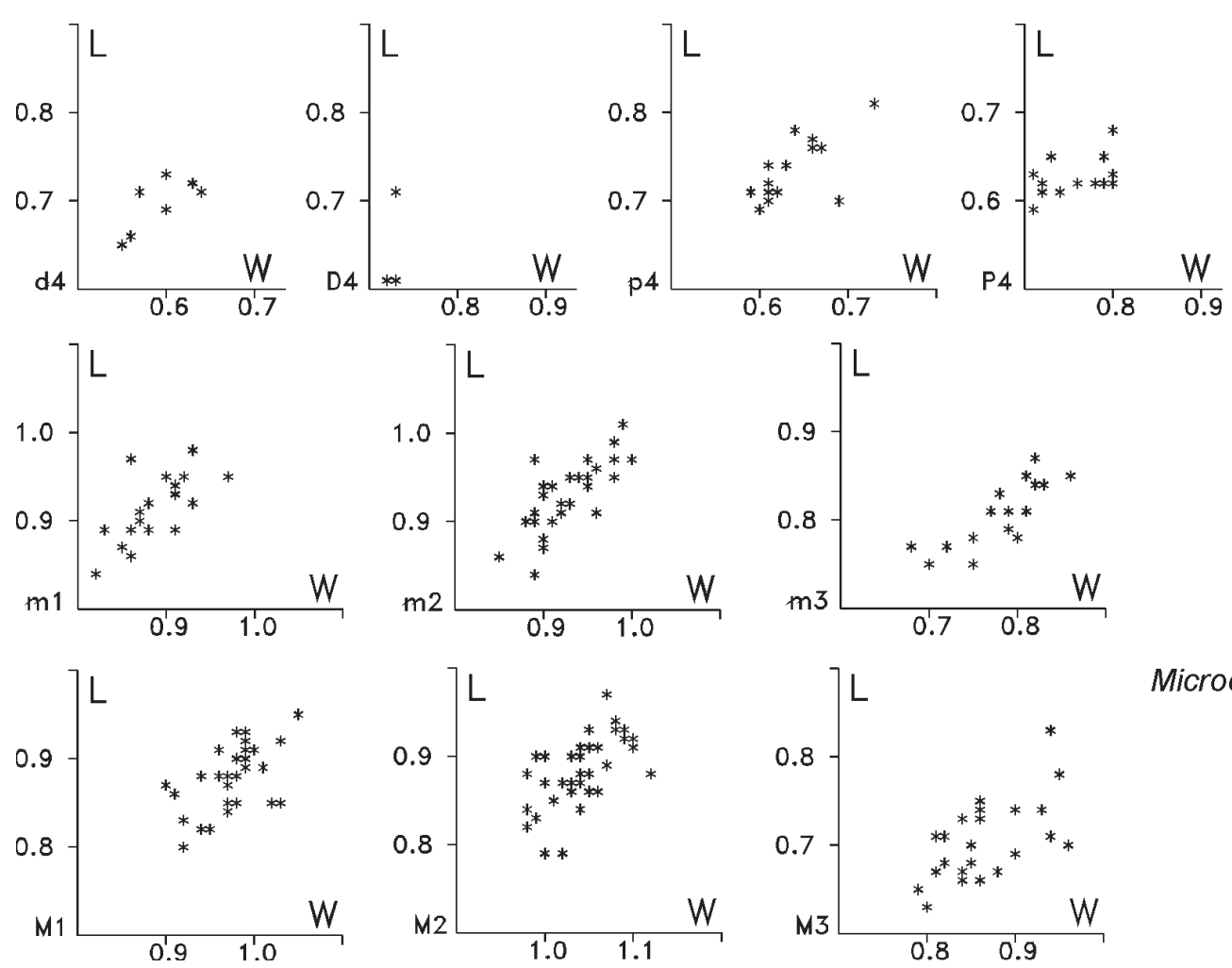

Microdyromys cf. legidensis

VIV

Figure 13. Length/width diagrams of Microdyromys cf. legidensis from Vivel del Río.

m1. Anterolophid labially connected. Anterotropid absent (2), very small (2), small (2), of medium length (6), or long (6). Metalophid free (6), low connected to the metaconid (1), or high connected to the metaconid (11). Centrolophid long. Centrolophid-metaconid connection absent (3) or high (15). Mesostylid absent. Mesoconid placed on the labial border. Mesolophid directed towards the entoconid (1) or connected to the entoconid (17). Posterotropid of medium length (2) or long (16).

m2. Anterolophid labially connected. Anterotropid absent (4), very small (4), small (5), of medium length (10), or long (7). Metalophid free (18), low connected to the metaconid (7), or high connected to the metaconid (5). Centrolophid of medium length (2) or long (30). Centrolophid-metaconid connection absent (4), low (2), or high (25). Mesostylid absent (28) or crest (3). Mesoconid placed on the labial border. Mesolophid directed towards the entoconid (1) or connected to the entoconid (30). Posterotropid of medium length (4) or long (28), double in one case.

m3. Anterolophid labially free (10) or labially connected (6). Anterotropid absent (9), very small (4), small (3), or of medium length (1). Metalophid free (14), low connected to the metaconid (1), or high connected to the metaconid (2). Centrolophid of medium length (2) or long (15). Centrolophid-metaconid connection absent (3), low (1), or high (11). Mesostylid absent. Mesoconid placed on the labial border. Mesolophid connected to the entoconid. Posterotropid of medium length (3) or long (13).

D4. Anteroloph short. Anterotrope absent. Precentroloph long. Postcentroloph absent. Prototrope absent. Metatrope absent. Centrolophs not connected. Posterotrope absent. Endoloph anteriorly interrupted (2) or complete (1). Lingual border smooth.

P4. Anteroloph short (1), of medium length (7), or long (6). Anterotrope absent. Precentroloph long. Midcentroloph absent. Postcentroloph absent (8), short (4), of medium length (1), or long (1). Prototrope absent. Metatrope absent. Centrolophs not connected. Posterotrope absent. Endoloph formed by the protocone alone (1), anteriorly interrupted (10), or complete (2). Lingual border smooth (9) or crenulated (4).

M1. Anteroloph lingually free (16), lingually low connected (7), or lingually high connected (9). Anterotrope absent (30), short (5), or of medium length (1). Precentroloph of medium length (1) or long (35). Precentroloph connected to the paracone. Midcentroloph absent. Postcentroloph of medium length (3) or long (33) nearly always shorter than precentroloph. Postcentroloph connected to the metacone (22), free from the metacone (8), or placed centrally (3). Prototrope short (4), of medium length (17), or long (15). Metatrope absent. Centrolophs not connected (33), connected lingually (2), or connected midway (1). Posterotrope absent (33), short (2), or of 
medium length (1). Endoloph anteriorly interrupted (16), posteriorly interrupted (1), or complete (16). Lingual border smooth (3) or crenulated (32).

M2. Anteroloph lingually free (4), lingually low connected (2), or lingually high connected (32). Anterotrope absent (28), short (8), of medium length (2), or long (1). Precentroloph long, generally longer than postcentroloph. Precentroloph connected to the paracone (38) or free from the paracone (1). Midcentroloph absent. Postcentroloph of medium length (1) or long (38). Postcentroloph connected to the metacone (17), free from the metacone (12), or placed centrally (8). Prototrope absent (3), short (2), of medium length (14), or long (20). Metatrope absent (31), of medium length (2), or long (5). centrolophs not connected (32), connected lingually (1), or connected midway (6). Posterotrope absent. Endoloph anteriorly interrupted (3) or complete (35). Lingual border smooth (4) or crenulated (30).

M3. Anteroloph lingually free (1), lingually low connected (2), or lingually high connected (20). Anterotrope absent (18), short (5), or of medium length (1). Postcentroloph short (3), of medium length (3), or long (17). Centrolophs not connected (16) or connected (5). Crests inside the trigone: two crests (1), three crests (17), or four crests (2). Mesostyl absent (14) or present (3). Posterotrope absent (21), short (1), or of medium length (1). Endoloph posteriorly interrupted (3) or complete (21). Lingual border smooth (8) or crenulated (13).

Discussion. The Microdyromys from Vivel was described as M. praemurinus by Hugueney et al. (1987), but that species is clearly smaller (Figs 9-10). Daams (1981) said that M. praemurinus differs from M. legidensis by the not-ornamented lingual wall of $\mathrm{M} 1,2$, and by the centrolophid which is not connected to the metaconid in 10 out of 14 specimens. Here we will discuss the features used by Daams (op. cit.):

1) Prototrope $M 1,2$. In $M$. legidensis from its typelocality VL2A 3 out of 21 specimens (16\%) lack a prototrope. In Vivel and Mirambueno this is the case in only 6 out of 124 specimens $(5 \%)$. In this respect (morphotype H) our material resembles $M$. legidensis fairly well.

2) Ornamentation. The lingual wall of M1,2 of $M$. legidensis is "generally ornamented" (Daams, 1981). In our material, 21 out of $115(18 \%)$ specimens have a smooth lingual wall. Also in this feature our material resembles M. legidensis (Table 11).

According to Daams (1981) such ornamentation is absent in the M1,2 of M. praemurinus from Gaimersheim; Kristkoiz (1992) mentions this feature, but apparently referred to something different from other authors, and furthermore said it to be subjective.

3) Metaconid-centrolophid connection. Daams reported a metaconid-centrolophid connection constantly present in
Table 11. Ornamentation of the lingual border of $M 1,2$ in Microdyromys.

\begin{tabular}{|c|c|c|c|c|}
\hline $\begin{array}{c}\text { Ornamentation } \\
\text { M1,2 }\end{array}$ & locality & $\mathbf{n}$ & state & source \\
\hline M. heissigi & GRB3 & 20 & few small holes $4 / 20$ & Uhlig (2001) \\
\hline M. monspeliensis & NFM & 12 & absent & $\begin{array}{l}\text { Aguilar } \\
\text { (1977) }\end{array}$ \\
\hline $\begin{array}{l}\text { M. monspeliensis } \\
\text { sensu Daams }\end{array}$ & Spain & & generally present & Daams (1981) \\
\hline M. praemurinus & GAIM & 11 & absent & Daams (1981) \\
\hline M. praemurinus & GAIM & 20 & $12 / 20$ present? & $\begin{array}{l}\text { Kristkoiz } \\
\text { (1992) }\end{array}$ \\
\hline M. hildebrandti & ULMW & 189 & strong & Werner (1994) \\
\hline M. cf. legidensis & VIV & 69 & absent $7 / 69$ & this paper \\
\hline M. cf. legidensis & MIR & 46 & absent $14 / 46$ & this paper \\
\hline M. legidensis & VL2A & & generally present & Daams (1981) \\
\hline
\end{tabular}

VL2A and absent in 10 out of 14 m1,2 from Gaimersheim. In our material from Vivel and Mirambueno, the connection is established in 66 out of 80 specimens (over $80 \%$ ), quite compatible with $M$. legidensis, and not with $M$. praemurinus (Table 12)

Table 12. Metaconid-centrolophid connection in $\mathrm{m} 1,2$ of Microdyromys cf. legidensis.

\begin{tabular}{|c|c|c|c|c|c|}
\hline & & $\mathrm{n}$ & absent $\%$ & present $\%$ & source \\
\hline M. praemurinus & GAIM & 14 & $71 \%$ & $29 \%$ & Daams (1981) \\
\hline M. praemurinus & GAIM & 34 & $44 \%$ & $56 \%$ & Kristkoiz (1992) \\
\hline M. cf. legidensis & VIV & 49 & $14 \%$ & $86 \%$ & ths work \\
\hline M. cf. legidensis & MIR & 62 & $15 \%$ & $85 \%$ & ths work \\
\hline M. legidensis & VL2A & $?$ & $0 \%$ & $100 \%$ & Daams (1981) \\
\hline
\end{tabular}

4) Other features. In the other features used by Daams Microdyromys and Peridyromys are treated together, and we don't know the character distribution of $M$. legidensis from VL2A. That means we cannot decide whether our material really belongs to $M$. legidensis and therefore we call it M. cf. legidensis.

According to Daams (1981) in the M1,2 of $M$. legidensis from VL2A the postcentroloph is not connected to the metacone in $73 \%(\mathrm{n}=15)$; in our material of $M$. $\mathrm{cf}$. legidensis the postcentroloph is predominantly connected (Table 13).

In view of the data from Daams (1981), M. legidensis from VL2A seems to have less-developed tropids than our material. However, the data from VL2A include Peridyromys murinus (Table 14).

Phylogeny of Microdyromys. The phylogeny of Microdyromys was discussed by Freudenthal \& MartínSuárez (2007a). Here we present a revised version of their figure 5 (Fig. 14). 
Table 13. Connection of the postcentroloph in M1,2 of Microdyromys. cf. legidensis.

\begin{tabular}{l|lllll} 
M1 & MIR4B & MIR4C & MIR1 & MIR2A & VIV \\
\hline & $\%$ & $\%$ & $\%$ & $\%$ & $\%$ \\
postcentroloph & $\mathrm{N}=5$ & $\mathrm{~N}=6$ & $\mathrm{~N}=7$ & $\mathrm{~N}=8$ & $\mathrm{~N}=33$ \\
to metacone & 80.0 & 33.3 & 85.7 & 50.0 & 66.7 \\
free & 20.0 & 16.7 & 0.0 & 50.0 & 24.2 \\
central & 0.0 & 50.0 & 14.3 & 0.0 & 9.1 \\
M2 & & & & & \\
postcentroloph & $\mathrm{N}=0$ & $\mathrm{~N}=2$ & $\mathrm{~N}=14$ & $\mathrm{~N}=7$ & $\mathrm{~N}=37$ \\
to metacone & 0.0 & 0.0 & 50.0 & 71.4 & 45.9 \\
free & 0.0 & 0.0 & 21.4 & 28.6 & 32.4 \\
central & 0.0 & 100.0 & 28.6 & 0.0 & 21.6 \\
\hline
\end{tabular}

Table 14. Absence/presence of tropids in $\mathrm{m} 1,2$ of $M$. $\mathrm{cf}$. legidensis; * includes Peridyromys.

\begin{tabular}{l|llllll} 
& MIR4B & MIR4C & MIR1 & MIR2A & VIV & VL2A $^{*}$ \\
\hline m1 & $\%$ & $\%$ & $\%$ & $\%$ & $\%$ & $\%$ \\
anterotropid & $\mathrm{N}=2$ & $\mathrm{~N}=4$ & $\mathrm{~N}=12$ & $\mathrm{~N}=7$ & $\mathrm{~N}=18$ & $\mathrm{~N}=35$ \\
absent & 0.0 & 50.0 & 33.3 & 0.0 & 11.1 & 71.4 \\
present & 100.0 & 50.0 & 66.7 & 100.0 & 88.9 & 28.6 \\
posterotropid & $\mathrm{N}=2$ & $\mathrm{~N}=4$ & $\mathrm{~N}=13$ & $\mathrm{~N}=7$ & $\mathrm{~N}=18$ & $\mathrm{~N}=35$ \\
absent & 0.0 & 0.0 & 0.0 & 0.0 & 0.0 & 65.7 \\
present & 100.0 & 100.0 & 100.0 & 100.0 & 100.0 & 34.3 \\
m2 & & & & & & \\
anterotropid & $\mathrm{N}=6$ & $\mathrm{~N}=7$ & $\mathrm{~N}=17$ & $\mathrm{~N}=7$ & $\mathrm{~N}=30$ & $\mathrm{~N}=30$ \\
absent & 83.3 & 57.1 & 23.5 & 28.6 & 13.3 & 76.6 \\
present & 16.7 & 42.9 & 76.5 & 71.4 & 86.7 & 23.3 \\
posterotropid & $\mathrm{N}=6$ & $\mathrm{~N}=7$ & $\mathrm{~N}=17$ & $\mathrm{~N}=7$ & $\mathrm{~N}=32$ & $\mathrm{~N}=30$ \\
absent & 16.7 & 0.0 & 0.0 & 0.0 & 0.0 & 76.6 \\
present & 83.3 & 100.0 & 100.0 & 100.0 & 100.0 & 23.3 \\
\hline
\end{tabular}

Freudenthal \& Martín-Suárez (2007a) mentioned Microdyromys sp. from the Eocene of Aguatón, but the oldest formally described species is M. misonnei (Vianey-Liaud, 1994) from the lower Oligocene (MP21) of Hoogbutsel, which is thought to be the ancestor of $M$. heissigi (Uhlig, 2001) from GRB3 (MP25). In $M$. misonnei, the anterotropid is absent in a few $\mathrm{m} 1,2$ and the postcentroloph is always present. In $M$. heissigi, a species of smaller size, the anterotropid is absent in some $\mathrm{m} 2$, the postcentroloph is absent in two out of 19 M1,2 and anterotropes are relatively frequent.

Microdyromys monspeliensis Aguilar, 1977 from NFM (lower Miocene, MN2) is one of the smallest Microdyromys known; it is characterized by a very simple dental pattern. In the $\mathrm{m} 1,2$, the anterotropid is absent and there is a well-developed posterotropid. In M1, the postcentroloph is absent (morphotype F as defined by Daams, 1981), in M2 it is absent or incipient in four out of six specimens (morphotype $\mathrm{F}$ or $\mathrm{G}$ ).

Among the stratigraphically older species, in the M1 of M. hildebrandti Werner, 1994 from Ulm-Westtangente (lower Miocene, MN2) the postcentroloph may be absent and in these specimens a posterotrope is present. Werner (1994) interprets this posterotrope as the labial part of the original metaloph and the present metaloph as a postcentroloph connected to the lingual part of the original metaloph. The curved shape of the metaloph makes this quite plausible, the more so since posterotropes are practically absent in all other species of Oligocene and lower Miocene Microdyromys: among a total of 225 M1 and 216 M2 from 12 populations examined by us, only $3 \mathrm{M} 1$ and $3 \mathrm{M} 2$ have a posterotrope. This crest becomes more frequent in younger populations, from Armantes 7 (MN8) onwards. If Werner's interpretation is correct $M$. monspeliensis and M. hildebrandti, both from MN2, cannot be directly related.

On the other hand M. monspeliensis may be a descendant of $M$. heissigi, characterized by a simplification of the dental pattern. M. monspeliensis may well be the ancestor of M. monspeliensis sensu Daams, 1981 from various Spanish localities, which is also characterized by the absence of anterotropids and postcentrolophs, but which is larger than M. monspeliensis Aguilar, 1977.

The other small Microdyromys species are $M$. praemurinus (Freudenberg, 1941) from Gaimersheim (MP28), and M. hildebrandti Werner, 1994 (MN2). These may form a phylogenetic lineage derived from $M$. heissigi, and characterized by an increasing complication of the dental pattern; however M. praemurinus is larger than $M$. heissigi and $M$. hildebrandti.

Uhlig (2002) described M. praemurinus from Bumbach 1(MP25), but these specimens are larger than $M$. praemurinus and the lingual wall of M1 is crenulated. We attribute this population to $M$. cf. legidensis.

All other Microdyromys species are larger. Two species from the lower Oligocene are considered here: $M$. misonnei and M. puntarronensis Freudenthal \& Martín-Suárez, 2007 from several MP22 localities in the Montalbán area (Teruel, Spain). M. puntarronensis is thought to be derived from M. misonnei. This lineage is characterized by the better-developed anterotropid, anterolophid-protoconid connection, and centrolophid-metaconid connection, the better developed prototrope, and the frequently detached postcentroloph. All these are considered to be advanced characters.

In the MP23 localities from the same area a species that cannot be distinguished from $M$. misonnei replaces $M$. puntarronensis. In these populations the anterotropid and prototrope are less developed, and the postcentroloph is less frequently detached than in the MP22 samples. Both species are equal in size and distinguished only on the basis of percentages of character states. If the two co-occur in a locality they are impossible to separate.

In the upper Oligocene localities, $M$. cf. legidensis Daams, 1981 appears. MIR4B (MP25) and MIR4C (MP26) are too poor to make reliable comparisons, but fairly good samples are available from MIR1 (MP27), MIR2A 


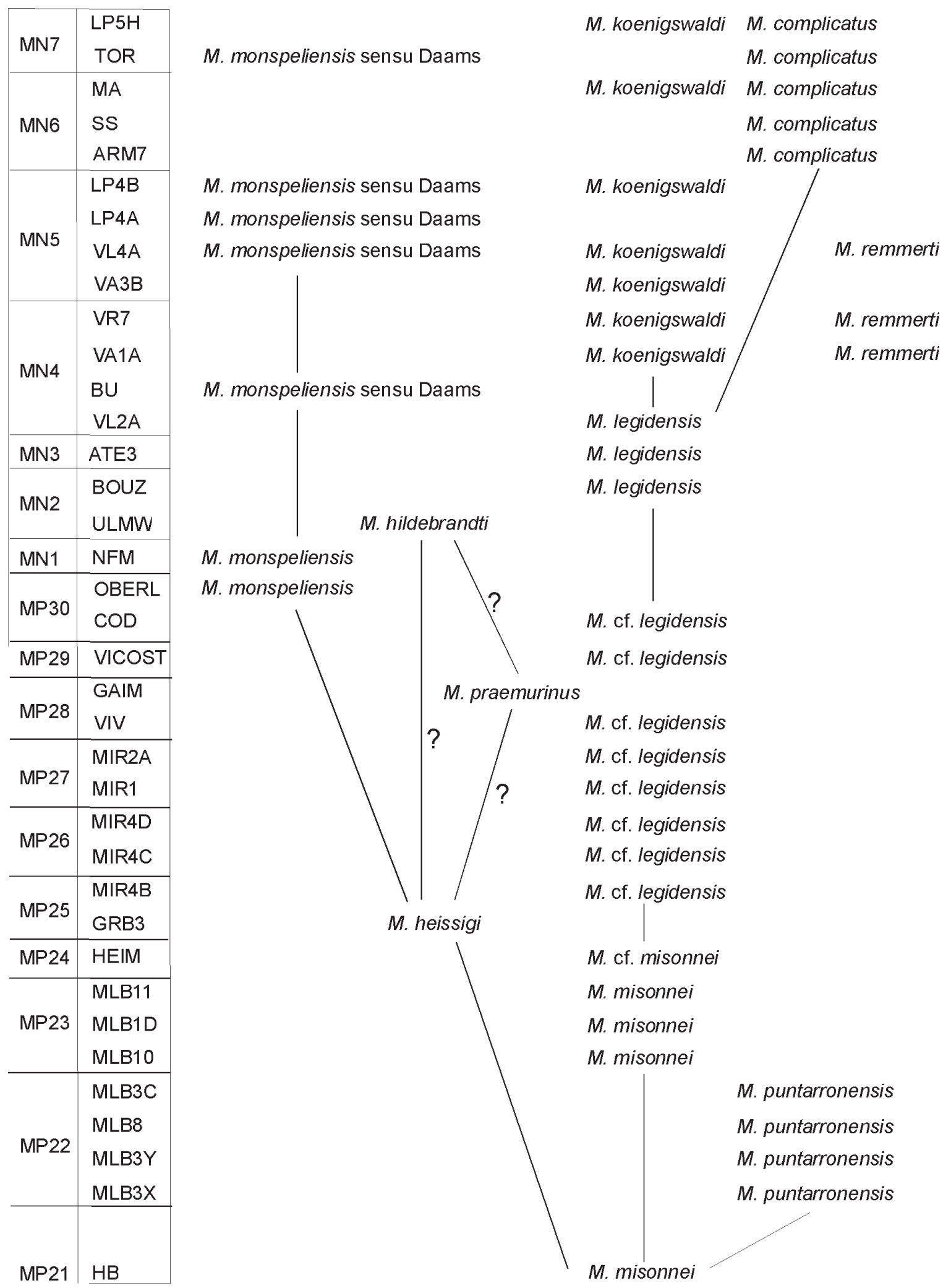

Figure 14. Phylogeny of Microdyromys. 
(MP27) and VIV (MP28). These are morphologically advanced in comparison with their ancestor M. misonnei (Vianey-Liaud, 1994). In the first and second molars, the anterolophid is always connected to protoconid, the centrolophid-metaconid connection is better developed, the anteroloph more frequently connected, the prototrope on average longer, the endoloph more complete, and -except for MIR2A- the lingual border of M1,2 is nearly always crenulated. $M$. puntarronensis cannot be excluded as the ancestor, but in that species the anterotropid is already more developed. It might be true $M$. legidensis, but the description of the lower molars of that species by Daams (1981) includes Peridyromys murinus, which makes comparison impossible. However, the oldest population, MIR4B, is from MP25, the type-locality of $M$. legidensis is VL2A (MN2) and it is reported from MN4, implying a time range of $13 \mathrm{Ma}$, which seems to be little probable. We therefore call it $M$. cf. legidensis.

The other Miocene species, M. koenigswaldi de Bruijn, 1966 and M. complicatus de Bruijn, 1966, are derived from M. legidensis. For M. remmerti García-Paredes et al., 2010, we are not sure.

Extra crests outside the trigone are frequent in $M$. complicatus, rare in M. remmerti, present in M. sinuosus (Alvarez Sierra \& García Moreno, 1986). According to Freudenthal \& Martín-Suárez (2013), M. sinuosus from the late Miocene of Ampudia 3 (MN10) belongs to the modern Gliridae that diversified in the Vallesian; consequently it is not a Microdyromys.

\section{Genus Paraglis Baudelot, 1970}

Type species Paraglis astaracensis Baudelot, 1970.

Diagnosis. (From Freudenthal \& Martín-Suárez, 2007b). "Medium-sized Bransatoglirinae. Number of crests in the lower molars like in Bransatoglis; upper molars with seven or eight crests, rarely more. In the lower molars the crests are often irregular and interrupted, in contrast with the parallel, well-developed, straight crests of Bransatoglis and Oligodyromys. The anterotrope may be absent and the posterotrope is usually absent or poorly developed; the extra crests are found inside the trigone. The precentroloph tends to get detached from the paracone and form a mesostyl, and it is often connected to the endoloph. The endoloph is complete, except for the oldest species".

$$
\text { Paraglis fugax (Hugueney, 1967) }
$$

Holotype. M2 sin., no 96223, Lyon

Type locality. Coderet, France (MP30).

Paraglis fugax was described as Pseudodryomys and Baudelot (1972) transferred it to the genus Paraglis. De Bonis (1973) synonymized Paraglis with Bransatoglis, an opinion shared by many later authors. Freudenthal \& Martín-Suárez (2007b) returned to the use of Paraglis.

Werner (1994) described $P$. aff. fugax from several MP30 localities in Germany, and stated that this material shows more accessory structures (tropids and tropes) that are subordinate or absent in the type material from Coderet.

Freudenthal \& Martín-Suárez (2007b) characterized Paraglis fugax as follow: the lower molars have seven ridges, the upper molars eight or nine. In the lower molars, the crests are quite discontinuous. Anterotrope and posterotrope are poorly developed. The endoloph is anteriorly interrupted. The centrolophs are not interconnected. The precentroloph almost reaches the endoloph. The metaloph of M3 is directed towards the labial border of the tooth. P4 is not known from the type locality, but a specimen from Paulhiac (de Bonis, 1973, fig. 7) shows a rounded shape and in this material the centrolophs may be interconnected.

\section{Paraglis cf. fugax (Hugueney, 1967)}

Our material is very scarce; one specimen from MIR1, three from MIR4B, and a small collection from MIR2A. For material and measurements see Table 15.

\section{Description of Paraglis cf. fugax from Mirambueno} 4B. (Figs. 4.21-4.22).

p4. Shape blunt. Anterolophid continuous. Anterotropid long. Metalophid high connected to the metaconid. Centrolophid long. Centrolophid-metaconid connection low. Mesostylid absent. Mesoconid placed on the labial border. Mesolophid connected to the entoconid. Posterotropid long.

m1. Worn specimen. Centrolophid long. Centrolophidmetaconid connection low. There is a second centrolophid, formed by a small cusp. Mesostylid absent. Mesoconid placed on the labial border. Mesolophid connected to the entoconid. Posterotropid long.

m2. Anterolophid labially free. Anterotropid long. Metalophid low connected to the metaconid. Centrolophid long. Centrolophid-metaconid connection absent. Mesostylid absent. Mesoconid placed on the labial border. Mesolophid connected to the entoconid. Posterotropid long.

Description of Paraglis cf. fugax from Mirambueno 1.

P4. Anteroloph long. Anterotrope absent. Precentroloph long. Midcentroloph absent. Postcentroloph short. Prototrope very thin and low. Metatrope absent. Centrolophs not connected. Posterotrope absent. Endoloph anteriorly interrupted. Lingual border smooth.

\section{Description of Paraglis cf. fugax from Mirambueno 2A.}

d4. Anterolophid continuous. Anterotropid of medium length. Metalophid high connected to the metaconid. Centrolophid of medium length. Centrolophid-metaconid 
Table 15. Measurements of Paraglis cf. fugax.

\begin{tabular}{|c|c|c|c|c|c|c|c|c|c|c|c|c|}
\hline \multirow[b]{2}{*}{$\mathrm{d} 4$} & \multicolumn{6}{|c|}{ Length } & \multicolumn{6}{|c|}{ Width } \\
\hline & $\mathrm{N}$ & Min. & Mean & Max. & $\mathrm{V}^{\prime}$ & $\sigma$ & $\mathrm{N}$ & Min. & Mean & Max. & $\mathrm{V}^{\prime}$ & $\sigma$ \\
\hline MIR2A & 1 & & 0.980 & & & & 1 & & 0.780 & & & \\
\hline p4 & & & & & & & & & & & & \\
\hline COD & 3 & 0.98 & 1.02 & 1.09 & 10.6 & & 3 & 0.81 & 0.88 & 1.01 & 22.0 & \\
\hline MIR2A & 2 & 1.05 & 1.140 & 1.23 & 15.8 & & 2 & 0.94 & 0.990 & 1.04 & 10.1 & \\
\hline $\begin{array}{l}\text { MIR4B } \\
\text { m1 }\end{array}$ & 1 & & 1.090 & & & & 1 & & 1.000 & & & \\
\hline MIR2A & 5 & 1.26 & 1.356 & 1.49 & 16.7 & 0.106 & 5 & 1.14 & 1.290 & 1.37 & 18.3 & 0.092 \\
\hline $\begin{array}{l}\text { MIR4B } \\
\text { m2 }\end{array}$ & 1 & & 1.260 & & & & 1 & & 1.240 & & & \\
\hline MIR2A & 1 & & 1.350 & & & & 1 & & 1.360 & & & \\
\hline $\begin{array}{l}\text { MIR4B } \\
\mathrm{m} 1,2\end{array}$ & 1 & & 1.350 & & & & 1 & & 1.470 & & & \\
\hline COD & 9 & 1.16 & 1.24 & 1.36 & 15.9 & & 9 & 1.26 & 1.33 & 1.44 & 13.3 & \\
\hline MIR2A & 6 & 1.26 & 1.355 & 1.49 & 16.7 & 0.095 & 6 & 1.14 & 1.302 & 1.37 & 18.3 & 0.087 \\
\hline $\begin{array}{l}\text { MIR4B } \\
\text { m3 }\end{array}$ & 2 & 1.26 & 1.305 & 1.35 & 6.9 & & 2 & 1.24 & 1.355 & 1.47 & 17.0 & \\
\hline $\begin{array}{l}\text { COD } \\
\text { D4 }\end{array}$ & 2 & 1.16 & 1.21 & 1.26 & 8.3 & & 2 & 1.16 & 1.20 & 1.25 & 7.5 & \\
\hline $\begin{array}{l}\text { COD } \\
\text { P4 }\end{array}$ & 1 & & 1.10 & & & & 1 & & 1.04 & & & \\
\hline COD & 1 & & 0.99 & & & & 1 & & 1.10 & & & \\
\hline MIR1 & 1 & & 0.980 & & & & 1 & & 1.150 & & & \\
\hline $\begin{array}{l}\text { MIR2A } \\
\text { M2 }\end{array}$ & 2 & 0.87 & 0.910 & 0.95 & 8.8 & & 3 & 1.01 & 1.110 & 1.17 & 14.7 & \\
\hline $\begin{array}{l}\text { MIR2A } \\
\text { M1,2 }\end{array}$ & 2 & 1.27 & 1.280 & 1.29 & 1.6 & & 2 & 1.47 & 1.515 & 1.56 & 5.9 & \\
\hline COD & 6 & 1.16 & 1.24 & 1.36 & 15.9 & & 5 & 1.26 & 1.33 & 1.44 & 13.3 & \\
\hline $\begin{array}{l}\text { MIR2A } \\
\text { M3 }\end{array}$ & 2 & 1.27 & 1.280 & 1.29 & 1.6 & & 2 & 1.47 & 1.515 & 1.56 & 5.9 & \\
\hline COD & 2 & 1.04 & 1.06 & 1.09 & 4.7 & & 1 & & 1.34 & & & \\
\hline MIR2A & 3 & 0.88 & 1.000 & 1.07 & 19.5 & & 3 & 1.22 & 1.253 & 1.30 & 6.3 & \\
\hline
\end{tabular}

connection absent. Mesostylid absent. Mesoconid placed on the labial border. Mesolophid directed towards the entoconid. Posterotropid long.

p4. Shape blunt. Anterolophid continuous. Anterotropid very small. Metalophid high connected to the metaconid. Centrolophid long. Centrolophid-metaconid connection low. Mesostylid absent. Mesoconid placed on the labial border. Mesolophid connected to the entoconid. Posterotropid long.

m1. Anterolophid labially free (4) or labially connected (1). Anterotropid of medium length (2) or long (3). Metalophid low connected to the metaconid (4) or high connected to the metaconid (1). Centrolophid of medium length (1) or long (4). Centrolophid-metaconid connection low. Mesostylid absent. Mesoconid placed on the labial border. Mesolophid connected to the metaconid through the centrolophid (1) or connected to the entoconid (4). Posterotropid long.
There may be a small second centrolophid. The posterotropid may be double or ramified.

m2. Anterolophid labially free. Anterotropid long. Metalophid low connected to the metaconid. Centrolophid long. Centrolophid-metaconid connection absent. Mesostylid absent. Mesoconid placed on the labial border. Mesolophid connected to the entoconid. Posterotropid long.

P4. Anteroloph of medium length (1) or long (2). Anterotrope absent. Precentroloph long. Midcentroloph absent. Postcentroloph absent. Prototrope absent. Metatrope absent. Centrolophs not connected. Posterotrope absent. Endoloph anteriorly interrupted (1) or complete (2). Lingual border smooth.

M2. Anteroloph lingually high connected . Anterotrope long. Precentroloph long. Precentroloph connected to the paracone. Midcentroloph absent. Postcentroloph long. Postcentroloph connected to the metacone. Prototrope absent. Metatrope long. Centrolophs not connected (1) or 
connected lingually (1). Posterotrope absent (1) or short (1). Endoloph complete. Lingual border smooth.

M3. Anteroloph lingually high connected . Anterotrope absent. Precentroloph of medium length. Postcentroloph long. Prototrope absent. Metatrope of medium length. Centrolophs not connected. Crests inside the trigone: 1 crest (1) or three crests (2). Mesostyl absent. Posterotrope absent. Endoloph complete. Lingual border smooth.

\section{RESULTS AND CONCLUSIONS}

Several fossil mammal localities in the upper Oligocene of the Montalbán depression contain rich populations of Gliridae. The first one of these is Vivel del Río, discovered by E. Moissenet in 1978 and first published by Hugueney et al. (1985). The other localities are Mirambueno 1, 2A, 4B, 4C and 4D, discovered and exploited by our team in the years 1986-1991.

The study of the Gliridae has permitted us to identify six species pertaining to five genera as one may see in Table 16, which gives the faunal lists for the taxonomic groups studied so far.
In our concept (see Freudenthal \& Martín-Suárez, 2013), the genus Gliravus is restricted to three upper Oligocene species (MP25-26): G. majori Stehlin \& Schaub, 1951, G. alvarezae Lacomba \& Morales, 1987, and $G$. caracensis Daams, Freudenthal, Lacomba \& Alvarez, 1989. Gliravus majori, the single species found in our area, was described by Stehlin and Schaub on the basis of a single skull fragment from the Quercy; its variability and exact age are unknown. In our material, Gliravus majori is typically restricted to MP26. We call it Gliravus majori because it differs from the other two known species of Gliravus. Whether it really belongs to the same species as the holotype is impossible to know.

The genus Butseloglis is represented by two species: Butseloglis bruijni is present in the oldest localities (MP2627). From MIR4 to MIR1 the dental pattern becomes more simple: tropes are lost, centroloph(id)s are lost. The mesoconid leaves the lingual border and may connect to the hypoconid. The metalophid-metaconid connection becomes more frequent. In the youngest locality $B$. bruijni has been replaced by Butseloglis bravoi, known only from its type locality Vivel; it may be derived from $B$. bruijni.

Peridyromys murinus appears for the first time in MP27 and its origin is not clear. Freudenthal \& MartínSuárez (2013) suggested that it may be derived either

Table 16. Faunal distribution.

\begin{tabular}{|c|c|c|c|c|c|c|}
\hline & \multicolumn{3}{|c|}{ MP26 } & \multicolumn{2}{|c|}{ MP27 } & \multirow{2}{*}{$\begin{array}{c}\text { MP28 } \\
\text { VIV }\end{array}$} \\
\hline & MIR4B & MIR4C & MIR4D & MIR1 & MIR2A & \\
\hline Gliravus majori & $\mathrm{X}$ & $\mathrm{X}$ & $\mathrm{X}$ & & & \\
\hline Butseloglis bruijni & & $\mathrm{X}$ & $\mathrm{X}$ & $\mathrm{X}$ & $\mathrm{X}$ & \\
\hline Butseloglis bravoi & & & & & & $\mathrm{X}$ \\
\hline Peridyromys murinus & & & & $\mathrm{X}$ & $\mathrm{X}$ & $\mathrm{X}$ \\
\hline Microdyromys cf. legidensis & $\mathrm{X}$ & $\mathrm{X}$ & $\mathrm{X}$ & $\mathrm{X}$ & $\mathrm{X}$ & $\mathrm{X}$ \\
\hline Paraglis fugax & $\mathrm{X}$ & & & $\mathrm{X}$ & $\mathrm{X}$ & \\
\hline Eucricetodon aff. dubius & & $\mathrm{X}$ & & $\mathrm{X}$ & $\mathrm{X}$ & $\mathrm{X}$ \\
\hline Eucricetodon martinensis & & $\mathrm{X}$ & $\mathrm{X}$ & & & \\
\hline Pseudocricetodon aff. simplex & $\mathrm{X}$ & $\mathrm{X}$ & $\mathrm{X}$ & & & \\
\hline Pseudocricetodon philippi & & $\mathrm{X}$ & & & & \\
\hline Pseudocricetodon adroveri & & & & & $\mathrm{X}$ & $\mathrm{X}$ \\
\hline Pseudocricetodon sp. & & & & $\mathrm{X}$ & & \\
\hline Allocricetodon incertus & $\mathrm{X}$ & $\mathrm{X}$ & $\mathrm{X}$ & & & $\mathrm{X}$ \\
\hline Allocricetodon landroveri & & $\mathrm{X}$ & $\mathrm{X}$ & & & $\mathrm{X}$ \\
\hline Allocricetodon cornelii & & & & $\mathrm{X}$ & $\mathrm{X}$ & $\mathrm{X}$ \\
\hline Heterocricetodon hausi & $\mathrm{X}$ & & & & & \\
\hline Heterocricetodon cf. stehlini & & $\mathrm{X}$ & $\mathrm{X}$ & $\mathrm{X}$ & & \\
\hline Plesiosminthus cf. margaritae & & & & $\mathrm{X}$ & & $\mathrm{X}$ \\
\hline Plesiosminthus aff. conjunctus & & & & & $\mathrm{X}$ & \\
\hline Plesiosminthus sp. & & & & & $\mathrm{X}$ & \\
\hline
\end{tabular}


from Microdyromys or from Butseloglis, but it cannot be discarded that it is an immigant with unknown roots. $P$. murinus seems to have a very long stratigraphical range.

Microdyromys is present in all our samples; in fact it has a very long distribution range from early Oligocene through middle Miocene. Our populations (MP26-27-28) are morphologically advanced in comparison with their ancestor M. misonnei (Vianey-Liaud, 1994).

Our material of Paraglis is so poor, that it permits no conclusions.

\section{ACKNOWLEDGEMENTS}

We thank Dr Israel García Paredes (Madrid) and Dr Hans de Bruijn (Utrecht) for valuable information on Microdyromys. This study was supported by the research group RNM190 of the "Junta de Andalucía" (Spain).

\section{REFERENCES}

Aguilar, J.P. 1977. Les gisements continentaux de Plaissan et de la Nouvelle Faculté de Médecine (Hérault), leur position stratigraphique. Géobios, 10, 81-101; doi: 10.1016/S00166995(77)80055-7.

Agustí, J. \& Arcas, A. 1997. Gliridae (Mammalia, Rodentia) from the Late Eocene of Sossis. Münchner Geowissenschaftliche Abhandlungen, A, Geologie Paleontologie, 34, 23-32.

Álvarez Sierra, M.A. \& García Moreno, E. 1986. New Gliridae and Cricetidae from the Middle and Upper Miocene of the Duero Basin, Spain. Studia Geologica Salmanticensia, 22, 145-189.

Bahlo, E. 1975. Die Nagetierfauna von Heimersheim bei Alzey (Rheinhessen, Westdeutschland) aus dem Grenzbereich Mittel/Oberoligozän und ihre stratigrafische Stellung. Abhandlungen Hessisches Landesamt für Bodenforschung, 71, 1-182.

Baudelot, S. 1970. Compléments à l'étude des micromammifères du gisement Miocène de Sansan (Gers). Comptes Rendus sommaires Société Géologique de France, 8, 303-304.

Baudelot, S. 1972. Etude des chiroptères, insectivores et rongeurs du Miocène de Sansan (Gers). Ph.D. Thesis, Université Toulouse, 496, 1-364.

Baudelot, S. \& de Bonis, L. 1966. Nouveaux Gliridés (Rodentia) de l'Aquitanien du Bassin d'Aquitainie. Comptes Rendus sommaires Société Géologique de France, 9, 341-342.

Bosma, A. \& de Bruijn, H. 1979. Eocene and Oligocene Gliridae (Rodentia, Mammalia) from the Isle of Wight, England. Part 1. The Gliravus priscus - Gliravus fordi lineage. Proceedings Koninklijke Nederlandse Akademie van Wetenschappen, $B, 82,367-384$.
Bosma, A. \& de Bruijn, H. 1982. Eocene and Oligocene Gliridae (Rodentia, Mammalia) from the Isle of Wight, England. Part II. Gliravus minor n.sp., Gliravus daamsi n.sp., Bransatoglis bahloi n.sp. Proceedings Koninklijke Nederlandse Akademie van Wetenschappen, B, 85, 365380.

Bowdich, T.E. 1821. Analysis of the Natural Classifications of Mammalia for the Use of Students and Travellers. J. Smith, Paris, $115 \mathrm{p}$.

Daams, R. 1981. The dental pattern of the dormice Dryomys, Myomimus, Microdyromys and Peridyromys. Utrecht Micropaleontological Bulletins, Special Publication, 3, $1-115$.

Daams, R. \& de Bruijn, H. 1995. A classification of the Gliridae (Rodentia) on the basis of dental morphology. Hystrix, 6, 3-50.

Daams, R., Freudenthal, M., Lacomba, J.I. \& Álvarez, M.A. 1989. Upper Oligocene micromammals from Pareja, Loranca Basin, prov. of Guadalajara, Spain. Scripta Geologica, 89, 27-56.

de Bonis, L. 1973. Contribution à l'Étude des Mammifères de l'Aquitanien de l'Agenais. Rongeurs, Carnivores, Perissodactyles. Mémoires Museum National Histoire Naturtelle, N. S., C, 28, 1-192.

de Bruijn, H. 1966. Some new Miocene Gliridae (Rodentia, Mammalia) from the Calatayud Area (prov. Zaragoza, Spain). Proceedings Koninklijke Nederlandse Akademie van Wetenschappen, $B, 69,1-21$.

de Bruijn, H. 1967. Gliridae, Sciuridae y Eomyidae (Rodentia, Mammalia) miocenos de Calatayud (provincia de Zaragoza, España) y su relación con la bioestratigrafía del área. Boletín del Instituto Geológico y Minero de España, 78, 187-373.

Díaz Molina, M. \& López Martínez, N. 1979. El Terciario continental de la Depresión Intermedia (Cuenca). Bioestratigrafía y paleogeografía. Estudios Geológicos, 35, 149-167.

Freudenberg, H. 1941. Die oberoligocänen Nager von Gaimersheim bei Ingolstadt und ihre Verwandten. Palaeontographica, 92, A, 99-164.

Freudenthal, M. 1963. Entwicklungsstufen der miozänen Cricetodontinae (Mammalia, Rodentia) Mittelspaniens und ihre stratigrafische Bedeutung. Beaufortia, 10, 51157.

Freudenthal, M. 1994. Cricetidae (Rodentia, Mammalia) from the Upper Oligocene of Mirambueno and Vivel del Río (Teruel, Spain). Scripta Geologica, 104, 1-55.

Freudenthal, M. 1996. The Early Oligocene rodent fauna of Olalla 4A (Teruel, Spain). Scripta Geologica, 112, 1-67.

Freudenthal, M. 1997. Paleogene rodent faunas from the province of Teruel (Spain). In: Actes du Congrès BiochroM'97 (eds Aguilar, J.P., Legendre, S. \& Michaux, J.). Mémoires Travaux E.P.H.E., Institut Montpellier, 21, 397-415.

Freudenthal, M. 2004. Gliridae (Rodentia, Mammalia) from the Eocene and Oligocene of the Sierra Palomera (Teruel, Spain). Treballs del Museu de Geologia de Barcelona, $12,97-173$. 
Freudenthal, M. \& Cuenca Bescós, G. 1984. Size variation of fossil rodent populations. Scripta Geologica, 76, 1-28.

Freudenthal, M. \& Martín-Suárez, E. 2007a. Microdyromys (Gliridae, Rodentia, Mammalia) from the Early Oligocene of Montalbán (Prov. Teruel, Spain). Scripta Geologica, 135, 179-211.

Freudenthal, M. \& Martín-Suárez, E. 2007b. Revision of the subfamily Bransatoglirinae (Gliridae, Rodentia, Mammalia). Scripta Geologica, 135, 241-273.

Freudenthal, M. \& Martín-Suárez, E. 2013. New ideas on the systematics of Gliridae (Rodentia, Mammalia). Spanish Journal of Palaeontology, 28, 239-252.

Freudenthal, M. \& Martín-Suárez, E. 2017. A revision of European Plesiosminthus (Rodentia, Dipodidae), and new material from the upper Oligocene of Teruel (Spain). Palaeontologia Electronica, 20.3.43A, 1-25; doi: $10.26879 / 678$

Freudenthal, M. \& Martín-Suárez, E. 2018. The Aragonian type area revisited; comments on paleontology and stratigraphy. Geologica Acta, 16, 149-162; doi: 10.1344/ GeologicaActa2018.16.2.3.

Freudenthal, M., Hugueney, M. \& Moissenet, E. 1994. The genus Pseudocricetodon (Cricetidae, Mammalia) in the Upper Oligocene of the province of Teruel (Spain). Scripta Geologica, 104, 57-114.

Freudenthal, M., van den Hoek Ostende, L.W. \& MartínSuárez, E. 2013. When and how did the Mikrotia fauna reach Gargano (Apulia, Italy)? Geobios, 46, 105-109; doi: 10.1016/j.geobios.2012.10.004.

García Moreno, E. \& López Martínez, N. 1986. Ramys, a new genus of Gliridae (Rodentia) from the Lower Vallesian of Spain. Proceedings Koninklijke Nederlandse Akademie van Wetenschappen, B, 89, 337-355.

García-Paredes, I., Peláez-Campomanes, P. \& Álvarez Sierra, M.A. 2009. Gliridae (Rodentia, Mammalia) with a simple dental pattern: a new genus and new species from the European Early and Middle Miocene. Zoological Journal of the Linnean Society, 157, 622-652; doi: 10.1111/j.10963642.2009.00527.x.

García-Paredes, I., Peláez-Campomanes, P. \& Álvarez Sierra, M.A. 2010. Microdyromys remmerti, sp. nov., a new Gliridae (Rodentia, Mammalia) from the Aragonian type area (Miocene, Calatayud-Montalbán Basin, Spain). Journal of Vertebrate Paleontology, 30, 1594-1609; doi: 10.1080/02724634.2010.501453.

Hartenberger, J.L. 1965. Gliravus robiacensis n. sp., nouveau Rongeur (Gliridae) de l'Eocène supérieur de Languedoc. Comptes Rendues sommaires Société Géologique de France, 1965, 326-327.

Hartenberger, J.L. 1971. Contribution à l'étude des genres Gliravus et Microparamys (Rodentia) de l'Eocène d'Europe. Palaeovertebrata, 4, 97-135.

Hugueney, M. 1967. Les Gliridés (Mammalia, Rodentia) de l'Oligocène supérieur de Coderet-Branssat (Allier). Comptes Rendus sommaires Société Géologique de France, 3, 91-92.

Hugueney, M., Adrover, R. \& Moissenet, E. 1985. Gliravus bravoi nov. sp., la plus grande espèce du genre Gliravus
(Mammalia, Rodentia, Gliridae) dans 1'Oligocène supérieur d'Espagne. Géobios, 18, 251-256; doi: 10.1016/ S0016-6995(85)80018-8.

Hugueney, M., Adrover, R., Moissenet, E. \& Schmidt-Kittler, N. 1987. Les Mammifères de Vivel del Río (prov. de Teruel, Espagne; Oligocène supérieur): un riche gisement stratifié en comparaison avec des faunes karstiques. In: International Symposium on Mammal. Biostratigraphy and Paleoecology of the European Paleogene (ed. SchmidtKittler, N.). Mainz, Münchner Geowissenschaftliche Abhandlungen, A, 10, 117-130.

Kretzoi M. 1943. Ein neuer Muscardinide aus dem Ungarischen Miozän. KüIönlenyomat a Földtani Közlöny, 73, 271- 273.

Kristkoiz, A. 1992. Zahnmorphologische und schädelanatomische Untersuchungen an Nagetieren aus dem Oberoligozän von Gaimersheim (Süddeutschland). Abhandlungen der Bayerischen Akademie der Wissenschaften, Mathematisch-Naturwissenschaftliche Klasse, neue Folge, 167, 1-137.

Lacomba, J.I. \& Morales, J. 1987. Los micromamíferos del Oligoceno superior de Carrascosa del Campo (Prov. Cuenca, España). In: International Symposium on Mammal. Biostratigraphy and Paleoecology of the European Paleogene (ed. Schmidt-Kittler, N.). Mainz, Münchner Geowissenschaftliche Abhandlungen, A, 10, 289-300.

Linnaeus, C. 1758. Systema Naturae Sive Regna Tria Naturae, Secundum Classes, Ordines, Genera, Species, cum Characteribus, Differentiis, Synonymis, Locis. Laurentii Salvii, Holmiae. 2th ed. Systema Naturae ed. 12 1-532.

Misonne, X. 1957. Mammifères Oligocènes de Hoogbutsel et Hoeleden. Bulletin de l'Institut Royal des Sciences Naturelles de Belgique, 33, 1-15.

Muirhead, L. 1819. Mazology. In: The Edinburgh Encyclopedia (ed. Brewster, D.). W. Blackwood, Edinburgh, 13, 393486.

Peigné, S., Vianey-Liaud, M., Pelissie, T. \& Sigé, B. 2014. Valbro: un nouveau site a vertébrés de l'Oligocène inférieur (MP22) de France (Quercy). I. Contexte géologique; Mammalia: Rodentia, Hyaenodontida, Carnivora. Annales de Paléontologie, 100, 1-45; doi: 10.1016/j.annpal.2013.11.002.

Pomel, A. 1853. Catalogue Méthodique et Descriptif des Vertébrés Fossiles Découverts dans le Bassin Hydrographique Supérieur de la Loire et Surtout dans la Vallée de Son Affluent Principal, l'Allier. J.B. Baillière, Paris, 1-193.

Schaub, S. 1958. Simplicidentata (Rodentia). In: Traité de Paléontologie (ed. Piveteau, J.). Masson, Paris. 6, 659818.

Stehlin, H.G. \& Schaub, S. 1951. Die Trigonodontie der simplicidentaten Nager. Schweizerische Paläontologische Abhandlungen, 67, 1-385.

Uhlig, U. 2001. The Gliridae (Mammalia) from the Oligocene (MP24) of Gröben 3 in the folded Molasse of Southern Germany. Palaeovertebrata, 30, 151-187.

Uhlig, U. 2002. Gliridae (Mammalia) aus den oligozänen Molasse-Fundstellen Gröben 2 in Bayern und Bumbach 1 
in der Schweiz. Neues Jahrbuch für Geologie und Paläontologie, Abhandlungen, 223, 145-162.

van Dam, J. 1998. The Gliridae from the Upper Eocene of Sossís, Roc de Santa and Claverol (Lleida, Spain). In: Geología y Paleontología del Eoceno de la Pobla de Segur (Lleida) (eds López-Martínez, N., Civis, J. \& Daams, R.). Universitat de Lleida, 131-180.

van de Weerd, A. 1976. Rodent faunas of the Mio-Pliocene continental sediments of the Teruel-Alfambra region, Spain. Utrecht Micropaleontological Bulletins, Special Publication, 2, 1-217.

Vianey-Liaud, M. 1969. Rongeurs de l'Oligocène moyen provenant de nouvelles fouilles dans les Phosphorites du Quercy. Palaeovertebrata, 2, 209-239.

Vianey-Liaud, M. 1989. Parallelism among Gliridae (Rodentia): the genus Gliravus Stehlin \& Schaub. Historical Biology, 2, 213-226.
Vianey-Liaud, M. 1994. La radiation des Gliridae (Rodentia) à l'Eocène supérieur en Europe Occidentale et sa descendance Oligocène. Münchner Geowissenschaftliche Abhandlungen, A, 26, 117-160.

Vianey-Liaud, M. 2004. Gliridae (Mammalia, Rodentia) de l'Oligocène européen origine de trois genres miocènes. Coloquios de Paleontología, Volumen Extraordinario, 1, 669-698.

Vianey-Liaud, M., Comte, B. \& Leveque, F. 1995. Le Garouillas et les sites contemporains (Oligocène, MP 25) des phosphorites du Quercy (Lot, Tarn-et-Garonne, France) et leurs faunes de vertébrés. 13. Rongeurs. Palaeontographica, A, 236, 257-326.

Werner, J. 1994. Beiträge zur Biostratigraphie der Untern Süsswasser-Molasse Süddeutschlands - Rodentia und Lagomorpha (Mammalia) aus den Fundstellen der Ulmer Gegend. Stuttgarter Beiträge Naturkunde, B, 200, 1-263. 